\title{
Nuclear Safeguards Reporting System Requirements Specification
}

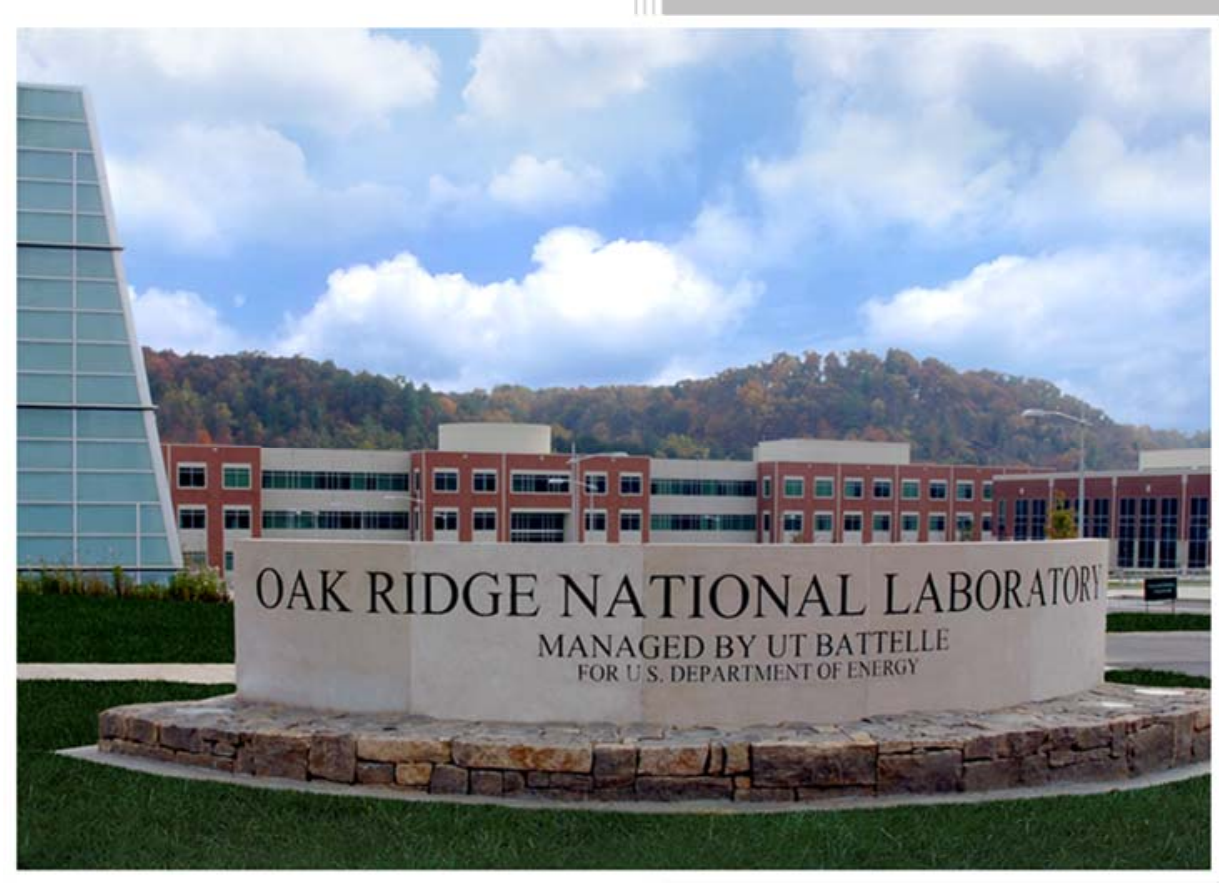

\section{Approved for public release. Distribution is unlimited.}
R. Cain
D. Kovacic
J. Oakberg
A. Pederson
S. Stewart
D. Samuel

February 2018 


\section{DOCUMENT AVAILABILITY}

Reports produced after January 1, 1996, are generally available free via US Department of Energy (DOE) SciTech Connect.

Website http://www.osti.gov/scitech/

Reports produced before January 1, 1996, may be purchased by members of the public from the following source:

National Technical Information Service

5285 Port Royal Road

Springfield, VA 22161

Telephone 703-605-6000 (1-800-553-6847)

TDD 703-487-4639

Fax 703-605-6900

E-mail info@ntis.gov

Website http://www.ntis.gov/help/ordermethods.aspx

Reports are available to DOE employees, DOE contractors, Energy Technology Data Exchange representatives, and International Nuclear Information System representatives from the following source:

Office of Scientific and Technical Information

PO Box 62

Oak Ridge, TN 37831

Telephone 865-576-8401

Fax 865-576-5728

E-mail reports@osti.gov

Website http://www.osti.gov/contact.html

This report was prepared as an account of work sponsored by an agency of the United States Government. Neither the United States Government nor any agency thereof, nor any of their employees, makes any warranty, express or implied, or assumes any legal liability or responsibility for the accuracy, completeness, or usefulness of any information, apparatus, product, or process disclosed, or represents that its use would not infringe privately owned rights. Reference herein to any specific commercial product, process, or service by trade name, trademark, manufacturer, or otherwise, does not necessarily constitute or imply its endorsement, recommendation, or favoring by the United States Government or any agency thereof. The views and opinions of authors expressed herein do not necessarily state or reflect those of the United States Government or any agency thereof. 


\section{NUCLEAR SAFEGUARDS REPORTING SYSTEM REQUIREMENTS SPECIFICATION}
R. Cain
D. Kovacic
J. Oakberg*
A. Pederson**
S. Stewart
D. Samuel**

*Consultant

** Subcontracted through Oak Ridge Associated Universities

Date Published: February 2018

Prepared by

OAK RIDGE NATIONAL LABORATORY

Oak Ridge, TN 37831-6283

managed by

UT-BATTELLE, LLC

for the

US DEPARTMENT OF ENERGY

under contract DE-AC05-00OR22725 



\section{CONTENTS}

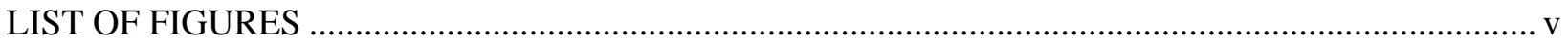

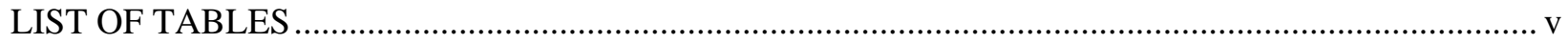

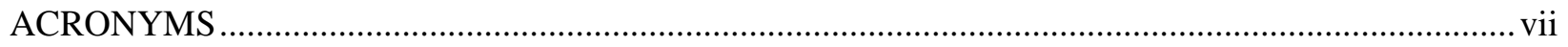

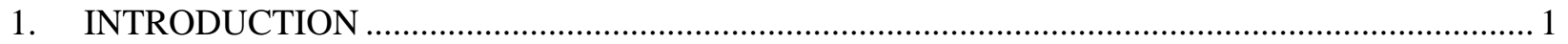

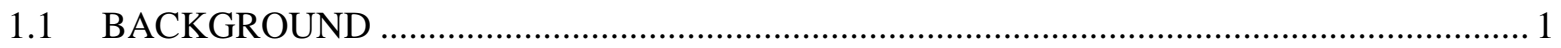

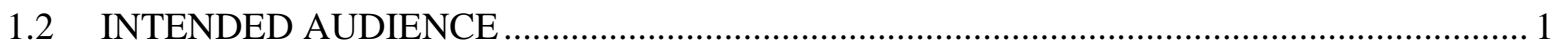

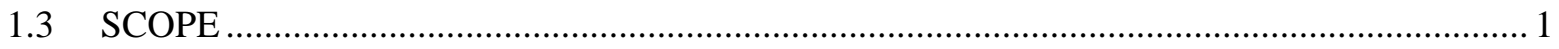

2. NUCLEAR MATERIAL ACCOUNTING AND REPORTING ................................................ 2

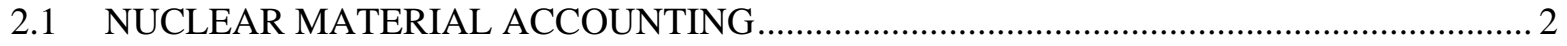

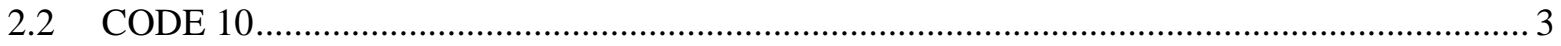

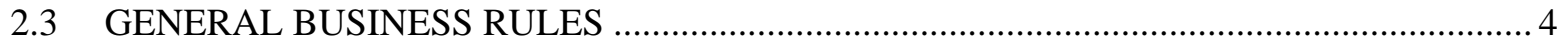

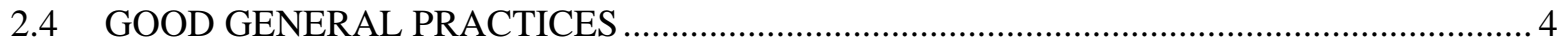

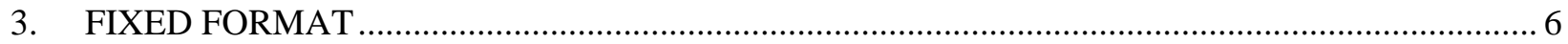

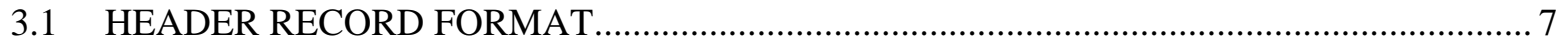

3.2 INVENTORY CHANGE REPORTS …….................................................................... 10

3.2.1 Inventory Change Reports for Additional Isotopes .................................................. 18

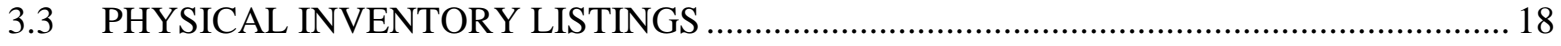

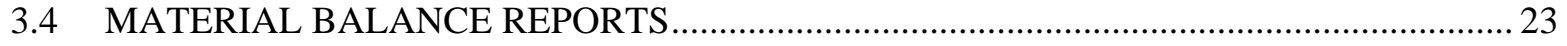

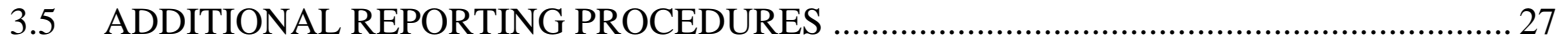

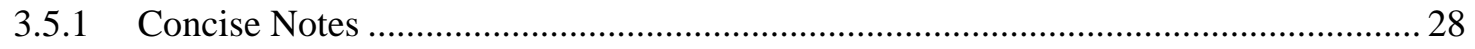

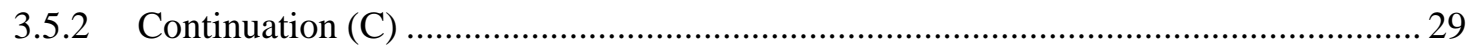

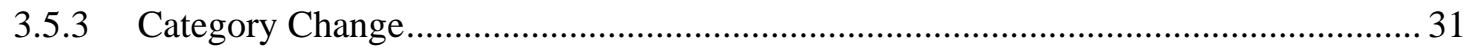

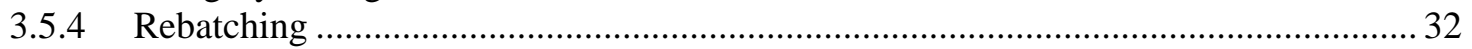

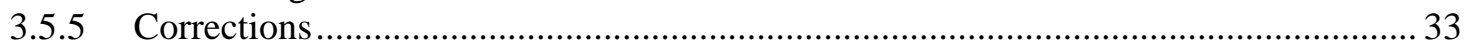

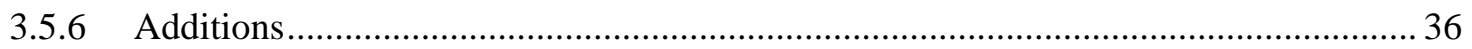

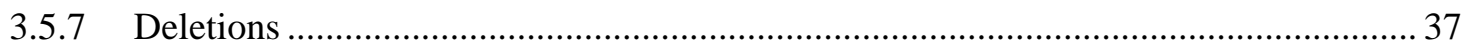

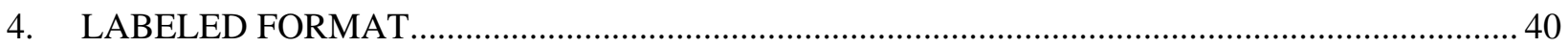

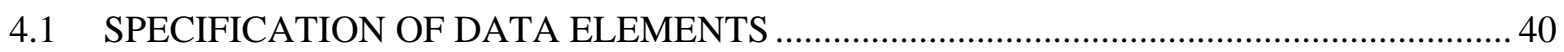

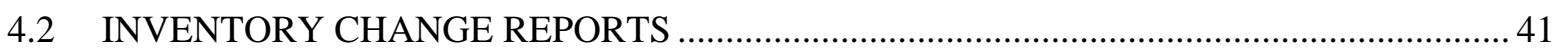

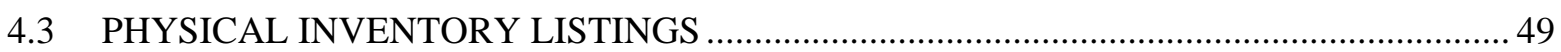

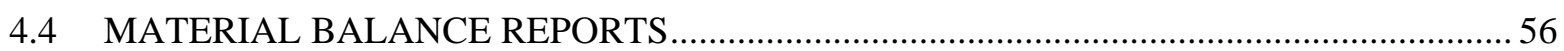

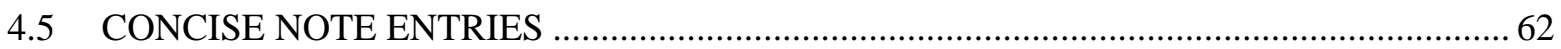

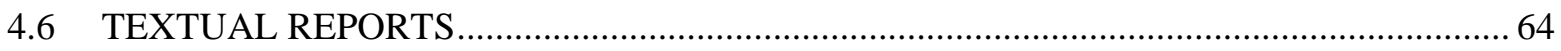

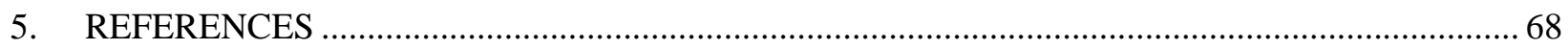

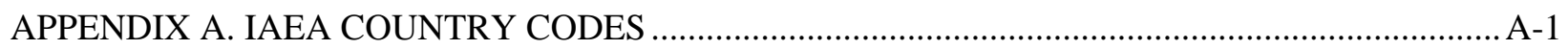

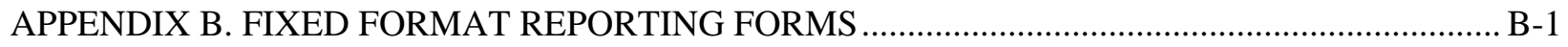

APPENDIX C. FIXED FORMAT REPORTING CODES ….................................................................

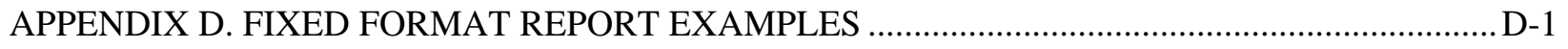

APPENDIX E. LABELED FORMAT REPORTING CODES …................................................ E-1

APPENDIX F. LABELED FORMAT REPORT EXAMPLES …........................................................ 



\section{LIST OF FIGURES}

Figure 2-1. Legal basis for Code 10 accounting reports. ...................................................................... 2

Figure 3-1. Flowchart for determining the measurement basis code. ................................................... 16

Figure 3-2. Example of how measurement basis is applied............................................................ 16

Figure 3-3. Continuation entry example for weights greater than eight digits. ........................................ 30

Figure 3-4. Continuation entry example for multiple elements in a batch.............................................. 31

Figure 3-5. Example of rebatching change in batch structure. …............................................................... 32

Figure 3-6. Example of rebatching to change the batch name................................................................ 32

Figure 3-7. Example of correction to an accounting report entry............................................................ 34

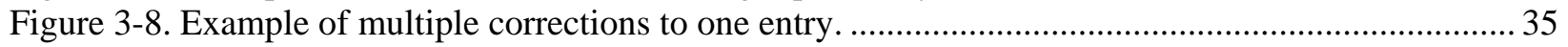

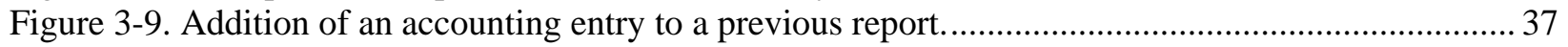

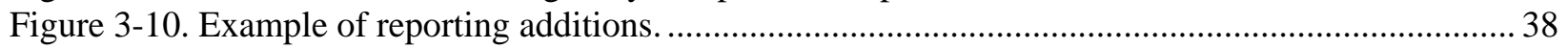

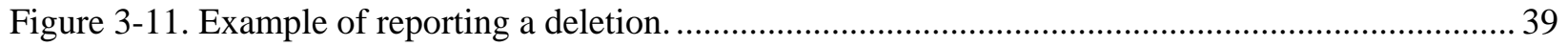

\section{LIST OF TABLES}

Table 2-1. Fixed versus labeled Code 10 formats............................................................................. 3

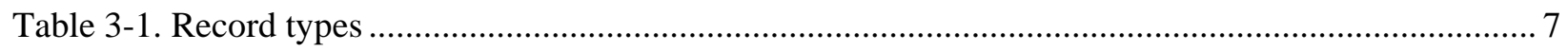

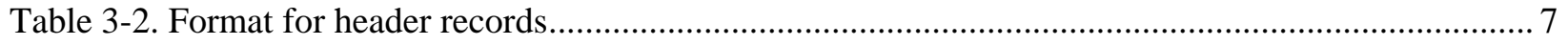

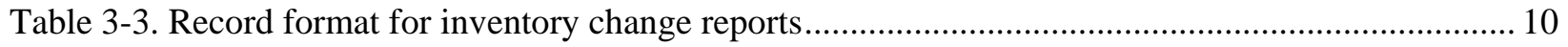

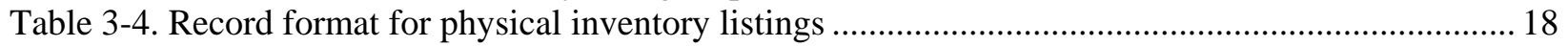

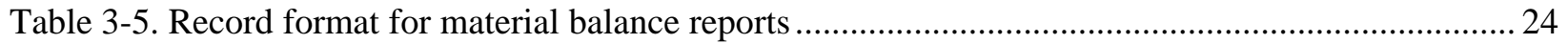

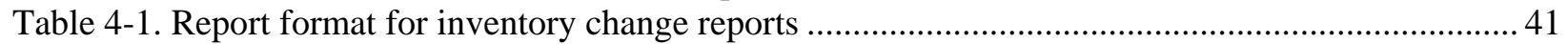

Table 4-2. Report format for physical inventory listings ............................................................................. 49

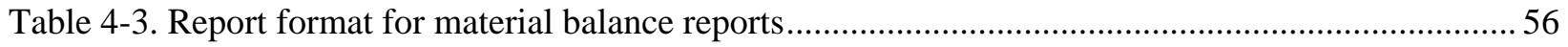

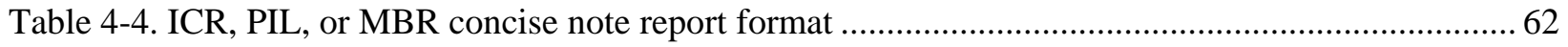

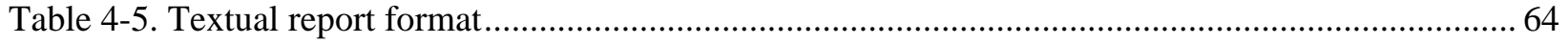





\section{ACRONYMS}

BA adjusted ending book inventory

CSA comprehensive safeguards agreement

DI shipper/receiver difference

HTR high-temperature reactor

IAEA International Atomic Energy Agency

ICR

KMP

MBA

MBR

MUF

NMA

NPT

PB

inventory change report

key measurement point

material balance area

material balance report

material unaccounted for

nuclear material accountancy

Treaty on the Non-Proliferation of Nuclear Weapons

$\mathrm{PE}$

physical beginning inventory

PIL

physical ending inventory

physical inventory listing

PIT physical inventory taking 



\section{INTRODUCTION}

\subsection{BACKGROUND}

States enter into safeguards agreements with the International Atomic Energy Agency (IAEA) to fulfill their nuclear non-proliferation commitments. Each nonnuclear-weapon State party to the Treaty on the Non-Proliferation of Nuclear Weapons (NPT) [1] is required, pursuant to Article III, to conclude a comprehensive safeguards agreement (CSA) with the IAEA.

IAEA document INFCIRC/153 (corrected), The Structure and Content of Agreements between the Agency and States required in Connection with the Treaty on the Non-Proliferation of Nuclear Weapons (hereinafter INFCIRC/153) [2], provides the basis for CSAs in connection with the NPT. Under a CSA, the State undertakes to accept IAEA safeguards on all source or special fissionable material in all peaceful nuclear activities within the territory of the State, under its jurisdiction, or carried out under its control. The State, through its safeguards regulatory authority, must provide the IAEA correct and complete safeguards information as required by INFCIRC/153, and detailed in Guidance for States Implementing Comprehensive Safeguards Agreements and Additional Protocols [3], on its nuclear material (i.e., forms, amounts, flows, locations, uses, and transfers); nuclear facilities and locations outside of facilities; and nuclear fuel cycle-related activities and locations. These reporting obligations and the IAEA's verification activities are designed to allow the IAEA to establish and maintain the nuclear material inventory of the State by verifying the reports submitted.

This document aims to provide information regarding the system requirements of software designed for comprehensive safeguards reporting.

\subsection{INTENDED AUDIENCE}

The intended audiences of this document include the computer software analysts and developers tasked with designing a system to fulfill nuclear material accountability reporting requirements to the IAEA, as well as those who test software against the requirements. This document is not meant to supersede existing IAEA requirements or guidance on reporting obligations. It attempts to interpret those requirements in a way that is most useful to individuals and groups who are experts in development of automated information systems, rather than subject matter experts in nuclear safeguards.

\subsection{SCOPE}

The scope of this document is to provide the reader with discrete and verifiable software requirements for CSA nuclear material accountancy reporting. Section 2 provides background on CSA reporting and nuclear material accounting. Section 3 describes CSA reporting in the fixed format, and Section 4 describes CSA reporting in the labeled format. References are provided in Section 5.

Depending on State-specific agreements, additional requirements and procedures may be necessary and are outside the scope of this document. 


\section{NUCLEAR MATERIAL ACCOUNTING AND REPORTING}

\subsection{NUCLEAR MATERIAL ACCOUNTING}

Nuclear material is accounted for within a structure of material balance areas (MBAs). MBAs are defined by the IAEA Safeguards Glossary [4] as "an area in or outside of a facility such that:

(a) The quantity of nuclear material in each transfer into or out of each 'material balance area' can be determined; and

(b) The physical inventory of nuclear material in each 'material balance area' can be determined when necessary, in accordance with specified procedures, in order that the material balance for Agency safeguards purposes can be established.”

The MBA structure used for material reporting, and which establishes the requirements of the content, format, and timing of nuclear material reports, is specified in Subsidiary Arrangements-General Parts and Attachments to a CSA, which is negotiated between each State and the IAEA. The General Part of the Subsidiary Arrangement is divided into subparts, called codes. Code 10 specifies the format and content of accounting reports to be submitted to the IAEA by the State and provides detailed procedures to be followed for reporting. Figure 2-1 depicts the legal basis for Code 10 reporting.

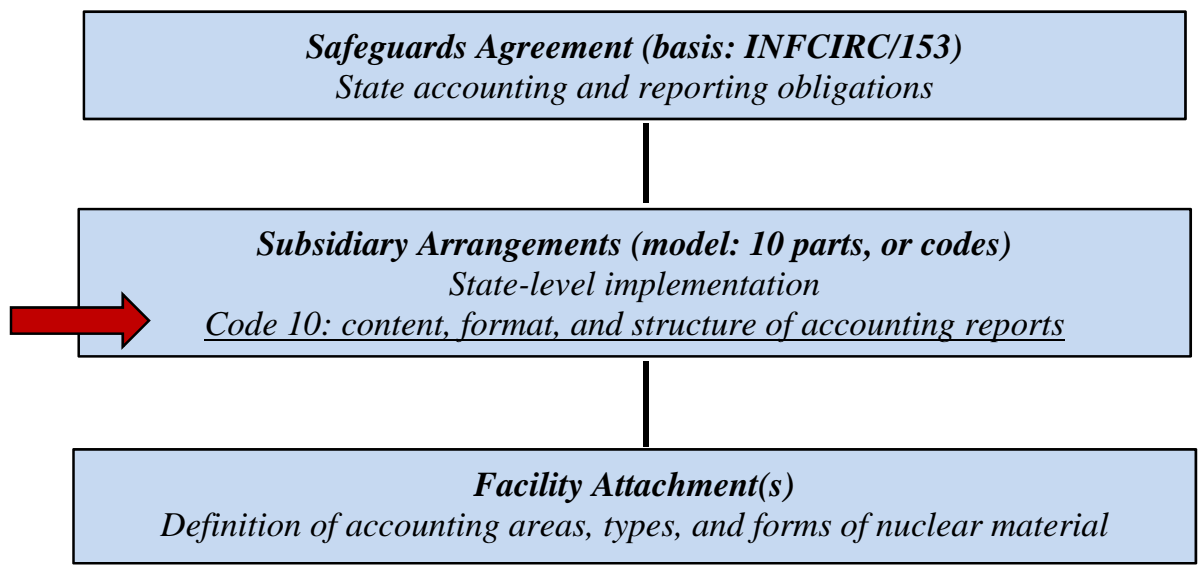

Figure 2-1. Legal basis for Code 10 accounting reports.

Furthermore, facility attachments describe the individual facilities and the manner in which safeguards will be applied. They also specify how Code 10 will be applied in producing records and preparing reports for the facility. Therefore, in determining how to formulate reporting software, developers must consult both the State's Subsidiary Arrangement and facility attachments for guidance.

There are three types of nuclear material accounting to report: inventory changes (Inventory Change Report-ICR), physical inventories (Physical Inventory Listing-PIL), and material balances (Material Balance Report-MBR).

The ICR shows all changes in quantities of nuclear material in an MBA, recording the date the change occurred or was established. ICR reporting criteria specify identification and descriptive information for each batch of nuclear material, date of inventory change, shipper, and receiver of nuclear material. ICRs must be sent to the IAEA within 30 days of the end of the month in which the change occurs. For example, if an inventory change is made on June 17, 2014, the ICR report is due to the IAEA by July 30, 2014 (i.e., June 30 plus 30 days). 
The PIL provides a statement of the physical inventory at the time of the inventory taking. PILs list all batches as separate entries, with each entry specifying the identification and descriptive information for each. PILs are attached to the MBA and must be submitted to the IAEA within 30 days of the date of inventory taking.

The purpose of the MBR is to report all nuclear material moved into or out of an MBA within the reporting period. The report contains separate entries for each type of safeguarded nuclear material within the MBA and indicates the material balance(s) for all nuclear material present in the MBA. MBAs are due to the IAEA within 30 days of the end of the material balance period.

In addition to nuclear material accounting reports, States can inform the IAEA of other information as text in the form of a Concise Note or Textual Report. Options for reporting text depend on the format of Code 10 for a State.

\subsection{CODE 10}

Code 10 specifications are the primary reference when addressing IAEA nuclear material accounting and reporting issues. There are two versions of Code 10, each having different reporting formats but both providing for the necessary data elements for reporting compliance as outlined in safeguards agreements.

One format utilizes fixed field definitions (i.e., fixed format) and the other flexible field definitions (i.e., labeled format). Each specification is available from the IAEA website (http://www.iaea.org) by searching on "SG-FM-1171." Only one of the formats can be used by a State and is determined by its Subsidiarity Arrangement. Both formats provide the necessary information for the implementation of IAEA safeguards, but there are procedural differences between each. Table 2-1 describes some of the key differences.

Table 2-1. Fixed versus labeled Code 10 formats

\section{Fixed format Code 10}

\section{Labeled format Code 10}

- $\quad$ Based on the 80-column card format from the early 1970s.

- Has additional procedures because of physical restrictions associated with fixed lengths of numeric data fields.

- Is practical for States with a developing or moderate nuclear program.

- Reporting by electronic means is possible and highly recommended by the IAEA.
Data fields are defined by labels and may also contain subfields.

- $\quad$ Specific procedures related to numeric data field lengths are not necessary.

- $\quad$ Format requires advanced information systems.

- $\quad$ Reports must be in electronic format; paper forms are not possible.

- Data fields have variable lengths.

- Additional data fields can be added, if so negotiated.

- Well-suited for States with well-developed nuclear programs and fuel cycle.

The IAEA has been working to develop a new reporting format based on >XML technology. As of the writing of this document, the format has not been finalized.

All nuclear material accounting reports are at the MBA level. For each MBA, reports are numbered sequentially beginning with 1 and increase by 1 with no gaps or duplication. Report numbers are independent of the report type. Within each MBA report, entries are also numbered sequentially beginning with 1 and increase by 1 with no gaps or duplication. For example: 


\section{MBA: NNA1}

Report 1, Entry 1

Report 1, Entry 2

Report 1, Entry 3

Report 2, Entry 1
MBA: NNA2

Report 1, Entry 1

Report 1, Entry 2

Report 2, Entry 1

Report 2, Entry 2

The combination of MBA, report number, and entry number uniquely identifies an accounting entry.

\subsection{GENERAL BUSINESS RULES}

- All reports must be in one of the official languages of the IAEA.

- Clear distinction should be made between the letter $O$ and the number zero. Throughout Code 10 , the letter is shaped as $\varnothing$, and the number is shaped as 0 .

- The codes specified in Code 10 must be used in nuclear material accounting reports and cannot be translated into another alphabet.

- The only data field that can be in another alphabet is the batch name. If a non-Latin (i.e., non-English) alphabet is used for batch names, procedures should be discussed and established with the IAEA beforehand.

- $\quad$ All reports are on an MBA basis.

- $\quad$ Reporting codes (such as MBA or Facility Code) must be the same as those used in the corresponding facility attachment.

- The following codes are defined in Code 10:

- Inventory change

- Key measurement

- Material description

- Element type

- Weight unit

- Isotope type

- Measurement basis

- The following are also specified in more detail in the facility attachment:

- Inventory change code

- Key measurement code

- Material description code

- Measurement basis code

\subsection{GOOD GENERAL PRACTICES}

- The State needs to know if material in transit has reached its destination, and therefore, the safeguards information system should have the capability to relate and record shipment and receipt records that match. With exports and imports, the State will not have the corresponding nuclear material accounting reports, but the State should have confirmation from the trading partner that the material 
involved was actually imported or exported. That confirmation information should be recorded in the State system. It is possible that there will be a one-to-one match of shipment and receipt records. There can also be one shipment record with several corresponding receipt records. In a similar manner, there can be multiple shipment records with only one corresponding receipt record. Furthermore, a shipment-receipt set of matched records may have several shipment records and several receipt records.

- With domestic transfers, it is useful to include a feature indicating that a corresponding receipt of shipment record has not been received within a given time, after which an investigation will be initiated.

- The IAEA sends reports to the State on the Agency's transit matching results, so it is a good practice for the State to be able to generate reports based on transit matching status for comparison to the IAEA information.

- A follow-up procedure should be implemented by the operator to notify the State when foreign transfers are not confirmed within a given time, including allowances for possible increased transit times as compared with domestic transfers. 


\section{FIXED FORMAT}

A fixed format report consists of one header record followed by up to 99 accounting entry records. All reports have a report number, and all entries have an entry number. The 99-entry-records restriction is a good example of the physical limitations associated with a fixed format report. Only two columns are available for the entry number, thus any report with more than 99 entries must continue with a new report number. Therefore, a good practice is to limit fixed format reports to 90 entries, which allows for the possibility of adding records to the report later if it becomes necessary.

As many reports as necessary should be used to report the accounting entries. For example:

Header Record (Report number: $n$ )

Entry Record: 1

Entry Record: 2

Entry Record: 3

.

-

Entry Record: 99

Header Record (Report number: $\mathrm{n}+1$ )

Entry Record: 1

Entry Record: 2

Entries are listed sequentially without gaps.

The IAEA uses the combination of MBA code, report number, and entry number to reference a specific entry (e.g., MBA NNA2, report number 24, entry number 16). Within each MBA, reports are numbered sequentially (regardless of report type) and without gaps or duplication in the sequence. For example:

1. PIL report number for MBA NNA2: 24

2. ICR report number for MBA NNA2: 25

3. PIL report number for MBA NNA2: 26

4. MBR report number for MBA NNA2: 27

5. $\quad$ PIL report number for MBA NNA2: 28

Multiple reports of different types can be sent to the IAEA in a single submission, but they should be sent in sequential order.

The different types of records, such as ICRs, PILs, and MBRs are designated by the Record Identification data field, column 80 of each record. Each record type and its associated designation are listed in Table 3-1. 
Table 3-1. Record types

\begin{tabular}{|c|c|c|}
\hline Column 80 value & Record type & Form \\
\hline 1 & ICR header record & R.01.1/c \\
\hline 2 & ICR entry record & R.01.1/c \\
\hline 3 & $\begin{array}{c}\text { ICR entry record } \\
\text { (additional isotopes) }\end{array}$ & R.01.2 \\
\hline 4 & PIL header record & R.02.c \\
\hline 5 & PIL entry record & R.02/c \\
\hline 6 & MBR header record & R.03 \\
\hline 7 & MBR entry record & R.03 \\
\hline "C" & Concise note & \\
\hline
\end{tabular}

${ }^{a}$ A separate ICR form (R.01.2) contains data fields for reporting additional isotopes. This form is used only when required in the relevant facility attachment. The header information for this form is the same as in R.01.1/c.

\section{Data Field Justification}

- All numeric data fields are right justified.

- All alphanumeric fields are left justified.

Appendix C, Fixed Format Reporting Codes, contains the reporting codes used in fixed format Code 10 reporting. Appendix D, Fixed Format Reporting Examples, provides completed examples of the various types of fixed format reports discussed below.

\subsection{HEADER RECORD FORMAT}

Regardless of type, each nuclear material accounting report begins with a header record. The header must include information on country, facility, MBA, period covered by the report, report number, and a report type identification number. The system requirements for these categories are the same for ICRs, PILs, and MBRs. Table 3-2 below provides the format for each header data field.

Table 3-2. Format for header records

\begin{tabular}{|c|c|l|l|c|}
\hline Record position & Length & \multicolumn{1}{|c|}{ Data field name } & \multicolumn{1}{|c|}{ Format } & Code 10 paragraph \\
\hline $1-2$ & 2 & Country Code & Alphabetic & n/a \\
\hline $3-4$ & 2 & Unused (left blank) & Alphanumeric & 2 \\
\hline $5-8$ & 4 & Facility Code & Alphanumeric & 2 \\
\hline $9-12$ & 4 & MBA Code & $\begin{array}{l}\text { Numeric } \\
\text { YYMMDD }\end{array}$ & 3 \\
\hline $13-18$ & 6 & $\begin{array}{l}\text { Meporting Period From Date (ICR and } \\
\text { MBR) }\end{array}$ & $\begin{array}{l}\text { Numeric } \\
\text { YYMMDD } \\
\text { MBR) or Inventory Date (PIL) }\end{array}$ & $\begin{array}{l}\text { Appendix to Code 10 } \\
\text { justified }\end{array}$ \\
\hline $19-24$ & 6 & $\begin{array}{l}\text { Reporting Period To Date (ICR and } \\
\text { Number of Entries }\end{array}$ & $\begin{array}{l}\text { n/a } \\
\text { Numeric, right } \\
\text { justified }\end{array}$ & 4 \\
\hline $28-69$ & 42 & Unused (left blank) for electronic \\
reporting and IAEA use & Report Number & \multicolumn{2}{|l|}{} \\
\hline $70-73$ & 4 & &
\end{tabular}


Table 3-2. Format for header records (continued)

\begin{tabular}{|c|c|l|l|c|}
\hline Record position & Length & Data field name & Format & Code 10 paragraph \\
\hline $74-79$ & 6 & $\begin{array}{l}\text { Unused (left blank) for electronic } \\
\text { reporting and IAEA use }\end{array}$ & n/a & \\
\hline 80 & 1 & Record Identification & Numeric & Appendix to Code 10 \\
\hline
\end{tabular}

\section{Business Rules: Header Records}

- $\quad$ Each report must begin with a header record.

- Header records for ICRs and MBRs have the same format.

- Header records for PILs are identical to those of ICRs and MBRs except instead of reporting on a date range, the PIL reports only the date of the (effective) inventory taking.

Below are detailed descriptions and associated business rules for each data field in a header record.

Data Field: Country Code

- Definition: Code of the reporting country.

- Business Rule:

- The current list of possible codes is provided in Appendix A, IAEA Country Codes.

Data Field: Facility Code

- Definition: Facility code of the facility being reported.

- Business Rules:

- The facility code is specified in the facility attachment agreed to with the IAEA.

- The first character(s) in the facility code are the same as the country code for the State.

Data Field: MBA Code

- Definition: MBA code of the MBA being reported.

- Business Rules:

- $\quad$ The MBA code is specified in the facility attachment agreed to with the IAEA.

- The first character(s) of the MBA code are the same as the country code for the State.

Data Field: Reporting Period From Date

- Definition: For ICRs, the beginning date of the reporting period; for MBRs, the beginning date of the material balance period.

- Business Rules:

- For ICRs, the beginning date must be at least equal to the earliest inventory change date in the report. This rule does not apply for corrections, additions, and deletions.

- For MBRs, it must be 1 day after the date of the PIL that ended the previous material balance period.

- For MBRs, it must be 1 day after the ending date of the previous material balance period.

- If reporting for the MBA begins with an ICR, the beginning date of the first material balance period should begin with the earliest inventory change date of the ICRs reported before the first 
PIL. If the first material balance period begins with a "null" PIL, the beginning date of the first ICR must be 1 day following the date of the null PIL.

- $\quad$ For PIL reports, this data field is left blank.

- $\quad$ The date format is YYMMDD.

\section{Data Field: Reporting Period To Date/Inventory Date}

- Definition: For ICR reports, the ending date of the reporting period. For MBRs, the ending date of the material balance period. For PIL reports, the date of the physical inventory taking.

- Business Rules:

- For ICRs, the ending date must be at least equal to the latest inventory change date in the report. This rule does not apply for corrections, additions, and deletions.

- For MBRs, it must be the same date as the PIL at the end of the current material balance period.

- For MBRs, the date is the same as that for the physical inventory taking at the end of the current material balance period.

- For PIL reports, the date of the inventory taking, this must be the same as the last date of the corresponding material balance period.

- The date format is YYMMDD.

\section{Data Field: Number of Entries}

- Definition: Number of entries in the report, including the header record.

- Business Rules:

- $\quad$ The number is the total for all 80-character records contained in a report. The header record and all entries in the report are included.

- The maximum number for the data field is 100 (99 entries plus 1 for the header record).

- If less than three columns are needed, the value is right justified.

\section{Data Field: Report Number}

- Definition: Number of the report.

- Business Rules:

- All reports submitted to the IAEA must be numbered consecutively, beginning with 1 and increasing by 1 , without any gaps. Report numbers are assigned regardless of the report type (e.g., PIL 1, ICR 2, ICR 3, PIL 4, MBR 5, ICR 6).

- If an electronic system is implemented to replace a manual (i.e., hard copy) procedure, the first report number in the electronic system must be the next number in the sequence. For example, if the last hard copy report submitted to the IAEA was 124, the first report number of the electronic system must be 125 .

- If less than four columns are needed, the value is right justified.

\section{Data Field: Record Identification}

- Definition: Header record type.

- Business Rules:

- If the header record is for an ICR report, this value must be 1 .

- If the header record is for a PIL report, this value must be 4 .

- $\quad$ If the header record is for an MBR report, this value must be 6 . 


\subsection{INVENTORY CHANGE REPORTS}

Over time, the inventory of nuclear material at an MBA may change due to shipments; receipts; nuclear transformation (e.g., production of plutonium and consumption of uranium); transfers to waste; process losses; and accidental gains or losses of material. Most inventory changes involve the movement of material across the MBA border; however, several inventory changes (e.g., nuclear transformations, uranium category changes and blending) occur within the MBA boundaries. These inventory changes must be reported to the IAEA in an ICR, indicating the key measurement point (KMP) involved in the change. ICRs must be sent to the IAEA within 30 days of the end of the month in which the change occurs.

The paper form for ICRs is also referenced as Form R.01.1/c. An example of the R.01.1/c form is provided in Appendix B, Fixed Format Reporting Forms. Electronic submissions follow the same format as paper forms except that some data fields on the paper form (e.g., Header Signature) may not apply to electronic submissions. Table 3-3 describes the record format for ICRs submitted electronically.

Table 3-3. Record format for inventory change reports

\begin{tabular}{|c|c|c|c|c|}
\hline $\begin{array}{l}\text { Record } \\
\text { position }\end{array}$ & Length & Data field name & Format & Code 10 paragraph \\
\hline $1-2$ & 2 & Entry Number & Numeric & 7 \\
\hline 3 & 1 & Continuation & Alphabetic & 8,55 \\
\hline $4-9$ & 6 & Date of Inventory Change & $\begin{array}{l}\text { Numeric: } \\
\text { YYMMDD }\end{array}$ & 9 \\
\hline $10-13$ & 4 & MBA/Country From & Alphanumeric & 10 \\
\hline $14-17$ & 4 & MBA/Country To & Alphanumeric & 10 \\
\hline $18-19$ & 2 & Type of Inventory Change & Alphabetic & 11 \\
\hline 20 & 1 & KMP Code & Alphanumeric & 12 \\
\hline $21-28$ & 8 & Name or Number of Batch & Alphanumeric & 13 \\
\hline $29-32$ & 4 & Number of Items in Batch & Numeric & 14 \\
\hline $33-36$ & 4 & Material Description & Alphanumeric & 15 \\
\hline 37 & 1 & Element & Alphabetic & 16 \\
\hline $38-45$ & 8 & Weight of Element & Alphanumeric & 17 \\
\hline $46-47$ & 2 & Weight Unit & Alphabetic & 18 \\
\hline $48-55$ & 8 & Weight of Fissile Isotopes & Alphanumeric & 8 \\
\hline 56 & 1 & Isotope Code & Alphabetic & 20 \\
\hline $57-71$ & 15 & Unused (left blank) & $\mathrm{n} / \mathrm{a}$ & \\
\hline 72 & 1 & Measurement Basis & Alphabetic & 21 \\
\hline 73 & 1 & Concise Note $^{a}$ & Alphabetic & 22 \\
\hline $74-77$ & 4 & $\begin{array}{l}\text { Correction To: Report } \\
\text { Number }^{b}\end{array}$ & Numeric & 23 \\
\hline $78-79$ & 2 & $\begin{array}{l}\text { Correction To: Entry } \\
\text { Number }^{b}\end{array}$ & Numeric & 23 \\
\hline 80 & 1 & $\begin{array}{l}\text { Record Identification } \\
\text { (2 for ICRs) }\end{array}$ & Numeric & \\
\hline
\end{tabular}

${ }^{a}$ This data field is left blank unless a concise note is attached that refers to the record.

${ }^{b}$ This data field is left blank unless the record is a correction to a previous record. 


\section{Business Rules: ICR}

- Report all changes in quantities of nuclear material in an MBA on the date the change occurred or was established.

- The beginning date of the reporting period must be the same date or prior to the earliest inventory change date in the report entries (excluding corrections and additions).

- The ending date of the period must be on or after the same date as the latest inventory change date in the report entries.

- If there is no inventory at an MBA when safeguards assessment begins, an ICR reporting the receipt of material will be the first accounting report normally received by the IAEA. Another option is for the first nuclear material accounting report to be a null PIL, indicating there are no batches on the inventory.

- Inventory changes that occur on the same date as a physical inventory taking (PIT) are to be reflected in the corresponding PIL.

Below are detailed descriptions and associated business rules for each data field in an ICR entry record.

Data Field: Entry Number

- Definition: Reference number of the accounting entry.

- Business Rules:

- Within a report number, the entry numbers always begin with 1 and increase sequentially with no gaps or duplications.

- $\quad$ There is a maximum of 99 entries in a report. If more than 99 lines are to be listed, two or more reports should be prepared, each of which should bear a different number.

\section{Data Field: Continuation}

- Definition: A new, continuation, or inactive entry.

- Business Rules:

- Leave blank for a new entry.

- Enter C for a continuation entry. For additional information on continuations, refer to Section 3.5.2 of this document.

- $\mathrm{C}$ is not allowed for the first entry on a report unless it is a correction to a previously reported C entry.

- Enter A to indicate that the content of the line in question should not influence any of the nuclear material accounts, which means the line is inactive as described in Section 3.5.7 of this document, which address deletions.

\section{Data Field: Date of Inventory Change}

- Definition: Date the inventory change occurred or was established.

- Business Rules:

- The date must be within the time defined by the From and To dates in the corresponding header record of the report.

- If the record is a correction to a previous report, the date must be within the header date period of the report being corrected. 
- If the record is in addition to a previous report, the date must be within the header date period of the report to which the entry is to be added.

- $\quad$ The date should not be later than the date the entry was reported to the IAEA.

\section{Data Field: MBA/Country From}

- Definition: Shipper of the nuclear material.

- Business Rules:

- For shipments, the code of the reporting MBA must be used.

- For imports, the code of the shipping country can be reported if the shipping MBA in that country is not known.

- Domestic receipts must indicate the shipping MBA.

- For inventory changes that do not involve a transfer of materials to or from the MBA (e.g. nuclear production of plutonium), the code of the reporting MBA should be used.

\section{Data Field: MBA/Country To}

- Definition: Receiver of the nuclear material.

- Business Rules:

- For receipts, the code of the reporting MBA must be used.

- For exports, the code of the receiving country can be reported if the receiving MBA in that country is not known.

- Domestic shipments must indicate the receiving MBA.

- For inventory changes that do not involve a transfer of materials to or from the MBA (e.g., nuclear production of plutonium), the code of the reporting MBA should be used.

\section{Data Field: Type of Inventory Change}

- Definition: Type of inventory change.

- Business Rules:

- The list of possible codes is provided in Appendix C.

- The facility attachment also lists those inventory change codes that are expected in the facility.

- This information need not be repeated if this is a continuation entry.

- An increase or decrease in a given batch content (codes RM and RP, respectively) should be reported simultaneously in separate entries as if they were inventory changes. This procedure may also be used whenever a batch ceases to exist altogether (i.e., all material is transferred into another batch, when a batch is simply renamed).

- A shipper/receiver difference (DI) is calculated by subtracting the receiver weight from the shipper weight; a negative DI is an increase in the inventory, and a positive DI is a decrease.

- When the category changes as a result of blending, enrichment, or irradiation, the entry should be as follows:

- First character: "original” element code.

- Second character: "resulting” element code.

\section{Data Field: KMP Code}

- Definition: A KMP is a location where nuclear material appears in such a form that it may be measured to determine material flow or inventory. KMPs thus include but are not limited to the inputs and outputs, including measured discards, and storages in MBAs. 
- Business Rules:

- The practice is for flow KMP codes in ICRs to be numbers, but it is possible for letters to be used, if the KMP structure requires more than $10 \mathrm{KMPs}$ and the use of letters is agreed in the facility attachment. For some inventory change codes (e.g., rebatching), the asterisk $\left(^{*}\right)$ may be specified in the facility attachment.

- Valid KMP codes are listed in the State's facility attachment.

- This information need not be repeated if this is a continuation entry.

\section{Data Field: Name or Number of Batch}

- Definition: Name or number given to a batch of nuclear material.

- Business Rules:

- Batch names/numbers are designated by the State.

- Where possible, batch names/numbers should be unique.

- Each batch of nuclear material must have a name or number.

- The name can consist of letters, numbers, and special characters such as commas and hyphens.

- The special characters of colon (:), semi-colon (;), slash (/), and number sign (\#) should be avoided if there are expectations the State will change to the labeled format Code 10 at some point in the future.

- The shipment from one MBA and the receipt in another MBA of a given batch of nuclear material should be reported under the same batch name.

- No two batches sent from the same shipper to the same receiver relating to material of the same material description on the same date should bear the same name.

- This information need not be repeated if this is a continuation entry.

Data Field: Number of Items in Batch

- Definition: A count of the items in a batch.

- Business Rules:

- Several items can be grouped into a single batch if those items have similar material characteristics as defined in the facility attachment.

- It is possible for the number of items to be zero for some type of bulk materials and when the number would not be meaningful.

- If the number of items is greater than four digits, additional entries should be reported, as described in the continuation procedure in Section 3.5.2 of this document.

\section{Data Field: Material Description}

- Definition: The physical, chemical, packaging, and irradiation status of a batch.

- Business Rules:

- The list of possible codes provided in Appendix C should be used unless otherwise indicated in the relevant facility attachment.

- Valid material description codes used in the MBA are defined in the State's facility attachment.

- The first character describes the physical form of the material.

- The second character describes the chemical form of the material.

- The third character describes the type of containment for the material.

- The fourth character describes the irradiation status of the material.

- This information need not be repeated if this is a continuation entry. 


\section{Data Field: Element}

- Definition: Element of the nuclear material being reported.

- Business Rules:

- The list of possible codes provided in Appendix C should be used unless otherwise indicated in the relevant facility attachment.

- If in a given MBA the code for unified uranium (U) is used, D, N, and E cannot be used.

- If uranium categories $\mathrm{D}, \mathrm{N}$, and $\mathrm{E}$ are used for uranium accounting in the MBA, U cannot be used.

\section{Data Field: Weight of Element}

- Definition: Weight of the element noted in the Element data field, including the decimal point.

- Business Rules:

- Weight units vary depending on the element being reported. The list of possible values is included in Appendix C.

- If desired, data may be rounded but not beyond the nearest integer of the unit used. (This may necessitate the reporting of rounding adjustments in MBRs.) If rounded, the weights of individual items in a batch should be added together before the sum is rounded. (Digits 1-4 should be rounded down. Digits 5-9 should be rounded up.)

- The system design should consider the level of significance to be reported to the IAEA and also should be reflected in facility records.

- In reporting weight data, the decimal point should be considered as a separate character.

- Shipper/receiver differences may have to be expressed by negative quantities, in which case the minus sign (which is also a separate character) should be placed in the same data field as, and just in front of, the number. In addition, there may be other specific accounting procedures where negative values will need to be reported, such as for the return of discharged fuel to a reactor core.

- For weights exceeding the eight-character length limit, additional entries should be reported as described in the continuation procedure in Section 3.5.2 of this document.

- The sum of the weights in all continuation entries for an entry must equal the total to be reported for the batch.

\section{Data Field: Weight Unit}

- Definition: Weight unit used in the Weight of Element data field.

- Business Rules:

- Use g for reporting grams of weight. This value should be left justified.

- Use kg for reporting kilograms of weight.

- Depleted uranium, natural uranium, and thorium are reported in kilograms.

- Enriched uranium, unified uranium, and plutonium are reported in grams.

\section{Data Field: Weight of Fissile Isotopes}

- Definition: Weight of the uranium isotope in the entry, including the decimal point.

- Business Rules:

- This data field is only for enriched uranium or unified uranium reporting. For all other reporting, it should be left blank, unless the facility attachment requires the fissile weight for depleted and/or natural uranium. The reporting of depleted and natural fissile content is used only for specific facility types and will be a point of negotiation in the facility attachment. Otherwise, the 
data field must be blank (i.e., a zero should not be reported), except for enriched and unified uranium.

- All fissile weights are reported in grams.

- For weight exceeding the eight-character length limit, additional entries should be reported as described in the continuation procedure in Section 3.5.2 of this document.

- The sum of weights in all continuation entries for an entry must equal the total to be reported for the batch.

\section{Data Field: Isotope Code}

- Definition: Type of uranium isotope being reported.

- Business Rules:

- This data field is only for enriched uranium or unified uranium reporting.

- The list of possible codes is provided in Appendix C.

- Other isotopes are not reported for uranium or other elements unless specified in the relevant facility attachment.

\section{Data Field: Measurement Basis}

- Definition: The source of weight values for a batch of nuclear material, including whether the batch weights are established in the reporting MBA or in another MBA and whether the batch weights have been reported before by the MBA.

- Business Rule(s):

- The list of possible codes is provided in Appendix C.

- The codes to be used in an MBA are specified in the relevant facility attachment.

- It is necessary to know and track the origin of the nuclear material quantities in a batch.

- The correct code to report can be determined by knowing if the batch quantities are measured/established in the reporting MBA and if it is the first time the amounts are being reported.

In the flowchart shown in Figure 3-1, the decision process for determining the measurement basis is specified. The data field is named Measurement Basis (i.e., determination of the nuclear material amounts) and does not necessarily indicate a measurement had been made. One example of this is the calculation of produced plutonium contained in discharged power reactor fuel. 
The measurement basis code indicates if the batch data is determined in the reporting MBA and if the data has been reported in a previous ICR or PIL

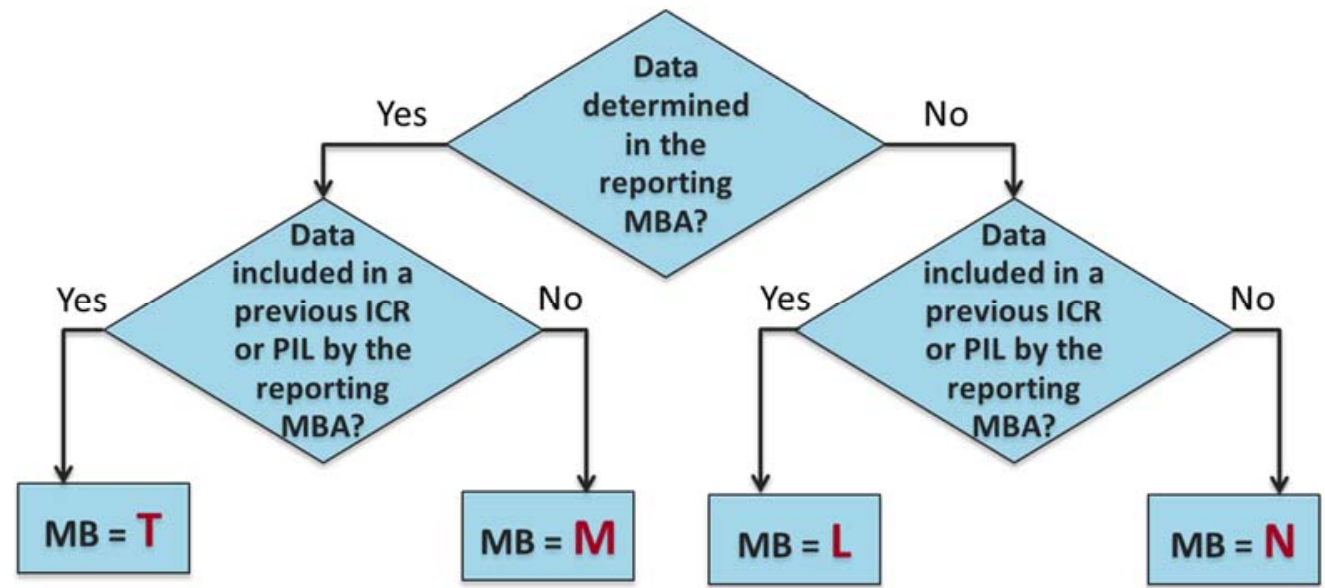

"Measurement" means the MBA determines the batch data by weighing, analysis or some other means, such as computing uranium burnup in reactor fuel

Figure 3-1. Flowchart for determining the measurement basis code.

The following diagram (Figure 3-2) provides an example of how the measurement basis changes as a fuel assembly moves from the manufacturer to the reactor, into the reactor core, discharge from the core and then shipment from the reactor MBA.

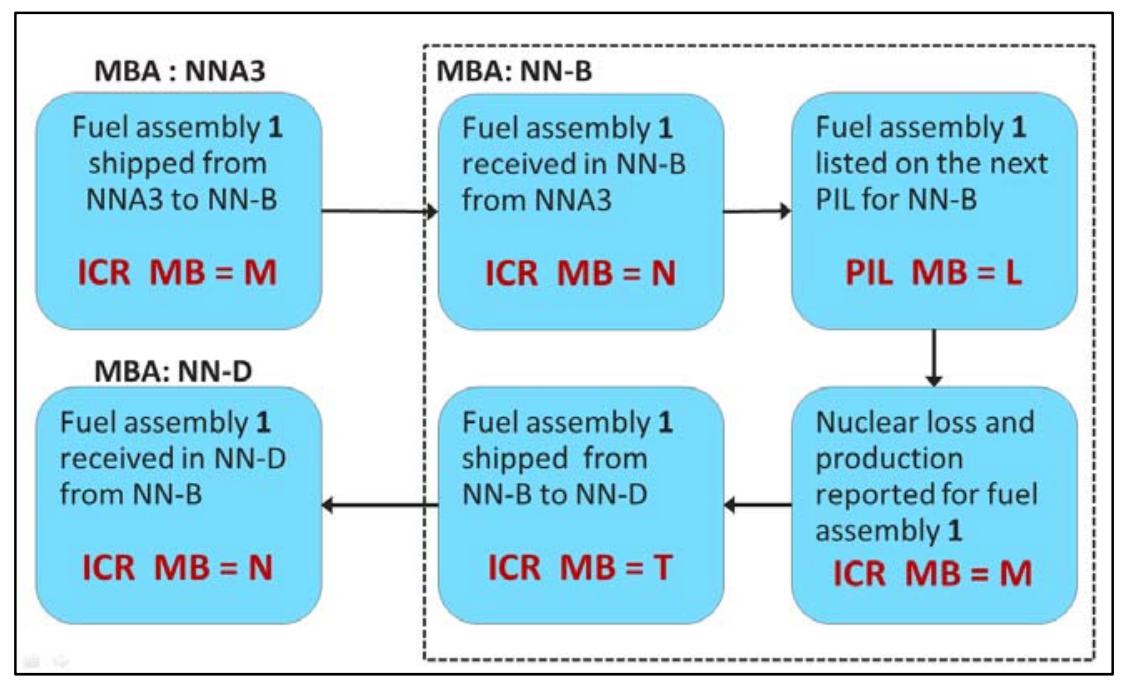

Figure 3-2. Example of how measurement basis is applied.

In MBA NNA3, the fuel assembly is completed, the amount of nuclear material is determined, and the assembly is shipped $(\mathrm{MB}=\mathrm{M})$ to the reactor MBA NN-B prior to the next PIL for NNA3. Upon receipt in NN-B, the shipper values are reported, and because the amounts were determined in another MBA (NNA3) and this is the first time the values have been reported in an accounting report for NN-B, $\mathrm{MB}=\mathrm{N}$. 
When the assembly is listed on the first PIL for NN-B, MB = L because the weights have been determined in another MBA (i.e., NNA3) and the amounts have been reported on a previous accounting report (i.e., an ICR from NN-B for the receipt).

Once the nuclear loss and production of uranium and plutonium have been calculated, those amounts are reported with $\mathrm{MB}=\mathrm{M}$ because NN-B has determined the values and this is the first time those are being reported. Likewise, when the fuel assembly is reported on the next PIL for NN-B, those amounts would also be reported with $\mathrm{MB}=\mathrm{M}$, reflecting the original assembly weights adjusted by the nuclear loss and production.

After remaining in the reactor spent fuel storage for (typically) a number of years during which the assembly would be listed on the interleaving PILs with $\mathrm{MB}=\mathrm{T}$, the shipment of the assembly would also be reported with $\mathrm{MB}=\mathrm{T}$.

Receipt of the fuel assembly in MBA NN-D would be reported with $\mathrm{MB}=\mathrm{N}$ because this is the first time the weights have been reported by NN-D and the amounts were determined in another MBA (i.e., NN-B).

\section{Data Field: Concise Note Indicator}

- Definition: Indicates if a concise note is attached that refers to the accounting record.

- Business Rule:

- An X indicates that there is a concise note record for this entry.

- If the entry is left blank, no concise note is attached.

\section{Data Field: Correction to Report Number}

- Definition: Report number in which a record will be added, corrected, or deleted.

- Business Rules:

- A valid report number must be included for the MBA.

- If this data field is left blank, the Correction to Entry Number data field must also be blank.

- An ICR can only be corrected by another ICR, a PIL can only be corrected by another PIL, and an MBR can only be corrected by another MBR.

\section{Data Field: Correction to Entry Number}

- Definition: Entry number of the Correction to Report Number data field related to an addition, correction, or deletion.

- Business Rules:

- If this data field is not left blank, the Correction to Report Number data field cannot be blank.

- For corrections and deletions, the entry number in the referenced report must be given.

- For additions, the entry number must be one greater than the entries in the referenced report, including all previous additions, and must be less than 100 .

\section{Data Field: Record Identification}

- Definition: Record type.

- Business Rule:

- $\quad$ For an ICR report, this value must be 2 . 


\subsubsection{Inventory Change Reports for Additional Isotopes}

As noted in Table 3-1, the ICR form for additional isotopes (R.01.2) is used only when it is required by the relevant facility attachment. If the facility attachment does provide for such use, the following business rules apply. An example of the R.01.2 form is provided in Appendix B.

\section{Business Rules: ICR (Additional Isotopes)}

- Additional isotope reporting is only for ICRs.

- Data are recorded as a percentage of the element weight.

- Each percentage has a maximum of six positions, one of which is a decimal point.

- For a batch with uranium and plutonium, two-line entries are needed, one for each element.

- The measurement basis should be the same as that for the primary ICR entry to which the isotope entry refers.

\subsection{PHYSICAL INVENTORY LISTINGS}

Each MBA contains an inventory of nuclear material that must be reported to the IAEA. The timing of the (effective) inventory taking is normally specified in the facility attachment. This inventory is reported as a PIL, indicating the batches present at each inventory KMP. The PIL provides a complete statement of the physical inventory of an MBA at the time of the physical inventory taking. The PIL is due to the IAEA within 30 days after taking the physical inventory.

The paper form for PILs is also referenced as Form R.02/c. An example of the R.02/c form is provided in Appendix B. Electronic submissions follow the same format as paper forms, except that some data fields on the paper form (e.g., header signature) may not apply to electronic submissions.

Table 3-4 describes the record format for PILs submitted electronically.

Table 3-4. Record format for physical inventory listings

\begin{tabular}{|c|c|l|l|c|}
\hline Record position & Length & \multicolumn{1}{|c|}{ Data field name } & \multicolumn{1}{|c|}{ Format } & Code 10 paragraph \\
\hline $1-2$ & 2 & Entry Number & Numeric & 31 \\
\hline 3 & 1 & Continuation & Alphabetic & 32 \\
\hline $4-19$ & 16 & Unused (left blank) & n/a & \\
\hline 20 & 1 & KMP Code & Alphanumeric & 33,12 \\
\hline $21-28$ & 8 & Name or Number of Batch & Alphanumeric & 13 \\
\hline $29-32$ & 4 & Number of Items in Batch & Numeric & 14 \\
\hline $33-36$ & 4 & Material Description & Alphanumeric & 15 \\
\hline 37 & 1 & Element & Alphabetic & 16 \\
\hline $38-45$ & 8 & Weight of Element & Alphanumeric & 17 \\
\hline $46-47$ & 2 & Weight Unit & Alphabetic & 18 \\
\hline $48-55$ & 8 & Weight of Fissile Isotopes & Alphanumeric & 19 \\
\hline 56 & 1 & Isotope Code & Alphabetic & 20 \\
\hline $57-71$ & 15 & Unused (left blank) & n/a & \\
\hline
\end{tabular}


Table 3-4. Record format for physical inventory listings (continued)

\begin{tabular}{|c|c|l|l|c|}
\hline Record position & Length & Data field name & Format & Code 10 paragraph \\
\hline 72 & 1 & Measurement Basis $^{a}$ & Alphabetic & 21 \\
\hline 73 & 1 & Concise Note $^{a}$ & Alphabetic & 22 \\
\hline $74-77$ & 4 & Correction To: Report Number $^{b}$ & Numeric & 23 \\
\hline $78-79$ & 2 & Correction To: Entry Number $^{b}$ & Numeric & 23 \\
\hline 80 & 1 & Record Identification (5 for PILs) $^{\text {Numeric }}$ & \\
\hline
\end{tabular}

${ }^{a}$ This data field is left blank unless a concise note is attached that refers to the record.

${ }^{b}$ This data field is left blank unless the record is a correction to a previous record.

\section{Business Rules: PILs}

- List all batches as separate entries. Typical batches in the MBA are defined in the relevant facility attachment.

- $\quad$ The PIL must be dispatched along with the associated MBR, as required in the safeguards agreement.

- The listing provides one entry for each batch of nuclear material present in the MBA as of midnight on the date of the PIT or on an agreed date (usually the last day) of a PIT that takes several days.

- If there is nuclear material in the MBA when the MBA comes under safeguards, an initial PIL is submitted listing all the nuclear material batches.

- A PIL should be prepared even if at the time of the PIT there is no nuclear material in the MBA. Such a "null" PIL should contain the heading information and a one-line entry with " $\mathrm{A}$ " in position 3 . The remainder of the line should be blank.

- If there is no inventory of nuclear material when the MBA comes under safeguards, a null initial PIL is not required but it is a good practice to provide one to the Agency.

- A PIL should be attached to each MBR or set of MBRs for different material categories pertaining to the same period.

- There are situations, due to rounding, when the physical inventory will not exactly match the information reported on the PIL. For reporting purposes, the weights of individual items in the batch shall be added together before rounding to the nearest unit. The corresponding values reported for inventory on the PIL and MBR must agree.

Below are detailed descriptions and associated business rules for each data field in an ICR entry record.

\section{Data Field: Entry Number}

- Definition: Reference number of the accounting entry.

- Business Rules:

- Within a report number, the entry numbers always begin with 1 and increase sequentially with no gaps or duplication.

- There is a maximum of 99 entries in a report. If more than 99 lines are to be listed, additional reports should be prepared, each of which should bear a different number. 


\section{Data Field: Continuation}

- Definition: A new, continuation, or inactive entry.

- Business Rules:

- Leave blank for a new entry.

- Enter C for a continuation entry. For additional information on continuations, refer to the continuation procedure in Section 3.5.2 of this document.

- “C” is not allowed for the first entry on a report unless it is a correction to a previously reported C entry.

- Enter A to indicate that the content of the line in question should not influence any of the nuclear material accounts, which means the line is inactive as described in Section 3.5.7 of this document, which addresses deletion.

\section{Data Field: KMP Code}

- Definition: A KMP is a location where nuclear material appears in such a form that it may be measured to determine material flow or inventory. KMPs thus include but are not limited to the inputs and outputs, including measured discards, and storages in MBAs.

- Business Rules:

- The practice is for inventory KMP codes in PILs to be letters, but numbers may be used if the KMP structure requires more than 26 KMPs and the use of numbers is agreed in the facility attachment. However, this option is rarely used, and the best solution is for another MBA to be established. This situation is common with MBAs for locations outside facilities.

- Only inventory KMP codes in the facility attachment can be used.

- This information need not be repeated if this is a continuation entry.

Data Field: Name or Number of Batch

- Definition: Name or number given to the batch of nuclear material reported in this entry.

- Business Rules:

- Batch Names/Numbers are designated by the State.

- Where possible, batch names/numbers should be unique.

- Each batch of nuclear material must have a name or number.

- The name can consist of letters, numbers, and special characters such as commas and hyphens.

- The special characters of colon (:), semi-colon (;), slash (/), and number sign (\#) should be avoided if there are expectations the State will change to the labeled format Code 10 at some point in the future.

- This information need not be repeated if this is a continuation entry.

\section{Data Field: Number of Items in Batch}

- Definition: A count of the number of items in a batch.

- Business Rules:

- Several items can be grouped into a single batch as long as those items have similar material characteristics, as defined in the facility attachment.

- It is possible for the number of items to be zero for some types of bulk materials and when the number would not be meaningful.

- If the number of items is greater than four digits, additional entries should be reported, as described in the continuation procedure in Section 3.5.2 of this document. 


\section{Data Field: Material Description}

- Definition: The physical, chemical, packaging, and irradiation status of a batch.

- Business Rules:

- The list of possible codes provided in Appendix C should be used unless otherwise indicated in the relevant facility attachment.

- Valid material description codes used in the MBA are defined in the State's facility attachment.

- The first character describes the physical form of the material.

- The second character describes the chemical form of the material.

- The third character describes the type of containment for the material.

- The fourth character describes the irradiation status of the material.

- This information need not be repeated if this is a continuation entry.

\section{Data Field: Element}

- Definition: Element of the nuclear material being reported.

- Business Rules:

- The list of possible codes provided in Appendix C should be used unless otherwise indicated in the relevant facility attachment.

- If in a given MBA the code for unified uranium (U) is used, D, N, and E cannot be used.

- If uranium categories (D, N, or E) are used for uranium accounting in the MBA, U cannot be used.

\section{Data Field: Weight of Element}

- Definition: The weight of the element noted in the Element data field.

- Business Rules:

- Weight units vary depending on the element being reported. The list of possible values is included in Appendix C.

- If desired, data may be rounded, but not beyond the nearest integer of the unit used. (This may necessitate the reporting of rounding adjustments in MBRs.) If rounded, the weights of individual items in a batch should be added together before the sum is rounded. (Digits 1-4 should be rounded down. Digits 5-9 should be rounded up.)

- The system design should consider the level of significance to be reported to the IAEA and also should be reflected in facility records.

- In reporting weight data, the decimal point should be considered as a separate character.

- For weights exceeding the eight-character length limit, additional entries should be reported, as described in the continuation procedure in Section 3.5.2 of this document.

- The sum of the weights in all continuation entries for an entry must equal the total to be reported for the batch.

\section{Data Field: Weight Unit}

- Definition: Weight unit used in reporting the Weight of Element data field.

- Business Rules:

- $\quad$ Use g for reporting grams of weight. This value should be left justified.

- Use kg for reporting kilograms of weight.

- Depleted uranium, natural uranium, and thorium are reported in kilograms.

- Enriched uranium, unified uranium, and plutonium are reported in grams. 


\section{Data Field: Weight of Fissile Isotopes}

- Definition: Weight of the uranium isotope in the entry, including the decimal point.

- Business Rules:

- This data field is only for enriched uranium or unified uranium reporting. For all other reporting, it should be left blank, unless the facility attachment requires the fissile weight for depleted and/or natural uranium. The reporting of depleted and natural fissile content is used only for specific facility types and will be a point of negotiation in the facility attachment. Otherwise, the data field must be blank (i.e., a zero should not be reported), except for enriched and unified uranium.

- All fissile weights are reported in grams.

- For weight exceeding the eight-character length limit, additional entries should be reported, as described in the continuation procedure in Section 3.5.2.

- The sum of weights in all continuation entries for an entry must equal the total to be reported for the batch.

\section{Data Field: Isotope Code}

- Definition: Type of uranium isotope being reported.

- Business Rules:

- This data field is only for enriched uranium or unified uranium reporting.

- Other isotopes are not reported for uranium or other elements unless specified in the State's relevant facility attachment.

- The list of possible codes is provided in Appendix C.

Data Field: Measurement Basis

- Definition: This data field is used to describe the source of weight values for a batch of nuclear material. It indicates if the batch weights are established in the reporting MBA or in another MBA. It also specifies if the MBA has reported the batch weights before.

- Business Rules:

- The list of possible codes is provided in Appendix C.

- $\quad$ The codes to be used in an MBA should be specified in the relevant facility attachment.

- It is necessary to know and track the origin of the nuclear material quantities in a batch.

- The correct code to report can be determined by knowing if the batch quantities are measured/established in the reporting MBA and if it is the first time the amounts are being reported.

Figure 3-2 in Section 3.2 provides an example of how the measurement basis can change as a fuel assembly moves from the manufacturer to the reactor, into the reactor core, discharge from the core, and then shipment from the reactor MBA.

\section{Data Field: Concise Note Indicator}

- Definition: Indicates if a concise note is attached that refers to the accounting record.

- Business Rules:

- $\quad \mathrm{X}$ indicates that there is a concise note record for this entry.

- Left blank if no concise note is attached. 


\section{Data Field: Correction to Report Number}

- Definition: Report number in which a record will be added, corrected, or deleted.

- Business Rules:

- $\quad$ Must be a valid report number for the MBA.

- If this data field is blank, the Correction to Entry Number data field must also be blank.

- An ICR can only be corrected by another ICR, a PIL can only be corrected by another PIL, and an MBR can only be corrected by another MBR.

Data Field: Correction to Entry Number

- Definition: Entry number of the Correction to Report Number data field related to an addition, correction, or deletion.

- Business Rules:

- If this data field is not blank, the Correction to Report Number data field cannot be blank.

- For corrections and deletions, there must be an entry number in the referenced report.

- For additions, the entry must be one greater than the entries in the referenced report (including all previous additions) and must be less than 100 .

\section{Data Field: Record Identification}

- Definition: Record type.

- Business Rule:

- $\quad$ For a PIL report, this value must be 5.

\subsection{MATERIAL BALANCE REPORTS}

MBRs provide a nuclear material accounting balance for each type of nuclear material in an MBA. An MBR sent to the IAEA should reflect information in the corresponding MBA records for a facility. For the reported material balance period and each nuclear material account, the MBR must be consistent with:

- the physical inventory at the end of the previous material balance period, which is also the physical beginning inventory (PB) of the period to be reported (i.e., the current period);

- $\quad$ the total of each inventory change type dated within the current period;

- $\quad$ the physical inventory at the end of the current material balance period;

- $\quad$ adjustments to the inventory, such as those due to rounding; and

- $\quad$ any material unaccounted for (MUF).

The balance begins 1 day after the date of the previous PIL and ends on the date of the PIL at the end of the balance period. The report for the time period between the consecutive PILs is referred to as the MBR. The MBR must be sent to the IAEA within 30 days of the end of the material balance period.

The paper form for MBRs is also referenced as Form R.03. An example of the R.03 form is provided in Appendix B. Electronic submissions follow the same format as paper forms except that some data fields on the paper form (e.g., header signature) may not apply to electronic submissions.

Table 3-5 describes the record format for MBRs submitted electronically. 
Table 3-5. Record format for material balance reports

\begin{tabular}{|c|c|c|c|c|}
\hline Record position & Length & Data field name & Format & Code 10 paragraph \\
\hline $1-2$ & 2 & Entry Number & Numeric & 31 \\
\hline 3 & 1 & Continuation & Alphabetic & 32 \\
\hline $4-17$ & 14 & Unused (left blank) & $\mathrm{n} / \mathrm{a}$ & \\
\hline $18-21$ & 4 & Entry Name & Alphabetic & 11,48 \\
\hline $22-36$ & 15 & Unused (left blank) & $\mathrm{n} / \mathrm{a}$ & \\
\hline 37 & 1 & Element & Alphabetic & 16 \\
\hline $38-45$ & 8 & Weight of Element & Alphanumeric & 17 \\
\hline $46-47$ & 2 & Weight Unit & Alphabetic & 18 \\
\hline $48-55$ & 8 & Weight of Fissile Isotopes & Alphanumeric & 19 \\
\hline 56 & 1 & Isotope Code & Alphabetic & 20 \\
\hline $57-72$ & 16 & Unused (left blank) & $\mathrm{n} / \mathrm{a}$ & \\
\hline 73 & 1 & Concise Note ${ }^{a}$ & Alphabetic & 22 \\
\hline $74-77$ & 4 & Correction To: Report Number ${ }^{b}$ & Numeric & 23 \\
\hline $78-79$ & 2 & Correction To: Entry Number ${ }^{b}$ & Numeric & 23 \\
\hline 80 & 1 & $\begin{array}{l}\text { Record Identification ( } 7 \text { for } \\
\text { MBRs) }\end{array}$ & Numeric & \\
\hline
\end{tabular}

${ }^{a}$ This data field is left blank unless the record indicates a concise note is attached to the record. ${ }^{b}$ This data field is left blank unless the record is a correction to a previous record.

\section{Business Rules: Material Balance Report}

- An MBR must be prepared for each category of nuclear material in the MBA, the codes of which are provided in Appendix C.

- $\quad$ The MBR must show the material balance(s) of all nuclear material present in the MBA.

- $\quad$ The MBR must cover the time period between two consecutive physical inventory takings.

- $\quad$ The MBR must include the PB inventory, ending book inventory, and physical ending inventory $(\mathrm{PE})$.

- An MBR must be prepared even if at the time of physical inventory taking there was no nuclear material in the MBA and there were no transactions during the material balance period. Such a null MBR should contain the heading information, and a one-line entry with A in position 3 . The remainder of the line should be blank.

- $\quad$ No MBR is required for a category of nuclear material that is established only upon shipment of that material, and for the exclusive purpose of reporting such a shipment, see the Category Change procedure in Section 3.5.3 of this document. Nevertheless, it is possible for a State to report an MBR for the shipped material.

- MBRs should be prepared on the basis of unrounded nuclear material quantity data obtained from the accounting records.

- The preparation of entry data requires summation (straightforward or algebraic); this should be done with unrounded data. 
- For reporting, the MBR data may be rounded, but not beyond the nearest integer unit (i.e., gram or kilogram, depending on the type of material).

- The use of rounding in any of the reports (i.e., ICRs, PILs, or MBRs) will generally necessitate the calculation and reporting of rounding adjustments in MBRs.

- The reporting period to which the MBR pertains should be deemed to be closed at midnight of the "To" date indicated; that is, any inventory change taking place on that date should be considered as being covered by the MBR. The next material balance period should begin at zero hour of the next day.

- $\quad$ Several MBRs may be transmitted together under the same report number.

Below are detailed descriptions and associated business rules for each data field in an MBR entry record.

\section{Data Field: Entry Number}

- Definition: Reference number of the accounting entry.

- Business Rules:

- Within a report number, the entry numbers always begin with 1 and increase sequentially with no gaps or duplications.

- $\quad$ There is a maximum of 99 entries in a report. If more than 99 lines are to be listed, two or more reports should be prepared, each of which should bear a different number.

Data Field: Continuation

- Definition: A new, continuation, or inactive entry.

- Business Rules:

- Leave blank for a new entry.

- Enter C for a continuation entry. For additional information on continuations, refer to the continuation procedure in Section 3.5.2 of this document.

- $\quad \mathrm{C}$ is not allowed for the first entry on a report unless it is correcting a $\mathrm{C}$ entry in a previous report.

- Enter A to indicate that the content of the line in question should not influence any of the nuclear material account, which means the line is inactive as described in Section 3.5.7 of this document, which addresses deletion.

Data Field: Entry Name

- Definition: Type of inventory, adjustment, or summarized MBR entry.

- Business Rules:

- Accounting entries as defined in paragraph 48 of Code 10 should be reported

- If any inventory changes are reported during the material balance period, those must be summarized and reported using the corresponding inventory change code. The list of possible codes is provided in Appendix C.

- Summarized inventory changes are reported as separate entries, one for each inventory change code.

- $\quad$ Rounding adjustments or materials unaccounted for should be reported, if necessary.

Data Field: Element

- Definition: Element of the nuclear material being reported. 
- Business Rules:

- The list of possible codes provided in Appendix C should be used unless otherwise indicated in the relevant facility attachment.

- If in a given MBA the code for unified uranium (U) is used, $\mathrm{D}, \mathrm{N}$, and $\mathrm{E}$ cannot be used.

- If uranium categories (D, N, or E) are used for uranium accounting in the MBA, U cannot be used.

\section{Data Field: Weight of Element}

- Definition: Weight of the element noted in the Element data field.

- Business Rules:

- If desired, data may be rounded, but not beyond the nearest integer of the unit used. (This may necessitate the reporting of rounding adjustments in MBRs.) If rounded, the weights of individual items in a batch should be added together before the sum is rounded. (Digits 1-4 should be rounded down. Digits 5-9 should be rounded up.)

- The system design should consider the level of significance to be reported to the IAEA and also should be reflected in facility records.

- In reporting data, the decimal point should be considered as a separate character.

- The system design should consider the level of significance to be reported to the IAEA and also should be reflected in facility records.

- Shipper/receiver differences, MUF, and rounding adjustments may have to be expressed by negative quantities, in which case the minus sign (which is also a separate character) should be placed in the same data field as, and just in front of, the number. In addition, there may be other specific accounting procedures where negative values will need to be reported, such as for the return of discharged fuel to a reactor core.

- For weights exceeding the eight-character length limit, additional entries should be reported, as described in the continuation procedure in Section 3.5.2 of this document.

- The sum of the weights in all continuation entries for an entry must equal the total to be reported for the batch.

\section{Data Field: Weight Unit}

- Definition: Weight unit used in reporting the Weight of Element data field.

- Business Rules:

- Weight units vary depending on the element being reported.

- Use g for reporting grams of weight. This value should be left justified.

- Use kg for reporting kilograms of weight.

- Depleted uranium, natural uranium, and thorium are reported in kilograms.

- Enriched uranium, unified uranium, and plutonium are reported in grams.

\section{Data Field: Weight of Fissile Isotopes}

- Definition: Weight of the uranium isotope in the entry, including the decimal point.

- Business Rules:

- This data field is only for enriched uranium or unified uranium reporting. For all other reporting, it should be left blank, unless the facility attachment requires the fissile weight for depleted and/or natural uranium. The reporting of depleted and natural fissile content is used only for specific facility types and will be a point of negotiation in the facility attachment. Otherwise, the data field must be blank (i.e. a zero should not be reported), except for enriched and unified uranium.

- All fissile weights are reported in grams. 
- For weight exceeding the 8-character length, additional entries should be reported, as described in the continuation procedure.

- The sum of weights in all continuation entries for an entry must equal the total to be reported for the batch.

Data Field: Isotope Code

- Definition: Type of uranium isotope being reported.

- Business Rules:

- This data field is only for enriched uranium or unified uranium reporting.

- Isotopes are not reported for other elements unless specified in the facility attachment.

- The list of possible codes is provided in Appendix C.

Data Field: Concise Note Indicator

- Definition: Indicates if a concise note accompanies the report to provide an explanation of or amplification to the entry.

- Business Rules:

- $\mathrm{X}$ indicates that there is a concise note record for this entry.

- Left blank if no concise note is attached.

\section{Data Field: Correction to Report Number}

- Definition: Report number in which a record will be added, corrected, or deleted.

- Business Rules:

- Must be a valid report number for the MBA.

- If this data field is blank, the "Correction to entry number" data field must also be blank.

- An MBR can be corrected at any time but only by another MBR.

Data Field: Correction to Entry Number

- Definition: Entry number of the Correction to Report Number data field related to an addition, correction, or deletion.

- Business Rules:

- If this data field is not blank, the Correction to Report Number data field cannot be blank.

- For corrections and deletions, must be an entry number in the referenced report.

- For additions, must be one greater than the entries in the referenced report (including all previous additions) and must be less than 100 .

Data Field: Record Identification

- Definition: Record type.

- Business Rule:

- $\quad$ For an MBR report, this value must be 7.

\subsection{ADDITIONAL REPORTING PROCEDURES}

There are times when a State may need to provide information that does not fit into the standard ICR, PIL, or MBR report format, or may need to report adjustments to reports already submitted to the IAEA. This section describes the methods for submitting supplemental remarks for an MBA, report, or entry 
(concise notes); stating values that are larger than the allocated data field length (continuation); and making corrections, additions, and deletions to previous reports.

\subsubsection{Concise Notes}

The purpose of the concise notes record is to allow the submitter to include supplemental information on an MBA, report, or entry. In some cases, concise notes are required by the relevant facility attachment.

Concise notes provide textual amplification to nuclear material accounting reports and are included in the electronic record transmission to the IAEA. The reference to the item to which the note applies is contained in the concise note entry itself and therefore no header record is necessary. An example of the concise notes paper form is provided in Appendix B.

Table 3-6 describes the entry record format for concise notes submitted electronically. The format is the same for PIL, ICR, and MBR reports.

Table 3-6. Record format for concise notes entries

\begin{tabular}{|c|c|l|l|l|l|}
\hline $\begin{array}{c}\text { Record } \\
\text { position }\end{array}$ & Length & \multicolumn{1}{|c|}{ Data field name } & \multicolumn{1}{|c|}{ Format } & Required field & Code 10 paragraph \\
\hline 1 & 1 & $\begin{array}{l}\text { Record Identifier (Always } \\
\text { contains C for a concise } \\
\text { note) }\end{array}$ & Alphabetic & Yes & Appendix to Code 10 \\
\hline $2-5$ & 4 & MBA Code & Alphanumeric & Yes & Appendix to Code 10 \\
\hline $6-9$ & 4 & Report Number & Numeric & Optional & Appendix to Code 10 \\
\hline $10-11$ & 2 & Entry Number & Numeric & Optional & Appendix to Code 10 \\
\hline $12-79$ & 68 & Note & Alphanumeric & Yes & Appendix to Code 10 \\
\hline 80 & 1 & $\begin{array}{l}\text { Record Identifier (Always } \\
\text { contains C for a concise } \\
\text { note) }\end{array}$ & Alphabetic & Yes & Appendix to Code 10 \\
\hline
\end{tabular}

\section{Business Rules: Concise Notes}

- If the Concise Note data field in a nuclear material accounting report entry is not blank (i.e., contains $\mathrm{X})$, there must be a corresponding concise note record that refers to the accounting entry.

- To include a concise note entry that refers only to an MBA, enter the MBA number and leave the Report and Entry data fields blank.

- To include a concise note entry that refers only to a report, enter the MBA and report numbers and leave the Entry data field blank.

- To include a concise note entry that refers to an entry, enter the MBA number, report number, and entry number, and report X in the Concise Note data field of the relevant ICR, PIL or MBR entry.

- For a concise note reported with reference to an MBA, report number, and line entry, that record should be in a nuclear material accounting report.

- Multiple lines of text can be reported for a single concise note. 
- When multiple lines of text are reported for a single concise note, they should be reported sequentially and organized in the same order as the concise note is meant to be read.

- When multiple lines of text are reported for a single concise note, the MBA Code, Report Number, and Entry Number data fields should be entered for all lines.

\subsubsection{Continuation (C)}

Because of the column length restrictions associated with fixed format reporting, it may not be possible to enter a complete value within the number of allocated columns. This situation occurs when:

- The element/isotope weight requires more than eight digits, including decimal point and minus sign (if present);

- A batch consists of several types of material; and

- $\quad$ The number of items in a batch is more than 9999.

In these cases, use the continuation procedure.

The record format for a continuation is the same as the record format for the type of report to which it applies. That is, use the ICR record format for continuation of an ICR entry, the PIL record format for continuation of a PIL entry, and the MBR format for the continuation of an MBR entry.

\section{Business Rules: Continuation Line}

- Column 3 of the continuation record should contain the character C.

- There is no limit to the number of continuation records that an entry can have.

- $\quad$ Each continuation record must have its own unique entry number.

- Entry numbers of continuation records must sequentially follow the entry being continued. (For example, the entry number for a continuation record that applies to entry 12 should be 13.)

- Weight of element values are added.

- For example, if the weight of element in the entry record is 70000000 and the weight of element in the continuation record is 40000000 , the total weight reported will be 110000000 .

- Applies to ICRs, PILs, and MBRs.

- Items from the same batch that have different element codes are reported by using continuation records.

- For example, if a batch contains both enriched uranium and plutonium, report one element as an entry record and use the continuation procedure to report the second.

- Batch reporting applies only to ICRs and PILs.

- $\quad$ Number of items in batch values are added.

- For example, if the number of items in the entry record is 6000 and the number of items in the continuation record is 7000, the total number of items reported in the batch will be 13000 .

- This applies only to ICRs and PILs. 
- Entering the following data fields in continuation records is optional:

- ICR and PIL

- KMP Code

- Name or Number of Batch

- Material Description

- ICR

- Date of Inventory Change

- MBA Country From

- MBA Country To

- Type of Inventory Change

In the example illustrated in Figure 3-3, the PB total element weight of enriched uranium (Element code = E) to be reported is $101375460.7 \mathrm{~g}$, and the isotope weight is $1297341.25 \mathrm{~g}$. The eight-character limitation on element weight and isotope weight requires the use of continuation entries (entry numbers 2 and 3).

Adding the three entries for element weight $(99999999+1375461+0.7=101375460.7)$ and isotope weight $(1297342+0.25+0=1297342.25)$ yields the correct values. Continuation entries for ICRs and PILs are made similarly.

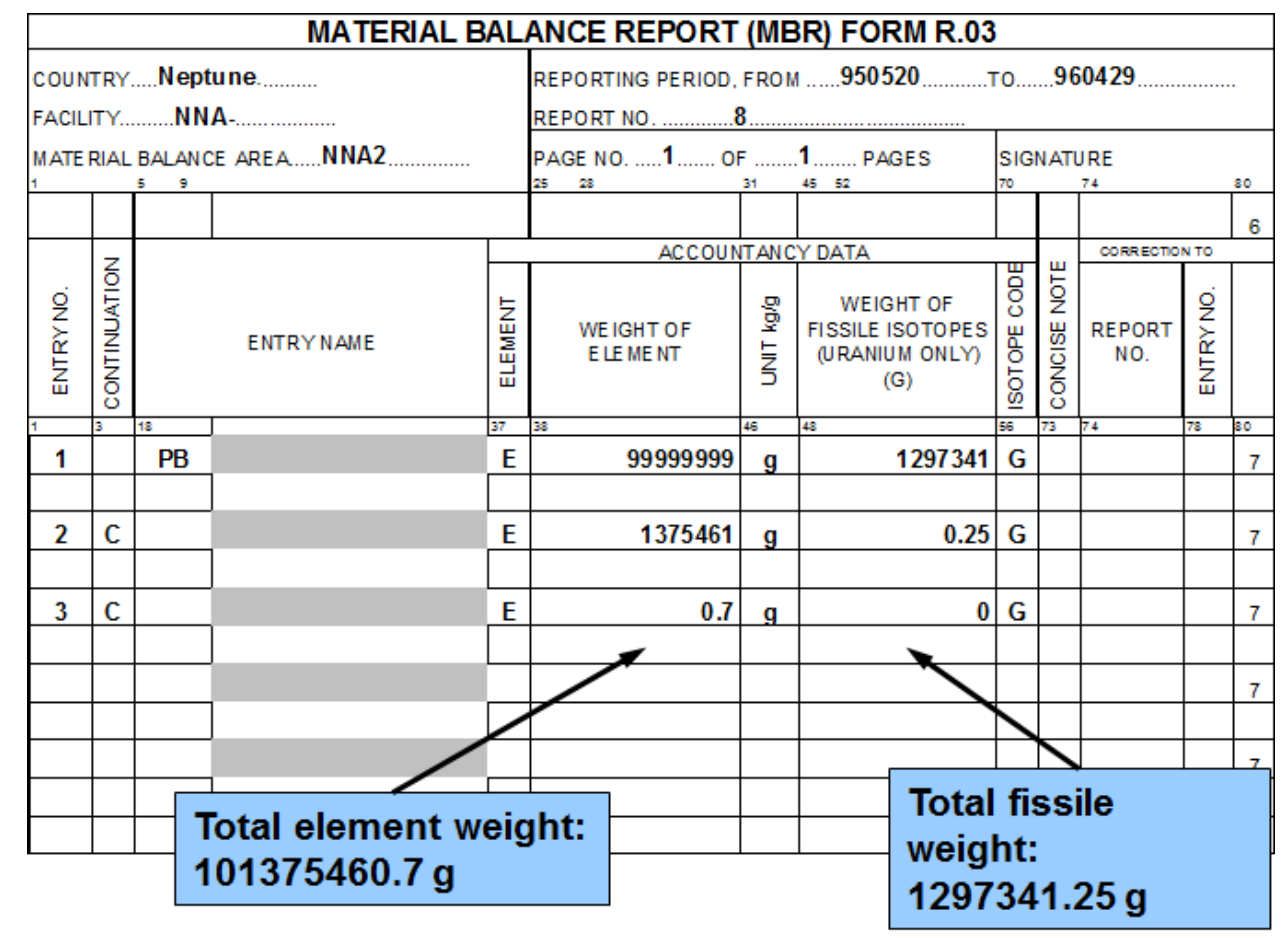

Figure 3-3. Continuation entry example for weights greater than eight digits.

Continuation entries can also be used when there is more than one element in a batch. In Figure 3-4, batch 045C8 contains both enriched uranium (element $=\mathrm{E}$ ) and plutonium (element $=\mathrm{P}$ ), both of which must be reported as separate entries. Continuation entries for MBRs and PILs are made similarly. 


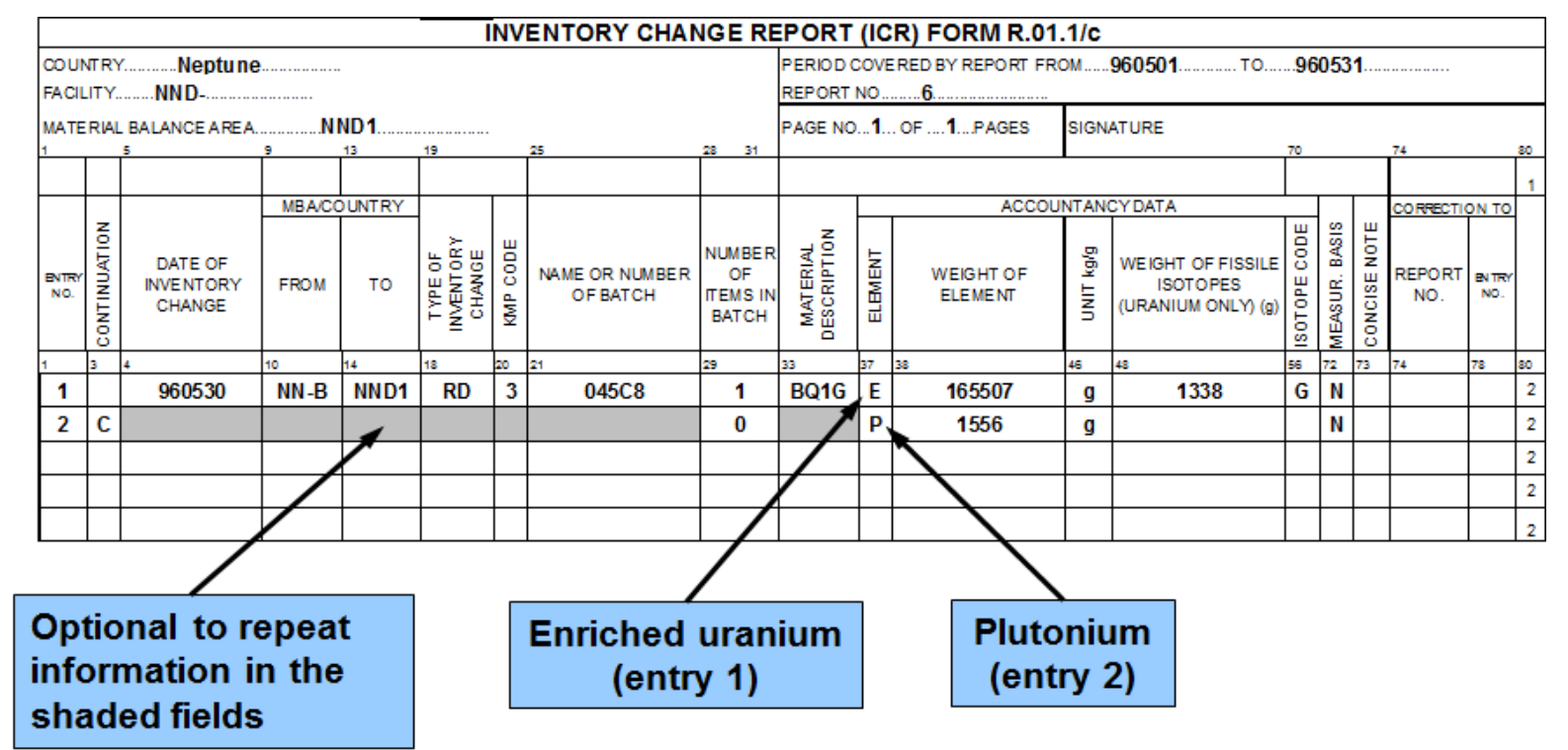

Figure 3-4. Continuation entry example for multiple elements in a batch.

\subsubsection{Category Change}

Where various categories of uranium are blended and accordingly combined into a single category, or where the category for uranium changes as a result of activities such as blending, the resulting change should be reported by means of an entry in the pertinent reports if the State's facility attachment so indicates. A category change is reported in the same way as any other inventory change.

Category changes are used to report increases and decreases in nuclear material accounts as the result of uranium changing from one category (i.e., enriched, natural, or depleted) to another. Such changes typically occur in enrichment plants, fuel fabrication plants, and on-load reactors. However, if an MBA reports in terms of "unified uranium,” category changes do not apply and are not reported.

For MBRs, the consolidated category changes should be reported as a decrease for the material balance pertaining to the category in which the uranium which has changed category originated, and as an increase for the material balance pertaining to the resulting uranium category. The keyword appropriate for category change is the same as for ICR, and the element, unit, and weight of fissile isotopes will be reported pursuant to the category covered in the MBR. If the resulting uranium category is established only upon shipment and for the exclusive purpose of such a shipment, it will be reported only in the relevant ICR, and no MBR shall be required for that category.

In nuclear material balances, the accounts of the two categories of uranium involved will be affected; one will increase, and the other will decrease by the same amount. The inventory change codes are EN, ED, $\mathrm{NE}, \mathrm{ND}, \mathrm{DE}$, and $\mathrm{DN}$; the letters indicate the types of uranium involved ( $\mathrm{E}$ = enriched, $\mathrm{N}=$ natural, $\mathrm{D}=$ depleted) and can be read as abbreviations, wherein the first character indicates the original category of uranium and the second character shows the resulting category after the category change has taken place. For example, NE is read "natural to enriched," as it indicates a category change from natural uranium to enriched uranium.

For example, in the case where $10 \mathrm{~kg}$ of natural uranium is blended with enriched uranium, the natural uranium account will decrease by $10 \mathrm{~kg}$, and the enriched uranium account will increase by 10,000 g, with an inventory change code of NE (i.e., natural to enriched). 
When material changes from one category to another, only the element code with the higher enrichment $(\mathrm{E}>\mathrm{N}>\mathrm{D}$ ) need be reported in an ICR. However, for MBRs, reporting an entry for both categories (i.e., each element code) is a good practice and results in complete MBR reports for each type of material.

\subsubsection{Rebatching}

Rebatching refers to an entry that reports a change in a batch name or structure. Rebatching reporting guidelines, if required, are specified in a facility's attachment. Reductions in batches are reported with an inventory change code as RM (rebatching, minus), and increases are reported as RP (rebatching, plus), as shown in Figure 3-5.

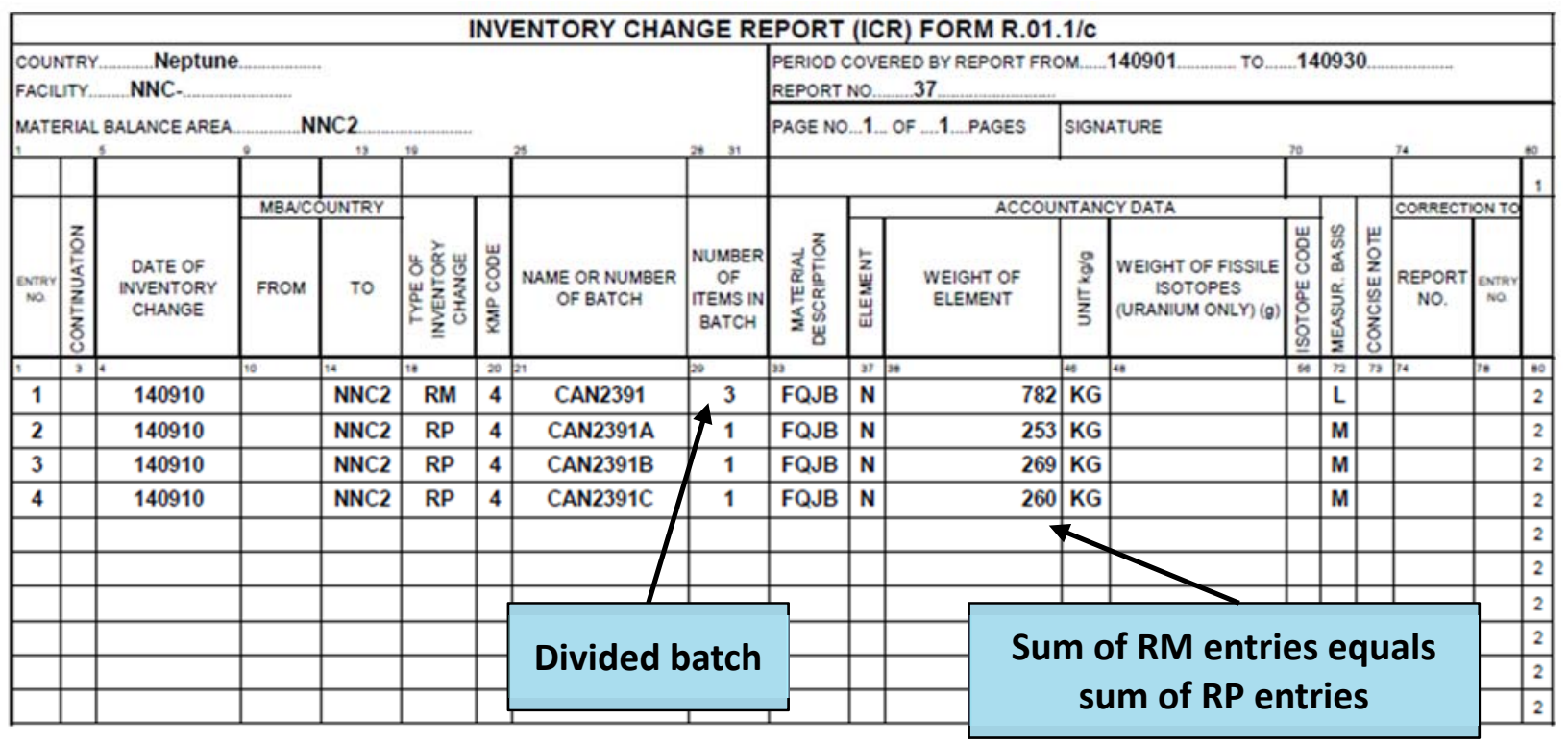

Figure 3-5. Example of rebatching change in batch structure.

Rebatching reporting can also be used to report a batch name change, as shown in Figure 3-6.

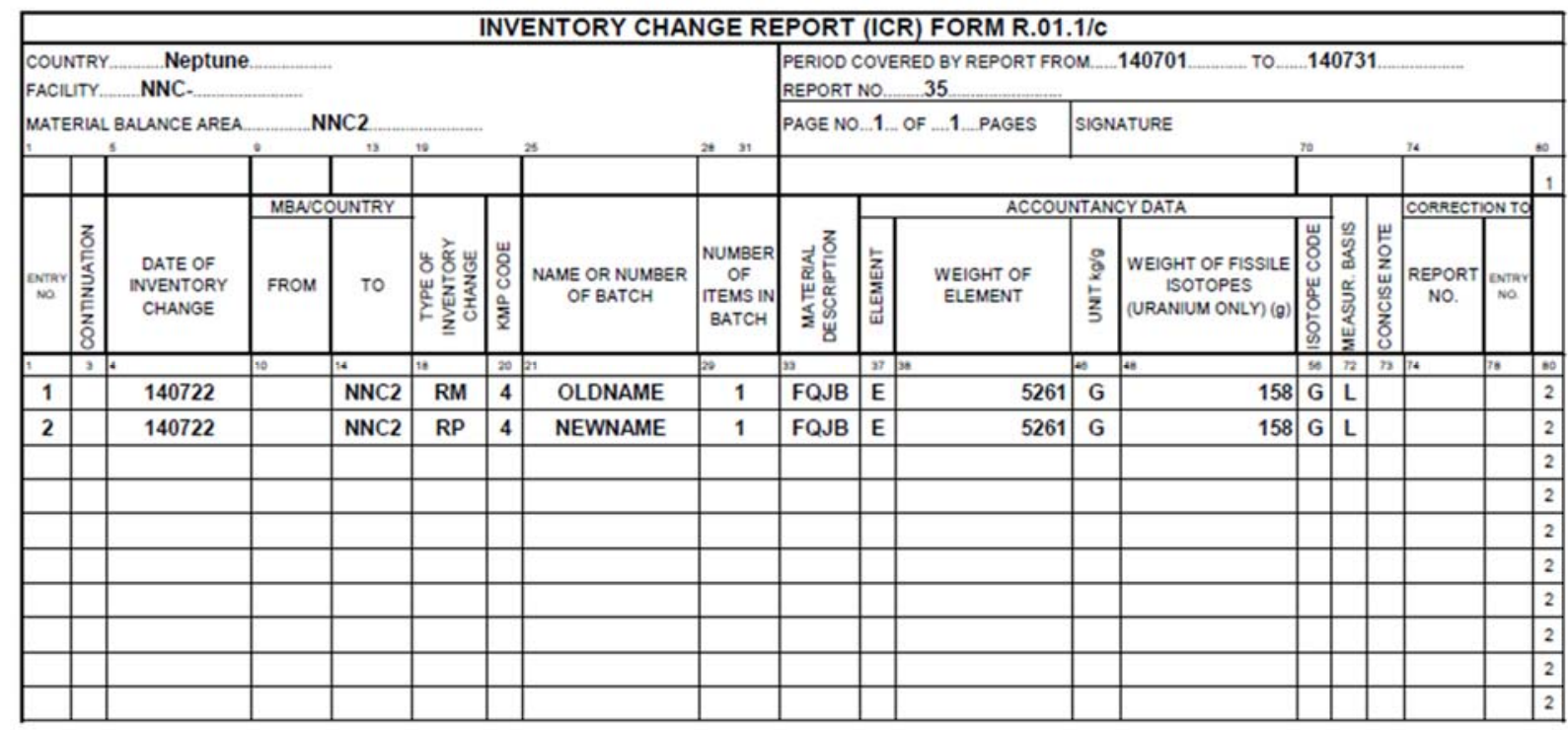

Figure 3-6. Example of rebatching to change the batch name. 


\section{Business Rules: Rebatching}

- Rebatching only reflects the name or structure of the inventory, so the overall inventory must not change.

- When reporting rebatching, the sum of all RM entries must equal the sum of all RP entries.

\subsubsection{Corrections}

The purpose of the correction record is to provide the submitter with a way to make modifications to previous reporting submissions. Corrections can be made to report entries and concise notes. Changes to report headers are handled separately.

\section{Business Rules: Correction}

- Corrections can be made to report headers or entry records.

- The report header or entry record being corrected must be one that has been previously reported.

- An ICR can only be corrected by another ICR; a PIL can only be corrected by another PIL; and an MBR can only be corrected by another MBR.

\subsubsection{Modifications to accounting report header records}

It is possible, but not common, that a change is needed to the header entry for a nuclear material accounting report that has been sent to the IAEA. The fixed format Code 10 does not provide a mechanism for the State to report a correction, addition, or deletion of ICR, PIL, and MBR accounting report headers. Therefore, the IAEA needs to be involved if any changes are to be made and will update header information in the IAEA system on behalf of the State.

Typically, header changes are needed when the IAEA quality assurance process detects a possible problem in a header entry and after the IAEA corresponds with the State to resolve the problem. Once changes are made at the IAEA, it is necessary for the State to reflect the changes in the corresponding State and facility records.

\subsubsection{Modifications to accounting report entry records}

The record format to correct an entry record that has already been sent to the IAEA is the same as the record format for the type of report to which it applies (except as noted below). That is, use the ICR record format for correction to an ICR entry, the PIL record format for a PIL entry, and the MBR format for an MBR entry.

Except for deletions, all data fields must be reported, even those that do not change. It is not correct to report only the data fields that have changed. See Figure 3-7. 


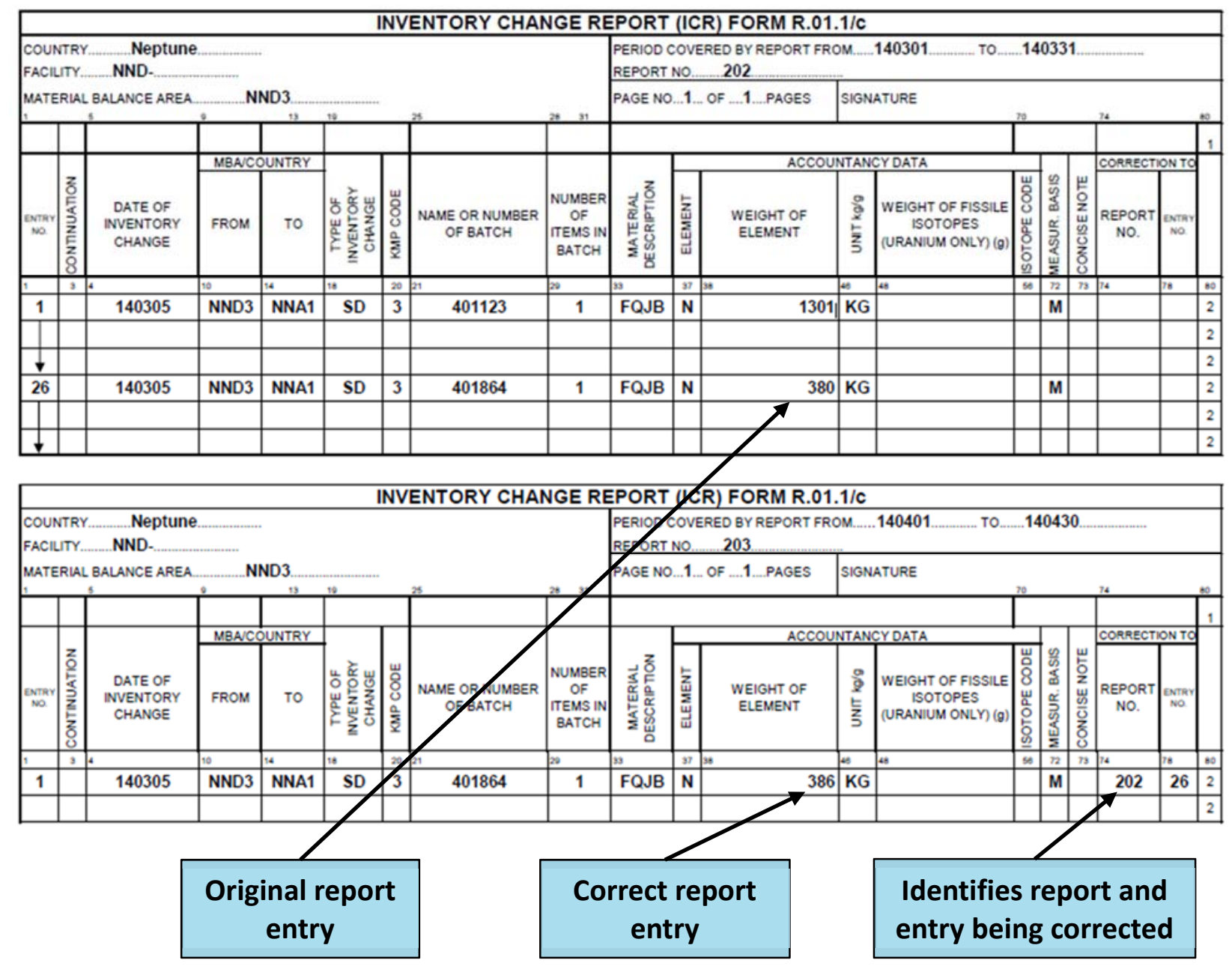

Figure 3-7. Example of correction to an accounting report entry.

Business Rules: Corrections to Accounting Records

- There is no time limit on when an entry record can be corrected. However, any change must be reported once it is determined to be needed.

- A record can be corrected as often as necessary.

- Once a record is corrected, the correction becomes the active accounting entry and is used for safeguards.

- The first correction to an accounting entry refers to the entry being corrected (the original entry). If another correction is needed, it must cross-reference with the most recent correction, and not to the original entry.

- For example, the flowchart in Figure 3-8 represents two corrections to an original entry, following the principle shown in Figure 3-7.

- $\quad$ The originally reported entry was MBA NN-B, Report Number 34, and Entry Number 61.

- The first correction record (MBA NN-B, Report Number 41, and Entry Number 14) refers to the original entry. 
- The second correction (MBA NN-B, Report Number 52, Entry Number 2) refers to the first correction entry (MBA NN-B, Report Number 41, Entry Number 14) and not to the original entry.

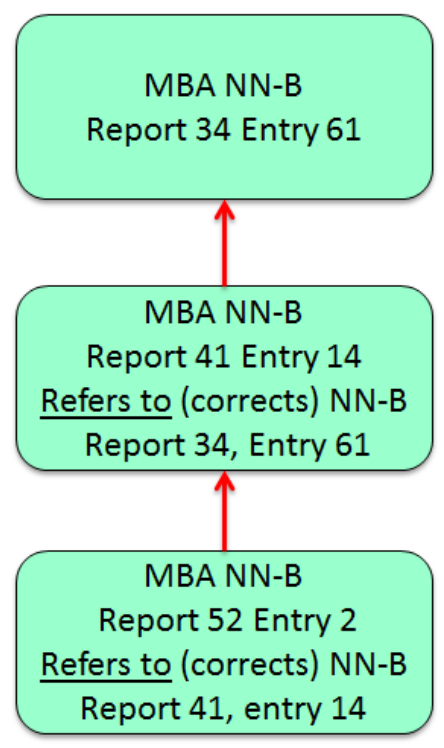

Figure 3-8. Example of multiple corrections to one entry.

- A correction record must include all data fields, even those that have not changed.

- All data fields follow the rules in the report specifications document for the relevant entry record.

- If a record that is corrected has an attached concise note and if it is desired that the reference to that concise note is to be carried forward with the correcting entry, the Concise Note data field in the correcting entry needs to be entered.

- If an entry has been deleted, the entry reporting the deletion can later be corrected, if necessary. In other words, a deleted entry can be undeleted.

- The following entry record data fields cannot be corrected using Code 10 procedures:

- MBA Code

- Report Number

- Entry Number

Correspondence with IAEA instructions is necessary to make changes to entry numbers, report numbers, and MBA codes. If changes are needed, the IAEA can make them to its system on behalf of the State. Depending on what needs to be changed, the IAEA may recommend possible courses of action. In any case, the IAEA will not make any changes in State information without approval from the State. Also, any changes made at the IAEA should also be reflected in the facility and State records.

Once a record is corrected, the correction becomes the active accounting entry and is used for safeguards. A correction record may be marked as inactive, but it is not removed from the IAEA information system. The next correction of the entry must refer to the most recent correction(s) and not the original entry. 


\subsubsection{Modifications to concise notes}

The fixed format Code 10 does not define a mechanism to correct or delete a concise note. Nevertheless, it is possible that changes to a concise note may be needed. In addition, the concise note information is affected when a correction is made to the accounting entry to which the concise note is attached.

\section{Business Rule(s): Corrections to Concise Notes}

- To correct a concise note, report a new concise note that contains the desired text with the same reference to MBA, report number, and entry number as in the original concise note.

- If a concise note is added that refers to a specific MBA, report number, and entry number and that accounting entry did not have a concise note attached, the accounting entry needs to be corrected to set the Concise Note data field (column 73) to X.

- Concise notes that refer to the MBA, or MBA and report number, can be added without modifying the Concise Note data field in any entry.

- If an MBA, report, or entry that has an attached concise note is corrected, and if it is desired that the reference to that concise note be carried forward with the correcting entry, the information contained in the Concise Note data field in the correcting records must be entered.

- When correcting a concise note, the new text should also indicate if it is an update or correction to a previous concise note.

- To remove a concise note reference from an accounting entry, a correction must be submitted that changes the Concise Note data field to blank, which results in the most recent correction not having a concise note.

\subsubsection{Additions}

It is possible for a report to include entries that are additions to previous nuclear material accounting reports.

All data fields must be reported, even those that do not change. It is not correct to report only the data fields that have changed. See Figure 3-9.

\section{Business Rule(s): Addition to an Accounting Report}

- To add an entry to a previous report, follow the same guidelines as when reporting a correction to an entry record; however, instead of referring to an entry already reported, refer to the next available entry number (the highest, plus 1 ).

- $\quad$ For example, Figure 3-10 represents two additions, following the principle shown in Figure 3-9.

- The originally reported entry was MBA NNA1, Report Number 118, and having the highest (last) Entry Number of 82.

- The first addition record occurs as part of MBA NNA1, Report Number 122, Entry Number 32, which refers to Report Number 118, Entry Number 83. In this way, the new entry (83) is added to Report Number 118.

- $\quad$ The second addition to MBA NNA1, Report Number 118 occurs in Report Number 124, which refers to MBA NNA1, Report Number 118, Entry Number 84. 


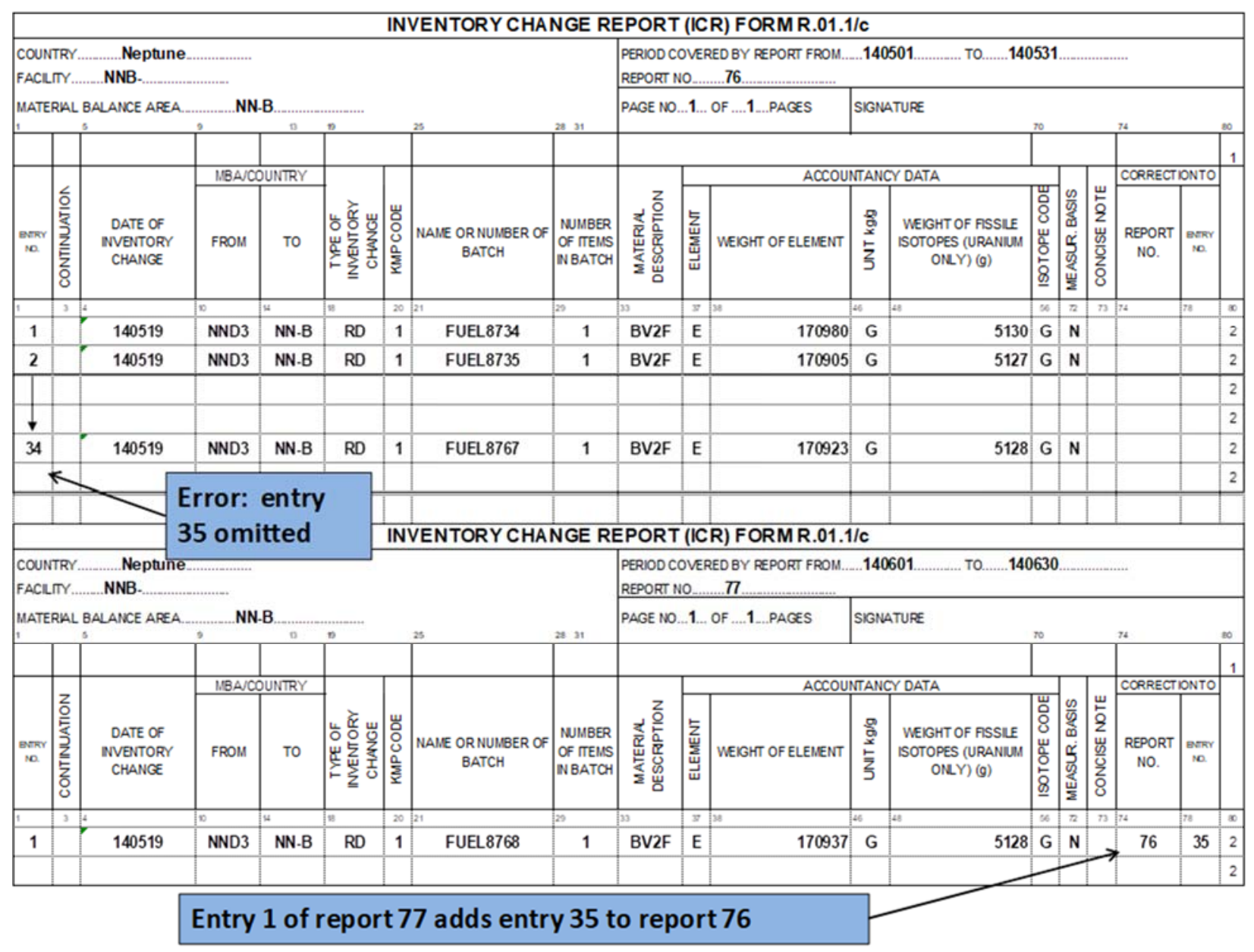

Figure 3-9. Addition of an accounting entry to a previous report.

- If more than one addition is submitted, the entry number should continue to increase sequentially by 1 .

- Because of the restricted maximum of 99 entries for a report, additions to reports already consisting of 99 entries are required to be part of a new report.

- Additions can be submitted at any time.

- Addition records are subject to the same content, requirement, and validation rules as regular ICR, PIL, and MBR records.

\subsubsection{Deletions}

Fixed format Code 10 does not specifically define the procedure for deleting a record. To delete a record, mark a record as being deactivated (e.g., deleted) by reporting a correction to the record with an A in position 3 of the correcting record. 


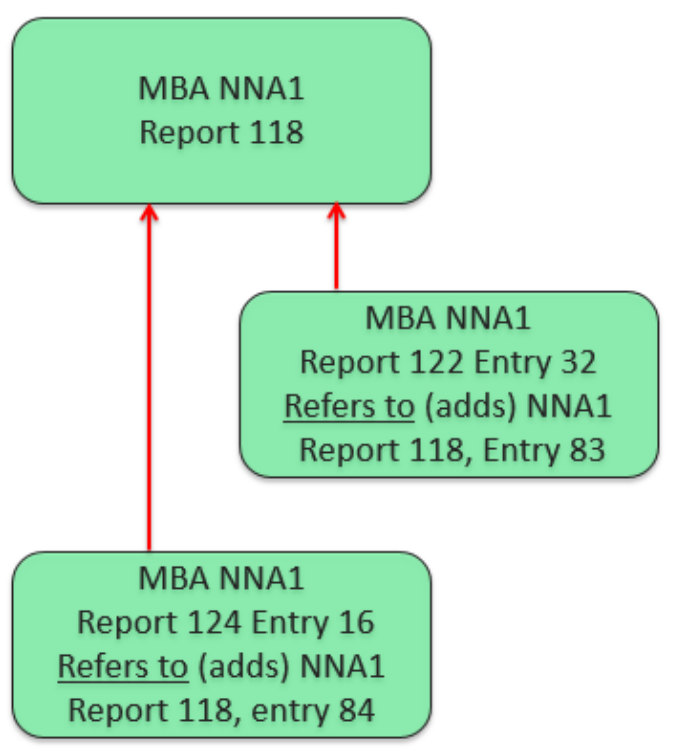

Figure 3-10. Example of reporting additions.

Business Rule(s): Deletions to Entry Records

Figure 3-11 illustrates the reporting of a deletion.

A deleted record can be corrected later if necessary by providing a new entry with a reference to the deleted record.

Deletion records need only report the entry number, the letter A in position 3, and the report number and entry number of the record to be deleted, in the Correction To data fields. 


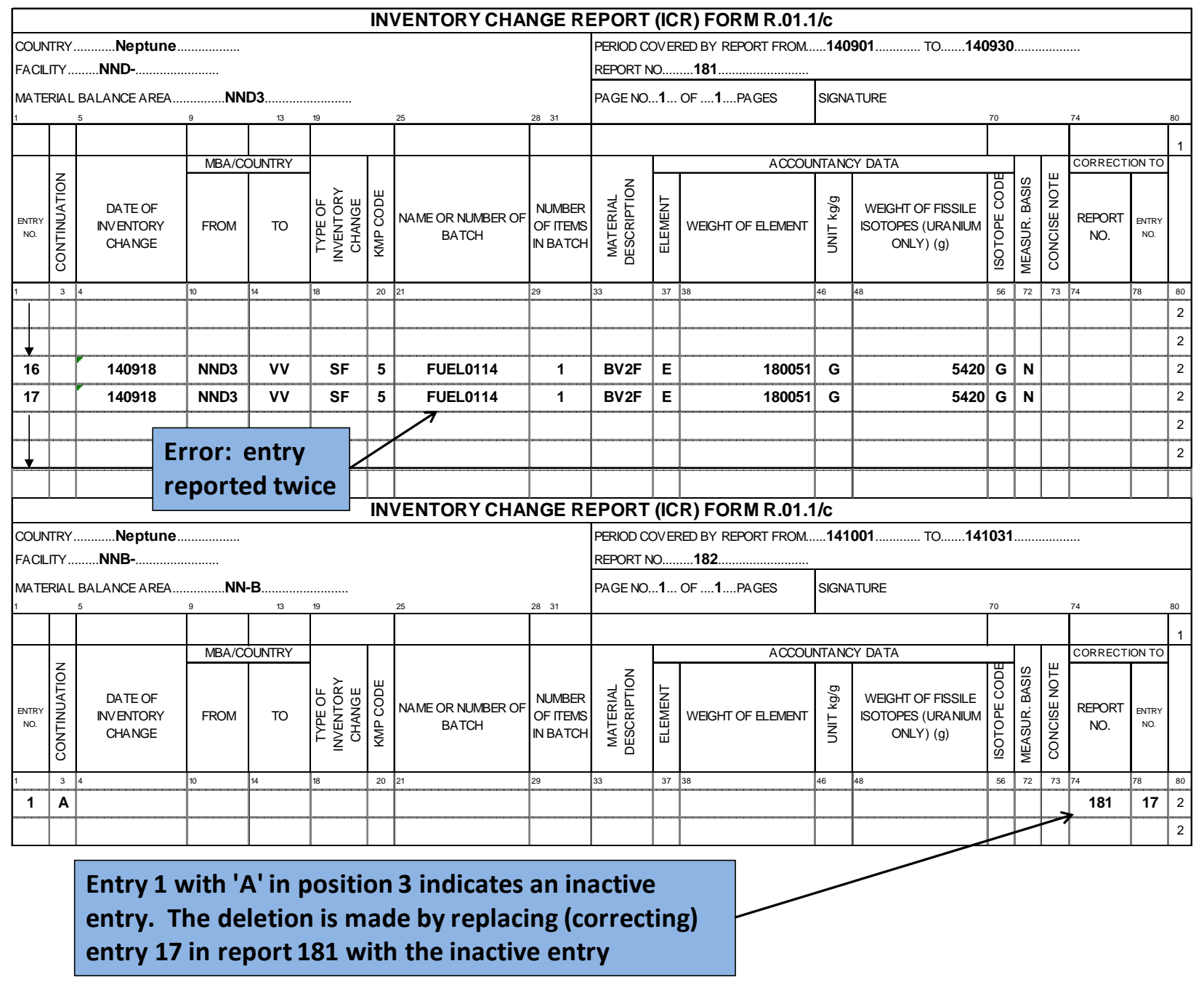

Figure 3-11. Example of reporting a deletion. 


\section{LABELED FORMAT}

The labeled format Code 10 was first developed and used in the late 1970s when it became clear that larger countries joining the NPT needed a mechanism to address the data field size limitations of the fixed format Code 10. Labeled format offers variable lengths for the data fields, which are defined by labels instead of positions. Specific procedures related to data field length are not necessary, and additional data fields can be added if so negotiated. Unlike the fixed format structure, all reports prepared in labeled format must be submitted in electronic form; reporting on paper forms is not an option.

Both the fixed format and labeled format Code 10 versions provided the necessary information for the IAEA to implement safeguards.

As in the fixed format, the basic reporting entity is an MBA. The same three types of accounting reports are used: ICRs, PILs, and MBRs. In addition, concise notes or textual report entries can be submitted to the IAEA to provide additional explanation and clarification at the country, facility, MBA, report, or entry level. Unlike fixed format Code 10, there are no separate forms for each report type.

Appendix E, Labeled Format Reporting Codes, contains the reporting codes used in labeled format Code 10 reporting. Appendix F, Labeled Format Reporting Examples, provides completed examples of the various types of labeled format reports discussed below.

\subsection{SPECIFICATION OF DATA ELEMENTS}

Nuclear material accounting reports (i.e., ICR, PIL, MBR) are identified by the report number (label 001), report type (label 010), and MBA (label 307). All associated entries must be reported in sequence by entry number (label 002) and within the entry, elements should be in label sequence.

The maximum number of characters permitted in an accounting entry is defined by the lengths specified in Code 10 for each data element, including the delimiter characters listed below.

A nuclear material accounting entry within a report is formed by a set of data elements, beginning with label 001 through the last label necessary to report the entry. Following the pound sign (\#) after the last data element in an entry, the next entry begins with label 001 . If the next entry has a different report number, type of report, or MBA, that indicates a new report must be filed.

One transmission of information can include multiple accounting reports, with entries for each report provided in sequence by entry number.

With the labeled format, data elements are identified by a unique three-digit number called a label. A label may identify a unique or composite data element. In the latter case, the components are internally separated by delimiters.

The following delimiters are used in the labeled format:

- $\operatorname{colon}(:)$

- $\operatorname{slash}(/)$

- $\quad$ semi-colon (;)

- $\quad$ pound sign (\#) to separate the label number and the content of the data element to separate data items within a composite data element to separate data items within a composite data element to indicate the end of a data element

Thus, a data element entry begins with the label number, followed by a colon, followed by one or more data values separated by a slash or semi-colon, and ends with the pound sign. 
The preferred date format for reporting is eight characters and must follow the IAEA standard of yearmonth-day (YYYYMMDD). If a State wishes to use a six-digit date (YYMMDD), that will need to be negotiated with the IAEA.

The delimiters form an integral part of the data element and must be reproduced as such in the reports transmitted to the IAEA. In exceptional cases, deviations from the standard set of delimiters may be agreed upon if the recording devices available to the State do not support the delimiters listed above. The delimiters may not be used within a data field as reported information (e.g., a delimiter cannot be used as a character in a batch name).

\subsection{INVENTORY CHANGE REPORTS}

Each ICR may consist of two types of records. The first type indicates changes in the inventory of nuclear material. The second type gives additional textual information related to concise notes that is not accommodated in any of the data elements included in the first report type (see Section 4.5 for discussion of concise note entries).

Table 4-1 describes the report format for ICRs. Where square brackets [ ] are used, either of the options given may be chosen. For example, the report date may be reported as an eight-digit date (YYYYMMDD) or a six-digit date (YYMMDD).

Table 4-1. Report format for inventory change reports

\begin{tabular}{|c|c|c|c|}
\hline Label & Data field name & Format & Comment(s) \\
\hline 001 & Reference Number & $* * / * * ; * * * \ldots * * * \#$ & \\
\hline 002 & Entry Number/Total Number of Entries & $* * * \ldots{ }^{* * *} / * * * \ldots{ }^{* * * \#}$ & \\
\hline 003 & Report Date & {$[* * * * * * * *][* * * * * *] \#$} & \\
\hline 006 & Encoder's Name & $* * * \ldots * * * \#$ & \\
\hline 010 & Report Type & *\# & \\
\hline 015 & Reporting Period & $\begin{array}{l}{[* * * * * * * * / * * * * * * * * *]} \\
{[* * * * * * / * * * * * *] \#}\end{array}$ & \\
\hline 207 & Facility Code & $* * * * \#$ & \\
\hline 307 & MBA Code & $* * * * \#$ & \\
\hline 309 & Entry Status and Cross Reference Code & $* / * * ; * * * \ldots * * * / * * * \ldots * * * \#$ & \\
\hline 310 & $\begin{array}{l}\text { State Accounting System Record } \\
\text { Identification }\end{array}$ & $* * * \ldots * * *$ & Optional \\
\hline 370 & Shipper of Nuclear Material & $* * / * * * * \#$ & $\begin{array}{l}\text { Required for imports, } \\
\text { exports, and transfers } \\
\text { between MBAs within the } \\
\text { State }\end{array}$ \\
\hline 372 & Receiver of Nuclear Material & $* * / * * * * \#$ & $\begin{array}{l}\text { Required for imports, } \\
\text { exports, and transfers } \\
\text { between MBAs within the } \\
\text { State }\end{array}$ \\
\hline 390 & Concise Note Indicator & *\# & $\begin{array}{l}\text { Required if entry is } \\
\text { referenced by a concise } \\
\text { note submitted in same } \\
\text { report }\end{array}$ \\
\hline 407 & Key Measurement Point Code & **\# & \\
\hline 411 & Type of Inventory Change & $* * \#$ & \\
\hline 412 & Date of Inventory Change & {$[* * * * * * * *][* * * * * *] \#$} & \\
\hline 430 & Material Description Code & $* / * / * / * \#$ & \\
\hline 435 & Operator’s Material Description Code & $* / * * * \ldots * * * \#$ & $\begin{array}{l}\text { Optional if operator's code } \\
\text { differs from Agency code }{ }^{a}\end{array}$ \\
\hline
\end{tabular}


Table 4-1. Report format for inventory change reports (continued)

\begin{tabular}{|c|l|l|l|}
\hline Label & \multicolumn{1}{|c|}{ Data field name } & \multicolumn{1}{|c|}{ Format } & \multicolumn{1}{c|}{ Comment(s) } \\
\hline 436 & Operator's Material Description Text & $* * * \ldots * * * \#$ & Optional \\
\hline 445 & Non-Latin Alphabet Identification & $* \#$ & $\begin{array}{l}\text { Required if entry includes } \\
\text { non-Latin letters }\end{array}$ \\
\hline 446 & Batch Name & $* * * \ldots * * * \#$ & \\
\hline 447 & Shipper's Batch Name & $* * * \ldots * * * \#$ & \\
\hline 469 & Measurement Identification Code & $* / * * \ldots * * * / * * \ldots * * * \#$ & \\
\hline 470 & Number of Items in Batch & $* * * \ldots * * * \#$ & \\
\hline $600-800$ & Weight Data & $* * * \ldots * * * \#$ & $\begin{array}{l}\text { If label } 600 \text { or } 630 \text { is used, } \\
\text { label } 640,660, \text { or } 670 \text { must } \\
\text { also be reported. }\end{array}$ \\
\hline
\end{tabular}

${ }^{a}$ Agency code is represented by label 430, Material Description Code.

${ }^{b}$ If non-Latin letters are used in the entry (e.g., in the batch name or encoder's name), a one-letter code (agreed upon with the IAEA) is placed in this data element. Otherwise this label should not be used.

\section{Business Rules: ICR}

- All entries have variable length, unless the permitted or prescribed number of characters is specifically indicated. Variable length is indicated by three asterisks followed by ellipses and three more asterisks: ${ }^{* * *} \ldots{ }^{* * *}$. Where only 2 asterisks are used $(* *)$, the data field contains two characters.

- Each ICR must contain at least one entry (i.e., record) of the first type, indicating a change in the inventory of nuclear material.

Below are detailed descriptions and associated business rules for each data field in an ICR record.

Data Field: Reference Number

- Definition: Unique report identifier for filing, processing, sorting, and reference purposes.

- Format: 001:**/**;***...***\#

- $\quad$ code ØI for accounting entries or code NC for concise note entries;

- $\operatorname{slash}(/)$;

- country code;

- semi-colon (;); and

- the numeric report number assigned by the reporting authority.

- Business rules:

- Report number must be unique for any given MBA.

- All reports, regardless of type, are numbered consecutively with respect to each MBA.

Data Field: Entry Number/Total Number of Entries

- Definition: Number for the specific entry within the set of ØI or NC entries contained in the report.

- Format: 002:***...***/*** ...**\#

- sequential number of the ØI or NC entry;

- $\operatorname{slash}(/)$; and

- $\quad$ total number of ØI or NC entries in the report. 
- Business rules:

- Always start with 1 within each set of ØI and NC entries.

- The total number of ØI or NC entries may be omitted, as well as the preceding slash in entries except for the first ØI and NC entry of a report, where it is mandatory.

Data Field: Report Date

- Definition: Date when the report was produced.

- Format: 003:[********][******]\#

- the [four] [last two] digits of the current year;

- the two-digit designation of the month; and

- the two-digit designation of the day.

- Business rules:

- As indicated by the square brackets in the data field format, the year can be indicated either with four digits or with the last two digits; therefore, the entry format can be either eight or six characters long. Unless specifically agreed otherwise, a four-digit year should be reported.

- The State can decide what they would like to use for the report date, such as the date the report was prepared for dispatch to the IAEA.

- The report date should not be after the date of dispatch.

- The date should be on or after the period ending date of the ICR.

Data Field: Encoder's Name

- Definition: Official responsible for the report.

- Format: 006:***...***\#

- family name;

- a comma (,); and

- the initials.

- Business rule:

- A maximum of 30 characters may be used.

Data Field: Report Type

- Definition: Type of report.

- Format: 010:*\#

- Single character.

- Business rule:

- I for ICR

Data Field: Reporting Period

- Definition: Beginning and ending dates of the period covered by the ICR.

- Format: 015:[********/********] [******/******]\#

- [eight][six] digits for the beginning date (as in the label Report Date above);

- slash (/); and

- $\quad$ [eight][six] digits for the ending date (as in the label Report Date above). 
- Business rules:

- The specified period should include the dates of inventory change reported in all new entries in the report.

- The inventory change dates of corrections, additions, or deletions are not included in the date period.

Data Field: Facility Code

- Definition: Identification code of the facility containing the reporting MBA.

- Format: 207:****\#

- four-character code.

- Business rule:

- The facility code is specified in the relevant facility attachment.

Data Field: MBA Code

- Definition: Identification code of the MBA submitting the report.

- Format: 307:****\#

- four-character code.

- Business rule:

- $\quad$ The MBA code is specified in the relevant facility attachment.

Data Field: Entry Status and Cross Reference Code

- Definition: Status of the entry and, when necessary, provides a reference to a previously reported entry.

- Format: 309:*/**;***...***/***...***\#

- one-character code to designate the status of the entry:

- $\mathrm{N}$ for new entries,

- U for invalid entries to be ignored,

- C for entries serving as corrections to earlier ones,

- D for entries deleting the one referenced by this entry, and

- A for an entry to be added to previous report.

- slash (/); this and the following reference codes are mandatory if the entry status code is C, D, or A. For N, they are not applicable; for U, they are optional.

- country code (same as in label 001, Reference Number);

- semi-colon (;);

- $\quad$ the report number assigned by the reporting authority as specified in the label 001 of the entry being referenced;

- $\operatorname{slash}(/)$; and

- entry number of the entry to be referenced (first subfield 002 of that entry), or in the case of an additional entry, the number of the entry as it will appear in the report to which the entry is being added.

- Business rules:

- If the entry is serving as a correction to an earlier one (C), the remainder of the entry should contain the same data elements and values of the referenced line entry except for those elements being corrected. 
- If the entry is deleting the one referenced by this entry, the data elements for the remainder of the entry are optional.

Data Field: State Accounting System Record Identification

- Definition: Unique identifier in the State accounting system that references the data contained in the State report.

- Format: $310: * * * \ldots * * *$

- Business rules:

- Optional.

- Maximum of 40 characters may be used.

Data Field: Shipper of Nuclear Material

- Definition: Shipper of nuclear material received by the MBA indicated in label 307.

- Format: 370:**/****\#

- country code;

- $\operatorname{slash}(/)$; and

- MBA (or, for imports, facility or country) code.

- Business rules:

- This data field is mandatory when reporting domestic receipt of nuclear material from another MBA, or import of nuclear material; otherwise, it may be omitted.

- If an import is reported and the shipping MBA (or facility) code is unknown to the receiver, it is sufficient to report only the country code.

Data Field: Receiver of Nuclear Material

- $\quad$ Definition: Receiver of nuclear material that has been shipped by the MBA indicated in label 307.

- Format: 372: **/****\#

- country code;

- $\quad$ slash (/); and

- MBA code (or, for exports, facility or country code).

- Business rules:

- This data field is mandatory when reporting domestic transfer of nuclear material to another MBA, or export of nuclear material; otherwise, it may be omitted.

- If an export is reported and the receiving MBA (or facility) code is unknown to the shipper, it is sufficient to report only the country code.

\section{Data Field: Concise Note Indicator}

- Definition: Indicates a concise note is included in the report or attached to it.

- Format: 390: *\#

- Business rules:

- Optional.

- $\mathrm{Y}$ indicates the presence of a concise note. 
Data Field: Text of Concise Note

- Definition: Text that provides clarifications, amplifications, and other unformatted information.

- Format: 391: ***...***\#

- Business rules:

- Optional.

- Concise note can be written in free format, using only Latin (i.e., English) capital letters, numerals, and permitted special symbols.

- A maximum of 2,000 characters of text may be reported in a single nuclear material accounting entry.

\section{Data Field: Key Measurement Point Code}

- Definition: The appropriate KMP code.

- Format: 407:**\#

- Business rule:

- The KMP codes to be used for a specific MBA are defined in the relevant facility attachment.

Data Field: Type of Inventory Change

- Definition: Type of inventory change reported.

- Format: 411:**\#

- Two alphabetic characters (see Appendix E-1).

- Business rules:

- All transactions and operations are related to individual batches, unlike in MBRs, where the same codes denote consolidated entries.

- In addition to the inventory changes, the inventory may be adjusted in accordance with the results of measurements performed in the MBA on nuclear material previously recorded and reported on shipper's data and can be reported as the shipper/receiver difference.

- Changes in batch identification and/or content may also be reported.

- The inventory change codes to be used for a specific MBA are defined in the relevant facility attachment.

\section{Data Field: Date of Inventory Change}

- Definition: Date on which the change in inventory occurred or was established.

- Format: 412: [********][******]\#

- [eight][six] numeric digits (as in label 003)

- Business rule:

- Either eight or six digits, depending on whether all four or the last two digits of the year are used.

Data Field: Material Description Code

- Definition: The physical and chemical form, containment, and irradiation status and quality of the nuclear material in the batch.

- Format: 430:*/*/*/*\#

- Four-character code (see Appendix E-2 for codes). 
- Business rules:

- The domestic shipment of a given batch from one MBA and its receipt in another MBA must be reported with the same material description code.

- If the codes are used in hard-copy communications, the slashes may be omitted.

- The material description codes to be used for a specific MBA are defined in the relevant facility attachment.

\section{Data Field: Operator’s Material Description Code}

- Definition: May be used to indicate that the operator's material description code is identical to the code used by the IAEA.

- Format: 435:*/***...***\#

- $\mathrm{Y}$ indicates that the codes are identical, and $\mathrm{N}$ indicates that the codes are different and that the operator's material description code follows.

- Slash (/), if operator's code follows.

- Operator's material description code.

- Business rules:

- If the operator's material description code differs from the code used by the IAEA, the operator's own code may be shown here.

- The operator's material description code can be reported as a maximum of 12 characters.

Data Field: Operator's Material Description (Text)

- Definition: Permits the inclusion of a textual description of the batch if the operator so wishes or has otherwise agreed in the facility attachment.

- Format: 436: ***...***\#

- Maximum of 100 characters.

- Business rule:

- Text should be composed of Latin capital letters, numerals, and permitted special characters.

Data Field: Non-Latin Alphabet Identification

- Definition: Indicates non-Latin letters are used in the entry (e.g., in the encoder's name).

- Format: 445:*\#

- Business rules:

- Entry should consist of a single-letter code agreed upon with the IAEA.

- If only Latin letters are used in the entry, this label should not be used.

Data Field: Batch Name

- Definition: Batch name of the nuclear material being reported.

- Format: 446: ***...***\#

- Business rules:

- When the ICR is reporting a receipt, the batch name may be assigned by the reporting MBA or may be the same one used by the shipper, as reported in label 447, Shipper's Batch Name (see next data field).

- $\quad$ The batch name reported should be unique to the reporting MBA for any transaction on a single date. 
- A maximum of 16 characters can be used.

Data Field: Shipper's Batch Name

- Definition: Shipper's batch name when known.

- Format: 447: ***...***\#

- Business rules:

- Only used in ICR entries reporting a receipt.

- This entry should be the batch name the shipper uses in the ICR entry reporting the shipment.

- If the shipper's batch name is unknown, the keyword UNKNOWN should be reported.

- A maximum of 16 characters can be used.

\section{Data Field: Measurement Identification Code}

- Definition: Measurement basis used, and if applicable, the KMP and/or method of measurement.

- Format: 469: */***...***/***...***\#

- Measurement basis code, consisting of one of the following letters:

- $\quad \mathrm{N}$, if the batch data are based on measurements made at another MBA;

- $\quad$ L, if the batch data are based on measurements made at another MBA and have been reported for the present MBA in a preceding ICR or PIL;

- $\quad M$, if the batch data are based on fresh measurements made at the MBA; and

- $\quad T$, if the batch data are based on measurements made at the present MBA and have been reported in a preceding ICR or PIL, and the measurements have not been repeated.

- Slash (/), if other data items follow.

- In cases noted by M as defined above, indicate the KMP where the measurement was made if it differs from the KMP names in the data element under label 407 (otherwise code not needed).

- Slash (/), if other data item follows.

- In cases denoted by $\mathrm{M}$ or $\mathrm{T}$ as defined above, indicate the method used for the measurement.

- Business rules:

- Measurement Identification Code $\mathrm{N}$ can only be used for reporting the original receipt of nuclear material, unless specified otherwise in the facility attachment.

- The measurement basis codes to be used for a specific MBA are defined in the relevant facility attachment.

Data Field: Number of Items in Batch

- Definition: Number of similar items in a batch.

- Format: 470:***...***\#

- Business rules:

- In the case of bulk material (when the number would not be meaningful), a zero should be placed in this data field.

- $\quad$ The number must be an integer.

\section{Data Field: Weight Data}

- Definition: Labels 600-800 provide the quantities of the nuclear material in the batch represented by the entry. The pertinent labels $600-800$ should be used.

- Format: $600:^{* * *} \ldots{ }^{* * * \#} 610: * * * \ldots{ }^{* * * \#} 620:^{* * *} \ldots{ }^{* * * \#} \ldots$ etc. ... 800:*** ...***\# 
- Labels 600-800 each follow the same format:

- numerical label;

- $\operatorname{colon}(:) ;$

- the numerical expression of the weight of the element (i.e., isotope or their combination of isotopes), as indicated by the label; and

- weight expressed as g for weight given in grams, or as kg for weight given in kilograms.

- Business rules:

- The weight data relate either to a specific chemical element or to its isotopes.

- The weight data are to be expressed in the following units:

- grams of plutonium (and its isotopes, if appropriate);

- grams of total uranium for enriched uranium;

- grams of isotopes of uranium; and

- kilograms of natural uranium, depleted uranium, and thorium.

- If label 600 (unified uranium) or 630 (enriched uranium) is used, label 640 (enriched/unified uranium $U_{233}$ content), 660 (enriched/unified uranium $U_{233}+U_{235}$ content), or 670 (enriched/unified uranium $\mathrm{U}_{235}$ content) must also be reported.

- Data covered by labels 650, 680, 690, 710, 720, 730, 740, 750, 760, 770, and 780 are optional, unless they are required by the facility attachment.

- Weights reported to a higher precision than milligrams will be rounded to the nearest milligram.

- While it is recommended that data be reported in unrounded figures, the data may be rounded, but not beyond the nearest integer to the unit used, which may necessitate the reporting of rounding adjustments in MBRs.

- Rounding should be done by first adding the weights of the individual items in the batch and then rounding their sum.

- Element and isotope weights may be reported in different units depending on the material.

\subsection{PHYSICAL INVENTORY LISTINGS}

Like ICRs, each PIL may consist of two types of records. The first type presents nuclear material batch data, and the second type provides concise notes and textual reports (see Section 4.5).

Table 4-2 describes the report format for PILs. Appendix E contains the reporting codes used in labeled format Code 10 reporting.

Table 4-2. Report format for physical inventory listings

\begin{tabular}{|c|l|l|l|}
\hline Label & \multicolumn{1}{|c|}{ Data field name } & \multicolumn{1}{c|}{ Format } & Comment(s) \\
\hline 001 & Reference Number & $* * * * ; * * * \ldots * * * \#$ & \\
\hline 002 & Entry Number/Total Number of Entries & $* * * \ldots * * * * * * . . * * * \#$ & \\
\hline 003 & Report Date & {$[* * * * * * * *][* * * * * *]$} & \\
\hline 006 & Encoder's Name & $* * * \ldots * * * \#$ & \\
\hline 010 & Report Type & $* \#$ & \\
\hline 015 & Reporting Period & {$[* * * * * * * * / * * * * * * * *]$} & \\
& & {$[* * * * * * / * * * * * *]$} & \\
\hline 207 & Facility Code & $* * * * \#$ & \\
\hline 307 & MBA Code & $* * * * \#$ & \\
\hline
\end{tabular}


Table 4-2. Report format for physical inventory listings (continued)

\begin{tabular}{|c|c|c|c|}
\hline Label & Data field name & Format & Comment(s) \\
\hline 309 & Entry Status and Cross Reference Code & $* / * * ; * * * \ldots * * * / * * * \ldots{ }^{* * * \#}$ & \\
\hline 310 & $\begin{array}{l}\text { State Accounting System Record } \\
\text { Identification }\end{array}$ & $* * * \ldots * * *$ & Optional \\
\hline 390 & Concise Note Indicator & $* \#$ & $\begin{array}{l}\text { Required if entry is } \\
\text { referenced by a concise } \\
\text { note submitted in same } \\
\text { report }\end{array}$ \\
\hline 407 & Key Measurement Point Code & $* * \#$ & \\
\hline 430 & Material Description Code & $* / * / * / * \#$ & \\
\hline 435 & Operator's Material Description Code & $* / * * * \ldots * * * \#$ & $\begin{array}{l}\text { Optional if operator's code } \\
\text { differs from Agency code }{ }^{a}\end{array}$ \\
\hline 436 & Operator’s Material Description Text & $* * * \ldots * * * \#$ & Optional \\
\hline 445 & Non-Latin Alphabet Identification & *\# & $\begin{array}{l}\text { Required if entry includes } \\
\text { non-Latin letters }^{b}\end{array}$ \\
\hline 446 & Batch Name & $* * * \ldots * * * \#$ & \\
\hline 469 & Measurement Identification Code & $* / * * * \ldots * * * / * * * \ldots * * * \#$ & \\
\hline 470 & Number of Items in Batch & $* * * \ldots * * * \#$ & \\
\hline $600-800$ & Weight Data & $* * * \ldots * * * \#$ & $\begin{array}{l}\text { If label } 600 \text { or } 630 \text { is used, } \\
\text { label } 640,660 \text {, or } 670 \text { must } \\
\text { also be reported. }\end{array}$ \\
\hline
\end{tabular}

${ }^{a}$ Agency code is represented by label 430, Material Description Code.

'bf non-Latin letters are used in the entry (e.g., in the batch name or encoder's name), a one-letter code (agreed upon with the IAEA) is placed in this data element. Otherwise this label should not be used.

\section{Business Rules: PIL}

- All entries can have variable length, unless the permitted or prescribed number of characters is specifically indicated.

- Each PIL must contain at least one entry (i.e., record) indicating a change in the inventory of nuclear material.

- A PIL must be prepared even if there was no nuclear material in the MBA at the time of the physical inventory taking. Such a PIL, known as a null or zero PIL, should have a single entry including the following data elements:

- 001, reference number;

- 002, entry number;

- 003, report date;

- 006, encoder's name;

- 010, report type;

- 015, reporting period;

- 207, facility code;

- 307, MBA code;

- $\quad 309$, entry status and cross reference code with a value of U; and

- 310, state accounting system record identification (optional).

Below are detailed descriptions and associated business rules for each data field in a PIL record. 
Data Field: Reference Number

- Definition: Unique report identifier for filing, processing, sorting, and reference purposes.

- Format: 001:**/**;***...***\#

- code ØI for accounting entries or code NC for concise note entries;

- $\operatorname{slash}(/)$;

- country code;

- semi-colon (;); and

- the numeric report number assigned by the reporting authority.

- Business rules:

- Report number must be unique for any given MBA.

- All reports, regardless of type, are numbered consecutively with respect to each MBA.

Data Field: Entry Number/Total Number of Entries

- Definition: Number for the specific entry within the set of ØI or NC entries contained in the report

- Format: 002:***...***/*** ...**\#

- sequential number of the ØI or NC entry;

- $\operatorname{slash}(/)$; and

- $\quad$ total number of ØI or NC entries in the report.

- Business rules:

- Always start with 1 within each set of ØI and NC entries.

- The total number of ØI or NC entries may be omitted, as well as the preceding slash in entries except for the first ØI and NC entry of a report, where it is mandatory.

Data Field: Report Date

- Definition: Date when the report was produced.

- Format: 003:[********][******]\#

- $\quad$ the [four] [last two] digits of the current year;

- the two-digit designation of the month; and

- the two-digit designation of the day.

- Business rules:

- The year can be indicated either with four digits or with the last two digits; therefore, the entry format can be either eight or six characters long.

- The State can decide what they would like to use for the report date, such as the date the report was prepared for dispatch to the IAEA.

- The report date should not be after the date of dispatch.

The date should be on or after the date of the physical inventory taking.

Data Field: Encoder's Name

- Definition: Official responsible for the report.

- Format: 006:***...***\#

- family name;

- a comma (,); and 
- the initials.

- Business rule:

- A maximum of 30 characters may be used.

Data Field: Report Type

- Definition: Type of report.

- Format: 010:*\#

- Single character.

- Business rule:

- $\quad$ P for PIL

\section{Data Field: Reporting Period}

- Definition: Date of a physical inventory taking and the corresponding PIL.

- Format: 015:[********]\#

- $\quad$ [eight][six] digits for the date of the PIL (as for Report Date data field);

- Business rules:

- The data field indicates the date of physical inventory taking.

- If the actual taking of the inventory lasts more than 1 day, common in large facilities, the IAEA and the facility will agree on a single date for purposes of nuclear material accounting.

- $\quad$ The PIL date must be the same as the period ending date of the corresponding MBR.

\section{Data Field: Facility Code}

- Definition: Identification code of the facility containing the reporting MBA.

- Format: 207:****\#

- Four-character code.

- Business rule:

- $\quad$ The facility code is specified in the relevant facility attachment.

Data Field: $M B A$ Code

- Definition: Identification code of the MBA submitting the report.

- Format: 307:****\#

- Four-character code.

- Business rule:

- $\quad$ The MBA code is specified in the relevant facility attachment.

Data Field: Entry Status and Cross Reference Code

- Definition: Status of the entry and, when necessary, provides a reference to a previously reported entry.

- Format: 309:*/**;***...***/***...***\#

- One-character code to designate the status of the entry: 
- $\quad \mathrm{N}$ for new entries;

- U for invalid entries to be ignored;

- C for entries serving as corrections to earlier ones;

- D for entries deleting the one referenced by the current entry; and

- A for an entry to be added to the previous report.

- Slash (/); this and the following reference codes are mandatory if the entry status code is C, D, or A. For N, they are not applicable; for U, they are optional.

- Country code (same as in label 001, Reference Number);

- semi-colon (;);

- the report number assigned by the reporting authority as specified in the label 001 of the entry being referenced;

- $\operatorname{slash}(/)$; and

- entry number of the entry to be referenced (i.e., first subfield 002 of that entry), or in the case of an additional entry, the number of the entry as it will appear in the report to which the entry is being added.

- Business rules:

- If the entry is serving as a correction to an earlier one (C), the remainder of the entry should contain the same data elements and values of the referenced line entry except for those elements being corrected.

- If the entry is deleting the one referenced by this entry, the data elements for the remainder of the entry are optional.

Data Field: State Accounting System Record Identification

- Definition: Unique identifier in the State accounting system that references the data contained in the State report.

- Format: $310: * * * \ldots * * *$

- Business rules:

- Optional.

- Maximum of 40 characters may be used.

Data Field: Concise Note Indicator

- Definition: Indicates a concise note is included in the report or attached to it.

- Format: 390:*\#

- Business rules:

- Optional.

- Y indicates the presence of a concise note.

Data Field: Text of Concise Note

- Definition: Text that provides clarifications, amplifications, and other unformatted information.

- Format: 391: ***...***\#

- Business rules:

- Optional.

- Concise note can be written in free format, using only Latin capital letters, numerals, and permitted special symbols. 
- A maximum of 2,000 characters of text may be reported in a single nuclear material accounting entry.

Data Field: Key Measurement Point Code

- Definition: The appropriate KMP code.

- Format: 407:**\#

- Business rule:

- The appropriate KMP code is assigned in the facility attachment.

Data Field: Material Description Code

- Definition: The physical and chemical form, containment, and irradiation status and quality of the nuclear material in the batch.

- Format: 430:*/*/*/*\#

- Four-character code (see Appendix E-2 for codes)

- Business rules:

- The domestic shipment of a given batch from one MBA and its receipt in another MBA must be reported with the same material description code.

- If the codes are used in hard-copy communications, the slashes may be omitted.

- The Material Description Code is specified in the relevant facility attachment.

Data Field: Operator's Material Description Code

- Definition: May be used to indicate that the operator's material description code is identical to the code used by the IAEA.

- Format: 435:*/***...***\#

- $\quad \mathrm{Y}$ indicates that the codes are identical; letter $\mathrm{N}$ indicates that the codes are different and that the operator's material description code follows.

- Slash (/), if operator's code follows.

- Operator's material description code.

- Business rules:

- If the operator's material description code differs from the code used by the IAEA, the operator's own code may be shown here.

- The operator's material description code can be reported as a maximum of 12 characters.

Data Field: Operator's Material Description (Text)

- Definition: Permits the inclusion of a textual description of the batch if the operator so wishes or has otherwise agreed in the facility attachment.

- Format: 436: ***...***\#

- Maximum of 100 characters

- Business rule:

- Text should be composed of Latin capital letters, numerals, and permitted special characters. 


\section{Data Field: Non-Latin Alphabet Identification}

- Definition: Indicates non-Latin letters are used in the entry (e.g., in the encoder's name).

- Format: 445: *\#

- Business rules:

- Entry should consist of a single-letter code agreed upon with the IAEA.

- If only Latin letters are used in the entry, this label should not be used.

\section{Data Field: Batch Name}

- Definition: Batch name of the nuclear material being reported.

- Format: 446: ***...***\#

- Business rules:

- The batch name reported should be unique to the reporting MBA for the inventory date.

- A maximum of 16 characters may be used.

\section{Data Field: Measurement Identification Code}

- Definition: Measurement basis used, and if applicable, the KMP and/or method of measurement.

- Format: 469: */***...***/*** ...**\#

- Measurement basis code, consisting of one of the letters:

- $\quad \mathrm{N}$, if the batch data are based on measurements made at another MBA;

- $\quad \mathrm{L}$, if the batch data are based on measurements made at another MBA and have been reported for the present MBA in a preceding ICR or PIL;

- $\quad \mathrm{M}$, if the batch data are based on fresh measurements made at the MBA; and

- $\quad T$, if the batch data are based on measurements made at the present MBA and have been reported in a preceding ICR or PIL and the measurements have not been repeated;

- Slash (/), if other data items follow.

- In cases denoted by M as defined above, indicate the KMP where the measurement was made if it differs from the KMP names in the data element under label 407; otherwise not needed.

- In cases denoted by $\mathrm{M}$ or $\mathrm{T}$ as defined above, indicate the method used for the measurement.

- Business rules:

- It is possible for M to be on a PIL (e.g., if a batch is manufactured and it is reported for the first time because of an inventory taking).

- When a batch is remeasured during a material balance period and that is the only activity for the batch, the next PIL should indicate M, even if the weights did not change.

Data Field: Number of Items in Batch

- Definition: Number of similar items in the batch.

- Format: 470: ***...***\#

- Business rules:

- In the case of bulk material (when the number would not be meaningful), a zero should be placed in this data field.

- The number must be an integer. 


\section{Data Field: Weight Data}

- Definition: Labels 600-800 provide the quantities of the nuclear material in the batch represented by the entry. The pertinent labels $600-800$ should be used.

- Format: $600:^{* * *} \ldots{ }^{* * * \#} 610: * * * \ldots{ }^{* * * \#} 620:^{* * *} \ldots{ }^{* * *} \ldots$ etc. ... 800:***...***\#

- Labels 600-800 each follow the same format:

- numerical label;

- $\operatorname{colon}(:)$;

- the numerical expression of the weight of the element (i.e., isotope or their combination of isotopes), as indicated by the label; and

- weight expressed as g for weight given in grams, or as kg for weight given in kilograms.

- Business rules:

- The weight data relates either to a specific chemical element or its isotopes.

- The weight data are to be expressed in the following units:

- grams of plutonium (and its isotopes, if appropriate);

- grams of total uranium for enriched uranium;

- grams of isotopes of uranium; and

- kilograms of natural uranium, depleted uranium, and thorium.

- If label 600 (unified uranium) or 630 (enriched uranium) is used, label 640 (enriched/unified uranium $U_{233}$ content), 660 (enriched/unified uranium $U_{233}+U_{235}$ content), or 670 (enriched/unified uranium $\mathrm{U}_{235}$ content) must also be reported.

- Data covered by labels 650, 680, 690, 710, 720, 730, 740, 750, 760, 770, and 780 are optional, unless they are required by the facility attachment.

- Weights reported to a higher precision than milligrams will be rounded to the nearest milligram.

- While it is recommended that data be reported in unrounded figures, the data may be rounded, but not beyond the nearest integer to the unit used, which may necessitate the reporting of rounding adjustments in MBRs.

- Rounding should be done by first adding the weights of the individual items in the batch and then rounding their sum.

\subsection{MATERIAL BALANCE REPORTS}

Like ICRs and PILs, each MBR may consist of two types of records. The first type presents nuclear balance data, and the second type of MBR record provides concise notes giving textual information (see Section 4.5).

Table 4-3 describes the report format for MBRs. Appendix E contains the reporting codes used in labeled format Code 10 reporting.

Table 4-3. Report format for material balance reports

\begin{tabular}{|c|l|l|c|}
\hline Label & \multicolumn{1}{|c|}{ Data field name } & \multicolumn{1}{|c|}{ Format } & Comment(s) \\
\hline 001 & Reference Number & $* * * * * ; * * * \ldots * * * \#$ & \\
\hline 002 & Entry Number/Total Number of Entries & $* * * \ldots * * * / * * * \ldots * * * \#$ & \\
\hline 003 & Report Date & {$[* * * * * * * *][* * * * * *] \#$} & \\
\hline 006 & Encoder's Name & $* * * \ldots * * * \#$ & \\
\hline 010 & Report Type & $* \#$ & \\
\hline
\end{tabular}


Table 4-3. Report format for material balance reports (continued)

\begin{tabular}{|c|c|c|c|}
\hline Label & Data field name & Format & Comment(s) \\
\hline 015 & Reporting Period & $\begin{array}{l}{[* * * * * * * * / * * * * * * * *]} \\
{[* * * * * * / * * * * * *] \#}\end{array}$ & \\
\hline 207 & Facility Code & $* * * * \#$ & \\
\hline 307 & MBA Code & $* * * * \#$ & \\
\hline 309 & Entry Status and Cross Reference Code & $* / * * ; * * * \ldots{ }^{* * * / * * *} \ldots{ }^{* * * \#}$ & \\
\hline 310 & $\begin{array}{l}\text { State Accounting System Record } \\
\text { Identification }\end{array}$ & $* * * \ldots * * *$ & Optional \\
\hline 390 & Concise Note Indicator & *\# & $\begin{array}{l}\text { Required if entry is } \\
\text { referenced by a concise } \\
\text { note submitted in same } \\
\text { report }\end{array}$ \\
\hline 411 & Type of Inventory Change & $\begin{array}{l}* * \# \text { or } * * * * \# \text { for rounding } \\
\text { adjustments }\end{array}$ & \\
\hline 445 & Non-Latin Alphabet Identification & $* \#$ & $\begin{array}{l}\text { Required if entry includes } \\
\text { non-Latin letters }{ }^{a}\end{array}$ \\
\hline $600-800$ & Weight Data & $* * * \ldots * * * \#$ & $\begin{array}{l}\text { If label } 600 \text { or } 630 \text { is used, } \\
\text { label } 640,660 \text {, or } 670 \text { must } \\
\text { also be reported. }\end{array}$ \\
\hline
\end{tabular}

${ }^{a}$ If non-Latin letters are used in the entry (e.g., in the batch name or encoder's name), a one-letter code (agreed upon with the IAEA) is placed in this data element. Otherwise this label should not be used.

Business Rules: $M B R$

- All entries have variable length, unless the permitted or prescribed number of characters is specifically indicated.

- $\quad$ Each MBR must contain at least one entry (i.e., record) of the first type, indicating the nuclear material balance.

- An MBR must be prepared even if at the time of the physical inventory taking there was no nuclear material in the MBA and there were no transactions during the material balance period. Such an MBR should contain a single entry including the following data elements:

- $\quad$ 001, reference number;

- 002, entry number;

- 003 , report date;

- 006, encoder's name;

- 010, report type;

- 015, reporting period;

- 207, facility code;

- 307, MBA code;

- 309, entry status and cross reference code with a value of U; and

- 310, state accounting system record identification (optional).

Below are detailed descriptions and associated business rules for each data field in an MBR record. 
Data Field: Reference Number

- Definition: Unique report identifier for filing, processing, sorting, and reference purposes.

- Format: 001:**/**;***...***\#

- code ØI for accounting entries or code NC for concise note entries;

- $\operatorname{slash}(/)$;

- country code;

- semi-colon (;); and

- $\quad$ the numeric report number assigned by the reporting authority.

- Business rules:

- Report number must be unique for any given MBA.

- All reports, regardless of type, are numbered consecutively with respect to each MBA.

Data Field: Entry Number/Total Number of Entries

- Definition: Number for the specific entry within the set of ØI or NC entries contained in the report.

- Format: 002:***...***/*** ...**\#

- sequential number of the ØI or NC entry;

- $\operatorname{slash}(/)$; and

- $\quad$ total number of ØI or NC entries in the report.

- Business rules:

- Always start with 1 within each set of ØI and NC entries.

- The total number of ØI or NC entries may be omitted, as well as the preceding slash in entries except for the first ØI and NC entry of a report, where it is mandatory.

Data Field: Report Date

- Definition: Date when the report was produced.

- Format: 003:[********][******]\#

- $\quad$ the [four] [last two] digits of the current year;

- the two-digit designation of the month; and

- the two-digit designation of the day.

- Business rules:

- The year can be indicated either with four digits or with the last two digits; therefore, the entry format can be either eight or six characters long.

- The State can decide what they would like to use for the report date (i.e., date the report was prepared for dispatch to the IAEA).

- The report date should not be after the date of dispatch.

- The date should be on or after the period ending date of an MBR.

Data Field: Encoder's Name

- Definition: Official responsible for the report.

- Format: 006:***...***\#

- family name;

- a comma (,); and

- the initials. 
- Business rule:

- A maximum of 30 characters may be used.

Data Field: Report Type

- Definition: Indicates the type of report.

- Format: 010:*\#

- Single character.

- Business rule:

- $\mathrm{M}$ for MBR.

Data Field: Reporting Period

- Definition: Beginning and ending dates of the period covered by the ICR.

- Format: 015:[********/********] [******/******]\#

- $\quad$ [eight][six] digits for the beginning date (as in the Report Date data field);

- slash (/); and

- $\quad$ [eight][six] digits for the ending date (as in the Report Date data field).

- Business rules:

- The specified period should include the dates of inventory change reported in all new entries in the report.

- $\quad$ The beginning date is 1 day after the date of the previous PIL.

- For the first MBR reported for an MBA where reporting does not begin with an initial PIL, the date should be that of the first inventory change for the MBA.

- $\quad$ The ending date of the MBR must be the same as the inventory date of the corresponding PIL.

Data Field: Facility Code

- Definition: Identification code of the facility containing the reporting MBA.

- Format: 207:****\#

- Four-character code.

- Business rule:

- The facility code is specified in the relevant facility attachment.

Data Field: $M B A$ Code

- Definition: Identification code of the MBA submitting the report.

- Format: 307:****\#

- Four-character code.

- Business rule:

- The MBA code is specified in the relevant facility attachment.

Data Field: Entry Status and Cross Reference Code

- Definition: Status of the entry and, when necessary, provides a reference to a previously reported entry. 
- Format: 309:*/**;***...***/***...***\#

- One-character code to designate the status of the entry:

- $\mathrm{N}$ for new entries;

- U for invalid entries to be ignored;

- C for entries serving as corrections to earlier ones;

- D for entries deleting the one referenced by this entry; and

- A for an entry to be added to previous report.

- Slash (/); this and the following reference codes are mandatory if the entry status code is C, D, or A. For N, they are not applicable; for U, they are optional.

- Country code (same as in label 001, Reference Number);

- semi-colon (;);

- $\quad$ the report number assigned by the reporting authority as specified in label 001 of the entry being referenced;

- $\operatorname{slash}(/)$; and

- entry number of the entry to be referenced (i.e., first subfield 002 of that entry), or in the case of an additional entry, the number of the entry as it will appear in the report to which the entry is being added.

- Business rules:

- If the entry is serving as a correction to an earlier one (C), the remainder of the entry should contain the same data elements and values of the referenced line entry, except for those elements being corrected.

- If the entry is deleting the one referenced by the current entry, the data elements for the remainder of the entry are optional.

Data Field: State Accounting System Record Identification

- Definition: Unique identifier in the State accounting system that references the data contained in the State report.

- Format: $310: * * * \ldots * * *$

- Business rules:

- Optional.

- Maximum of 40 characters may be used.

Data Field: Concise Note Indicator

- Definition: Indicates a concise note is included in the report or attached to it.

- Format: 390:*\#

- Business rules:

- Optional.

- Y indicates the presence of a concise note.

Data Field: Text of Concise Note

- Definition: Text that provides clarifications, amplifications, and other unformatted information.

- Format: 391:***...***\#

- Business rules:

- Optional. 
- Concise note can be written in free format, using only Latin capital letters, numerals, and permitted special symbols.

- A maximum of 2,000 characters of text may be reported in a single nuclear material accounting entry.

\section{Data Field: Type of Inventory Change}

- Definition: Type of inventory change reported.

- Format: 411:**\# or 411:****\# for rounding adjustments

- two alphabetic characters (see Appendices E-1 and E-4); and

- when indicating rounding adjustments, code is four alphabetic characters.

- Business rules:

- The code denotes consolidated entries (i.e., the sums of all individual operations with the same code over the material balance period), unlike ICRs, in which all transactions and operations are related to individual batches.

- In MBRs, the inventory change code can relate to inventories and adjustments not reported in ICRs.

- If the entry includes rounding adjustments, the code should be entered as RAXX, where XX stands for the code of the entry to which the rounding adjustment pertains (see Appendix E-4 for additional details).

\section{Data Field: Non-Latin Alphabet Identification}

- Definition: Indicates non-Latin letters are used in the entry (e.g., in the encoder's name).

- Format: 445: *\#

- Business rules:

- Entry should consist of a single-letter code agreed upon with the IAEA.

- If only Latin letters are used in the entry, this label should not be used.

\section{Data Field: Weight Data}

- Definition: Labels 600-800 provide the quantities of the nuclear material in the batch represented by the entry. The pertinent labels $600-800$ should be used.

- Format: $600:^{* * *} \ldots{ }^{* * * \#} 610: * * * \ldots{ }^{* * * \#} 620:^{* * *} \ldots{ }^{* * *} \ldots$ etc. .. 800:***...***\#

- Labels 600-800 each follow the same format:

- numerical label;

- colon (:);

- the numerical expression of the weight of the element (i.e., isotope or their combination of isotopes), indicated by the label; and

- $\quad$ weight expressed as g for weight given in grams, or as kg for weight given in kilograms.

- Business rules:

- The weight data relates either to a specific chemical element or to its isotopes.

- The weight data are to be expressed in the following units:

- grams of plutonium (and its isotopes, if appropriate);

- grams of total uranium for enriched uranium;

- grams of isotopes of uranium; and

- kilograms of natural uranium, depleted uranium, and thorium. 
- If label 600 (unified uranium) or 630 (enriched uranium) is used, label 640 (enriched/unified uranium $U_{233}$ content), 660 (enriched/unified uranium $U_{233}+U_{235}$ content), or 670 (enriched/unified uranium $\mathrm{U}_{235}$ content) must also be reported.

- Data covered by labels 650, 680, 690, 710, 720, 730, 740, 750, 760, 770, and 780 are optional, unless they are required by the facility attachment.

- Weights reported to a higher precision than milligrams will be rounded to the nearest milligram.

- While it is recommended that data be reported in unrounded figures, the data may be rounded, but not beyond the nearest integer to the unit used, which may necessitate the reporting of rounding adjustments in MBRs.

- Rounding should be done by first adding the weights of the individual items in the batch and then rounding their sum.

- See Appendix E-3 for a list of the individual numeric labels in this data element.

\subsection{CONCISE NOTE ENTRIES}

The second type of ICRs, PILs, and MBRs provide concise notes, which give additional textual information not accommodated in any of the data elements. The format is the same for a concise note entry whether it appears in an ICR, PIL, or MBR. Table 4-4 describes the report format.

Table 4-4. ICR, PIL, or MBR concise note report format

\begin{tabular}{|c|c|c|c|}
\hline Label & Data field name & Format & Required field \\
\hline 001 & Reference Number & $* * / * * ; * * * \ldots * * * \#$ & \\
\hline 002 & Entry Number/Total Number of Entries & $* * * \ldots * * * / * * * \ldots * * * \#$ & \\
\hline 003 & Report Date & {$[* * * * * * * *][* * * * * *] \#$} & \\
\hline 099 & Concise Note Reference & $* / * * * \ldots * * * \#$ & Optional \\
\hline 207 & Facility Code & $* * * * \#$ & \\
\hline 307 & MBA Code & $* * * * \#$ & \\
\hline 391 & Text of Concise Note & $* * * \ldots * * * \#$ & \\
\hline
\end{tabular}

\section{Business Rules: Concise Note Entry}

- The data recorded for labels 001,207 , and 307 must be the same as those recorded for the entry of the first type to which the concise note refers, with NC replacing ØI in label 001.

Below are detailed descriptions and associated business rules for each data field in a record containing concise notes.

\section{Data Field: Reference Number}

- Definition: Unique report identifier for filing, processing, sorting, and reference purposes.

- Format: 001:**/**;***...***\#

- code ØI for accounting entries or code NC for concise note entries;

- $\operatorname{slash}(/)$;

- country code;

- semi-colon (;); and

- the numeric report number assigned by the reporting authority. 
- Business rules:

- Report number must be unique for any given MBA.

- All reports, regardless of type, are numbered consecutively with respect to each MBA.

Data Field: Entry Number/Total Number of Entries

- Definition: Number for the specific entry within the set of ØI or NC entries contained in the report.

- Format: 002:***...***/***...***\#

- sequential number of the ØI or NC entry;

- $\operatorname{slash}(/)$; and

- $\quad$ total number of $\varnothing \mathrm{I}$ or NC entries in the report.

- Business rules:

- Always start with 1 within each set of ØI and NC entries.

- The total number of ØI or NC entries may be omitted, as well as the preceding slash in entries except for the first ØI and NC entry of a report, where it is mandatory.

Data Field: Report Date

- Definition: Date when the report was produced.

- Format: 003:[********][******]\#

- the [four] [last two] digits of the current year;

- the two-digit designation of the month; and

- the two-digit designation of the day.

- Business rules:

- The year can be indicated either with four digits or with the last two digits; therefore, the entry format can be either eight or six characters long.

- The State can decide what they would like to use for the report date (e.g., date the report was prepared for dispatch to the IAEA).

- The report date should not be after the actual date of dispatch.

Data Field: Concise Note Reference

- Definition: Entry or report to which the concise note refers.

- Format: 099:*/***...***\#

- E, if it is related to a specific entry; in this case followed by a

- slash (/); and

- the number of the entry in question or;

- $\quad \mathrm{R}$, if the concise note refers to the report as a whole.

- Business rules:

- Only used in concise note entries.

- Should refer the entry (if appropriate) to the report or to a specific accounting entry in the ØI report with the same report number.

Data Field: Facility Code

- Definition: Identification code of the facility containing the reporting MBA. 
- Format: 207:****\#

- Four-character code.

- Business rule:

- $\quad$ The facility code is specified in the relevant facility attachment.

\section{Data Field: MBA Code}

- Definition: Identification code of the MBA submitting the report.

- Format: 307:****\#

- Four-character code.

- Business rule:

- The MBA code is specified in the relevant facility attachment.

Data Field: Text of Concise Note

- Definition: Free-format text that provides clarifications, amplifications, and other unformatted. information (e.g., relevant burn-up values, relevant aspects of the operational program)

- Format: 391:***...***\#

- Business rules:

- Text is free format, but can use only Latin capital letters, numerals, and permitted special symbols.

- Maximum of 2,000 characters may be used in a single entry.

\subsection{TEXTUAL REPORTS}

If desired, freely formulated information not incorporated into accounting reports may be reported to the IAEA as separate sets of records accumulated into any number of textual reports. Such reports should be formatted as free-standing concise notes. Table 4-5 describes the report format.

Table 4-5. Textual report format

\begin{tabular}{|c|c|c|c|}
\hline Label & Data field name & Format & Required field \\
\hline 001 & Reference Number & $* * / * * ; * * * \ldots * * * \#$ & \\
\hline 002 & Entry Number/Total Number of Entries & $* * * \ldots * * * / * * * \ldots{ }^{* * * \#}$ & \\
\hline 003 & Report Date & {$[* * * * * * * *][* * * * * *] \#$} & \\
\hline 010 & Report Type & *\# & Optional \\
\hline 099 & Concise Note Reference & $* / * * * \ldots * * * \#$ & Optional \\
\hline 207 & Facility Code & $* * * * \#$ & Optional \\
\hline 307 & MBA Code & $* * * * \#$ & Optional \\
\hline 391 & Text of Concise Note & $* * * \ldots * * * \#$ & \\
\hline
\end{tabular}

Business Rules: Textual Reports

- $\quad$ Each textual report must have a unique reference code and consist of at least one record.

- A textual report should be subdivided into an appropriate number of records. 
- If the text of the note refers to a specific facility and/or MBA, labels 207 (facility code) and/or 307 (MBA code) may be used.

- If a reference to a specific accounting report is desired, labels 010 (report type) and 099 (concise note reference) may also be used.

Below are detailed descriptions and associated business rules for each data field in a textual report.

Data Field: Reference Number

- Definition: Unique report identifier for filing, processing, sorting, and reference purposes.

- Format: $001: * * / * * ; * * * \ldots * * * \#$

- code NC;

- $\operatorname{slash}(/)$

- country code;

- semi-colon (;); and

- $\quad$ the numeric report number assigned by the reporting authority.

- Business rules:

- Report number must be unique for any given MBA.

- All reports, regardless of type, are numbered consecutively with respect to each MBA.

Data Field: Entry Number/Total Number of Entries

- Definition: Number for the specific entry within the set of ØI or NC entries contained in the report.

- Format: 002:***...***/***...***\#

- sequential number of the ØI or NC entry;

- $\quad$ slash (/); and

- total number of ØI or NC entries in the report.

- Business rules:

- Always start with 1 within each set of ØI and NC entries.

- The total number of ØI or NC entries may be omitted, as well as the preceding slash in entries except for the first ØI and NC entry of a report, where it is mandatory.

\section{Data Field: Report Date}

- Definition: Date when the report was produced.

- Format: 003:[********][******]\#

- the [four] [last two] digits of the current year;

- the two-digit designation of the month; and

- the two-digit designation of the day.

- Business rule:

- The year can be indicated either with four digits or with the last two digits; therefore, the entry format can be either eight or six characters long.

Data Field: Report Type

- Definition: Type of report. 
- Format: 010:*\#

- Single character.

- Business rules:

- $\quad$ T should be used for textual report.

- Optional; may use if referring to a specific accounting report.

Data Field: Concise Note Reference

- Definition: Entry or report to which the concise note refers.

- Format: 099:*/***...***\# or 099:*/***...***/***...***\#

- $\quad \mathrm{R}$, if the concise note refers to a report as a whole; in this case followed by a

- $\operatorname{slash}(/)$; and

- report number to which the concise note refers;

- $\quad$ E, if it is related to a specific entry; in this case followed by a

- $\operatorname{slash}(/)$;

- report number;

- another slash (/); and

- the entry number within the report to which the concise note refers.

- Business rule:

- Optional; may be used if referring to a specific accounting report.

Data Field: Facility Code

- Definition: Identification code of the facility containing the reporting MBA.

- Format: 207:****\#

- Four-character code.

- Business rules:

- Optional.

- The facility code is specified in the relevant facility attachment.

Data Field: $M B A$ Code

- Definition: Identification code of the MBA submitting the report.

- Format: 307:****\#

- Four-character code.

- Business rules:

- Optional.

- The MBA code is specified in the relevant facility attachment.

Data Field: Text of Concise Note

- Definition: Free-format text that provides clarifications, amplifications, and other unformatted information (e.g., relevant burn-up values, relevant aspects of the operational program).

- Format: 391:***...***\# 
- Business rules:

- Text is free format, but can use only Latin capital letters, numerals, and permitted special symbols.

- Maximum of 2,000 characters may be used in a single entry. 


\section{REFERENCES}

[1] Treaty on the Non-Proliferation of Nuclear Weapons, INFCIRC/140 (Vienna: International Atomic Energy Agency [IAEA], 1970).

[2] The Structure and Content of Agreements between the Agency and States Required in Connection with the Treaty on the Non-Proliferation of Nuclear Weapons, INFCIRC/153 (Corrected) (Vienna: International Atomic Energy Agency [IAEA], 1972).

[3] Nuclear Material Accounting Handbook, Services Series 15 (Vienna: IAEA, 2008).

[4] Guidance for States Implementing Comprehensive Safeguards Agreements and Additional Protocols, Services Series 21 (Vienna: IAEA, 2012).

[5] Safeguards Implementation Practices Guide on Provision of Information to the IAEA, Services Series 33 (Vienna: IAEA, 2016).

[6] IAEA Safeguards Glossary, International Nuclear Verification Series No. 3 (Vienna: IAEA, 2001). 



\section{APPENDIX A. IAEA COUNTRY CODES}





\section{APPENDIX A. IAEA COUNTRY CODES}

Table A-1. Country codes used in fixed and labeled format reports.

\begin{tabular}{|c|c|c|c|}
\hline \multicolumn{4}{|c|}{ LIST OF IAEA COUNTRY CODES FOR NUCLEAR MATERIAL ACCOUNTANCY PURPOSES 2003-05-01 } \\
\hline *EURATOM* & $\mathrm{W}$ & LIBYAN ARAB JAMAHIRIYA & LI \\
\hline ABACC & $\mathrm{Y}$ & LIECHTENSTEIN & LN \\
\hline AFGHANISTAN & $\mathrm{AF}$ & LITHUANIA, REPUBLIC OF & LT \\
\hline ALBANIA & $\mathrm{AL}$ & LUXEMBOURG & LX \\
\hline ALGERIA & $\mathrm{DZ}$ & MACAO & ME \\
\hline ANDORRA & $\mathrm{AD}$ & MADAGASCAR & RM \\
\hline ANGOLA & AG & MALAWI & MW \\
\hline ANTIGUA AND BARBUDA & $\mathrm{AB}$ & MALAYSIA & MY \\
\hline ARGENTINA & RA & MALDIVES & MD \\
\hline ARMENIA & $\mathrm{AM}$ & MALI & ML \\
\hline AUSTRALIA & AS & MALTA & MT \\
\hline AUSTRIA & $\mathrm{AU}$ & MARSHALL ISLANDS & MH \\
\hline AZERBAIJAN & AR & MARTINIQUE & $\mathrm{MQ}$ \\
\hline BAHAMAS & BA & MAURITANIA & MU \\
\hline BAHRAIN & $\mathrm{BH}$ & MAURITIUS & MS \\
\hline BANGLADESH & $\mathrm{BD}$ & MEXICO & MX \\
\hline BARBADOS & $\mathrm{BB}$ & MICRONESIA, FEDERATED STATES OF & MF \\
\hline BELARUS, REPUBLIC OF & BY & MONACO & MC \\
\hline BELGIUM & $\mathrm{BL}$ & MONGOLIA & MN \\
\hline BELIZE & $\mathrm{BZ}$ & MONTSERRAT & MR \\
\hline BENIN & $\mathrm{BE}$ & MOROCCO & MA \\
\hline BERMUDA & BM & MOZAMBIQUE & MB \\
\hline BHUTAN & $\mathrm{BT}$ & MYANMAR & $\mathrm{BU}$ \\
\hline BOLIVIA & $\mathrm{BO}$ & NAMIBIA & NM \\
\hline BOSNIA AND HERZEGOVINA & $\mathrm{HB}$ & NAURU & NU \\
\hline BOTSWANA & $\mathrm{RB}$ & NEPAL & NP \\
\hline BRAZIL & $\mathrm{BR}$ & NETHERLANDS & NL \\
\hline BRITISH VIRGIN ISLANDS & $\mathrm{BV}$ & NETHERLANDS ANTILLES & NA \\
\hline BRUNEI DARUSSALAM & $\mathrm{BN}$ & NEW CALEDONIA & NC \\
\hline BULGARIA & BG & NEW ZEALAND & NZ \\
\hline BURKINA FASO & $\mathrm{HV}$ & NICARAGUA & NI \\
\hline BURUNDI & RU & NIGER & NG \\
\hline CAMBODIA & KR & NIGERIA & NF \\
\hline CAMEROON & TC & NIUE & NE \\
\hline CANADA & $\mathrm{CN}$ & NORWAY & NO \\
\hline CAPE VERDE & $\mathrm{CV}$ & OMAN & $\mathrm{AO}$ \\
\hline CAYMAN ISLANDS & $\mathrm{CM}$ & PACIFIC ISLANDS & PC \\
\hline CENTRAL AFRICAN REPUBLIC & CA & PAKISTAN & PK \\
\hline CHAD & CD & PALAU, REPUBLIC OF & PU \\
\hline CHILE & $\mathrm{CE}$ & PALESTINE & PT \\
\hline CHINA,PEOPLE'S REPUBLIC OF(*) & $\mathrm{X}$ & PANAMA & $\mathrm{PA}$ \\
\hline COLOMBIA & $\mathrm{CO}$ & PAPUA NEW GUINEA & PN \\
\hline COMOROS & KM & PARAGUAY & PY \\
\hline CONGO, PEOPLE'S REPUBLIC OF & $\mathrm{CB}$ & PERU & $\mathrm{PE}$ \\
\hline COOK ISLANDS & KS & PHILIPPINES & PI \\
\hline COSTA RICA & CR & POLAND & PL \\
\hline
\end{tabular}


Table A-1. Country codes used in fixed and labeled format reports (continued).

\begin{tabular}{|c|c|c|c|}
\hline \multicolumn{4}{|c|}{ LIST OF IAEA COUNTRY CODES FOR NUCLEAR MATERIAL ACCOUNTANCY PURPOSES 2003-05-01 } \\
\hline COTE D'IVOIRE & $\mathrm{CI}$ & PORTUGAL & $\mathrm{PO}$ \\
\hline CROATIA & $\mathrm{CT}$ & PUERTO RICO & $\mathrm{PR}$ \\
\hline CUBA & $\mathrm{CU}$ & QATAR & SQ \\
\hline CYPRUS & CY & REPUBLIC OF MOLDOVA & MO \\
\hline CZECH REPUBLIC & $\mathrm{CZ}$ & ROMANIA & RO \\
\hline DEMOCRATIC PEOPLE'S REP. OF KOREA & $\mathrm{KD}$ & RUSSIA & $\mathrm{Z}$ \\
\hline DEMOCRATIC REPUBLIC OF THE CONGO & CK & RWANDA & RW \\
\hline DENMARK & DK & SAINT HELENA & SH \\
\hline DJIBOUTI & DJ & SAINT KITTS AND NEVIS & SK \\
\hline DOMINICA & DM & SAINT LUCIA & SC \\
\hline DOMINICAN REPUBLIC & $\mathrm{DO}$ & SAINT VINCENT AND THE GRENADINES & VG \\
\hline ECUADOR & EC & SAMOA & SS \\
\hline EGYPT & ET & SAN MARINO & SM \\
\hline EL SALVADOR & SV & SAO TOME AND PRINCIPE & ST \\
\hline EQUATORIAL GUINEA & GE & SAUDI ARABIA & SA \\
\hline ERITREA & ER & SENEGAL & $\mathrm{SE}$ \\
\hline ESTONIA, REPUBLIC OF & EA & SERBIA AND MONTENEGRO & IU \\
\hline ETHIOPIA & EP & SEYCHELLES & SY \\
\hline FIJI & IF & SIERRA LEONE & SL \\
\hline FINLAND & SF & SINGAPORE & SG \\
\hline FRANCE & $\mathrm{F}$ & SLOVAKIA & SX \\
\hline FRENCH GUIANA & GF & SLOVENIA & $\mathrm{VE}$ \\
\hline GABON & GA & SOLOMON ISLANDS & SB \\
\hline GAMBIA & GM & SOMALIA & SO \\
\hline GEORGIA & GO & SOUTH AFRICA & $\mathrm{AZ}$ \\
\hline GERMANY & $\mathrm{DF}$ & SPAIN & ES \\
\hline GHANA & GH & SRI LANKA & CL \\
\hline GREECE & GR & SUDAN & SN \\
\hline GREENLAND & GL & SURINAME & SI \\
\hline GRENADA & GD & SWAZILAND & SD \\
\hline GUATEMALA & GT & SWEDEN & SW \\
\hline GUINEA BISSAU & GI & SWITZERLAND & $\mathrm{CH}$ \\
\hline GUINEA, REPUBLIC OF & GN & SYRIAN ARAB REPUBLIC & SR \\
\hline GUYANA & GU & TAJIKISTAN & TK \\
\hline HAITI & $\mathrm{RH}$ & THAILAND & $\mathrm{TH}$ \\
\hline HOLY SEE & HS & THE FORMER YUGOSLAV RP OF MACEDONIA & MK \\
\hline HONDURAS & $\mathrm{HO}$ & TOGO & TG \\
\hline HUNGARY & $\mathrm{HU}$ & TOKELAU & $\mathrm{TL}$ \\
\hline IAEA TOKYO FIELD OFFICE & IJ & TONGA & TO \\
\hline IAEA TORONTO FIELD OFFICE & IC & TRINIDAD AND TOBAGO & TT \\
\hline ICELAND & IS & TUNISIA & $\mathrm{TN}$ \\
\hline INDIA & IN & TURKEY & TR \\
\hline INDONESIA & RI & TURKMENISTAN & TM \\
\hline INTERNATIONAL ATOMIC ENERGY AGENCY & IA & TUVALU & $\mathrm{TU}$ \\
\hline IRAN, ISLAMIC REPUBLIC OF & IR & UGANDA & EU \\
\hline IRAQ & IQ & UKRAINE & RK \\
\hline IRELAND & ID & UNITED ARAB EMIRATES & $\mathrm{AE}$ \\
\hline ISRAEL & IL & UNITED KINGDOM & $\mathrm{Q}$ \\
\hline ITALY & IT & UNITED REPUBLIC OF TANZANIA & TA \\
\hline JAMAICA & $\mathrm{AJ}$ & UNITED STATES OF AMERICA & $\mathrm{U}$ \\
\hline
\end{tabular}


Table A-1. Country codes used in fixed and labeled format reports (continued).

\begin{tabular}{|l|c|l|c|}
\hline \multicolumn{1}{|c|}{ LIST OF IAEA COUNTRY CODES FOR NUCLEAR MATERIAL ACCOUNTANCY PURPOSES 2003-05-01 } \\
\hline JAPAN & J & URUGUAY & GY \\
\hline JORDAN & HJ & UZBEKISTAN & KT \\
\hline KAZAKHSTAN & KA & VANUATU & VU \\
\hline KENYA & KN & VENEZUELA & NV \\
\hline KIRIBATI & KI & VIET NAM, SOCIALIST REPUBLIC OF & RV \\
\hline KOREA, REPUBLIC OF & KO & VIRGIN ISLANDS (USA) & VI \\
\hline KUWAIT & KW & WESTERN SAHARA & SJ \\
\hline KYRGYZSTAN & KY & YEMEN, REPUBLIC OF & EN \\
\hline LAO PEOPLE'S DEMOCRATIC REPUBLIC & LA & ZAMBIA & RZ \\
\hline LATVIA, REPUBLIC OF & LV & ZIMBABWE & MI \\
\hline LEBANON & RL & & \\
\hline LESOTHO & LS & & \\
\hline LIBERIA & LB & $(*)$ CODE FOR TAIWAN, CHINA: TW & \\
\hline
\end{tabular}

Notes to the country code list:

1. Euratom uses W for all MBA codes for the nonnuclear weapon States. Foreign partners should indicate the nonnuclear weapon States with the partner country code of W.

2. For the nuclear weapon States of France (F) and the United Kingdom (Q), which are members of Euratom, the codes F and $\mathrm{Q}$ are reported on their own and not under the Euratom code W.

3. When reporting imports and exports, if the partner MBA or Facility Code is not known, report the partner country code. 

APPENDIX B. FIXED FORMAT REPORTING FORMS 

APPENDIX B-1. INVENTORY CHANGE REPORT FORM R.01.1/C

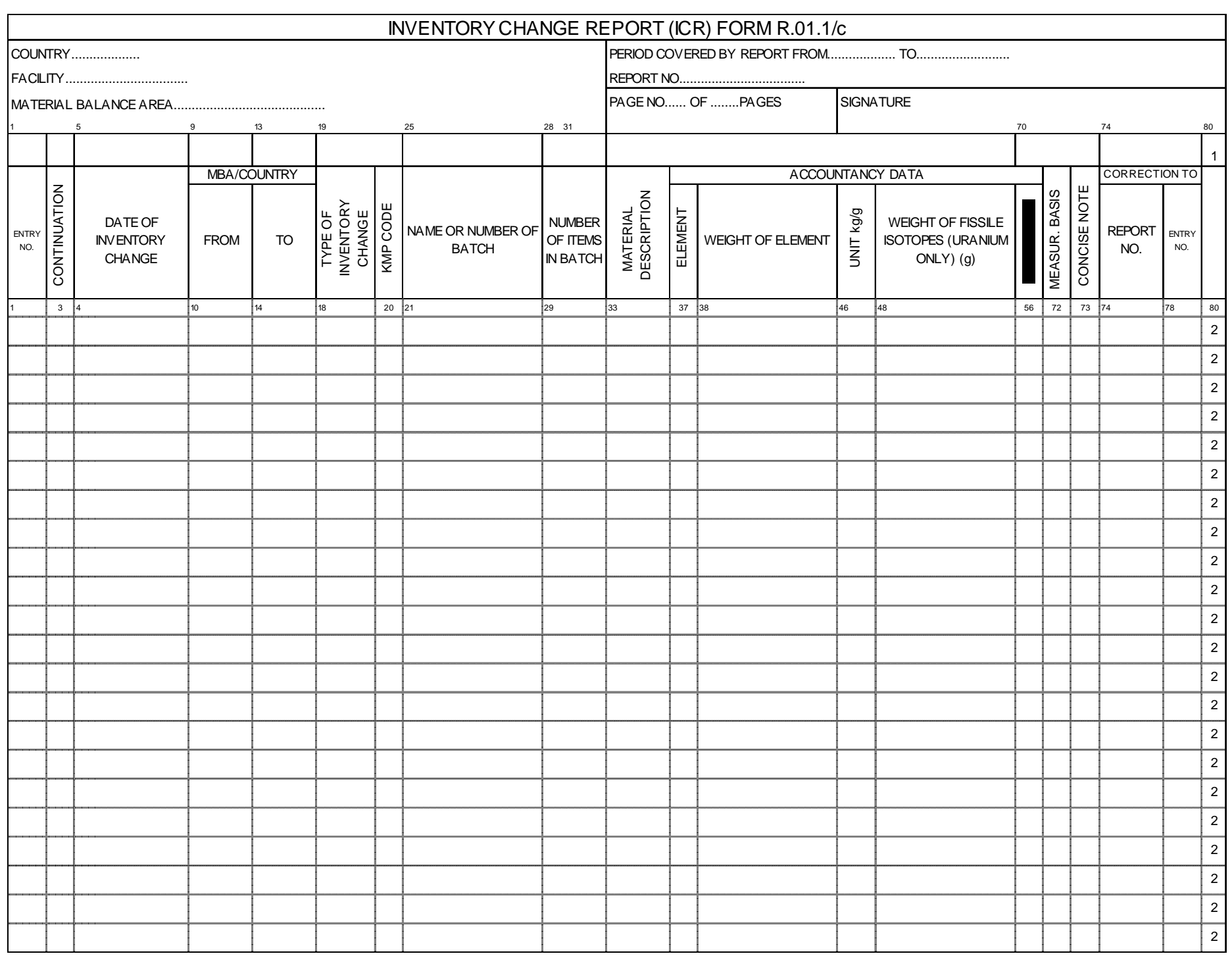

Figure B-1. Inventory Change Report form R.01.1/c. 
APPENDIX B-2. INVENTORY CHANGE REPORT FORM R.01.2 FOR ADDITIONAL ISOTOPES

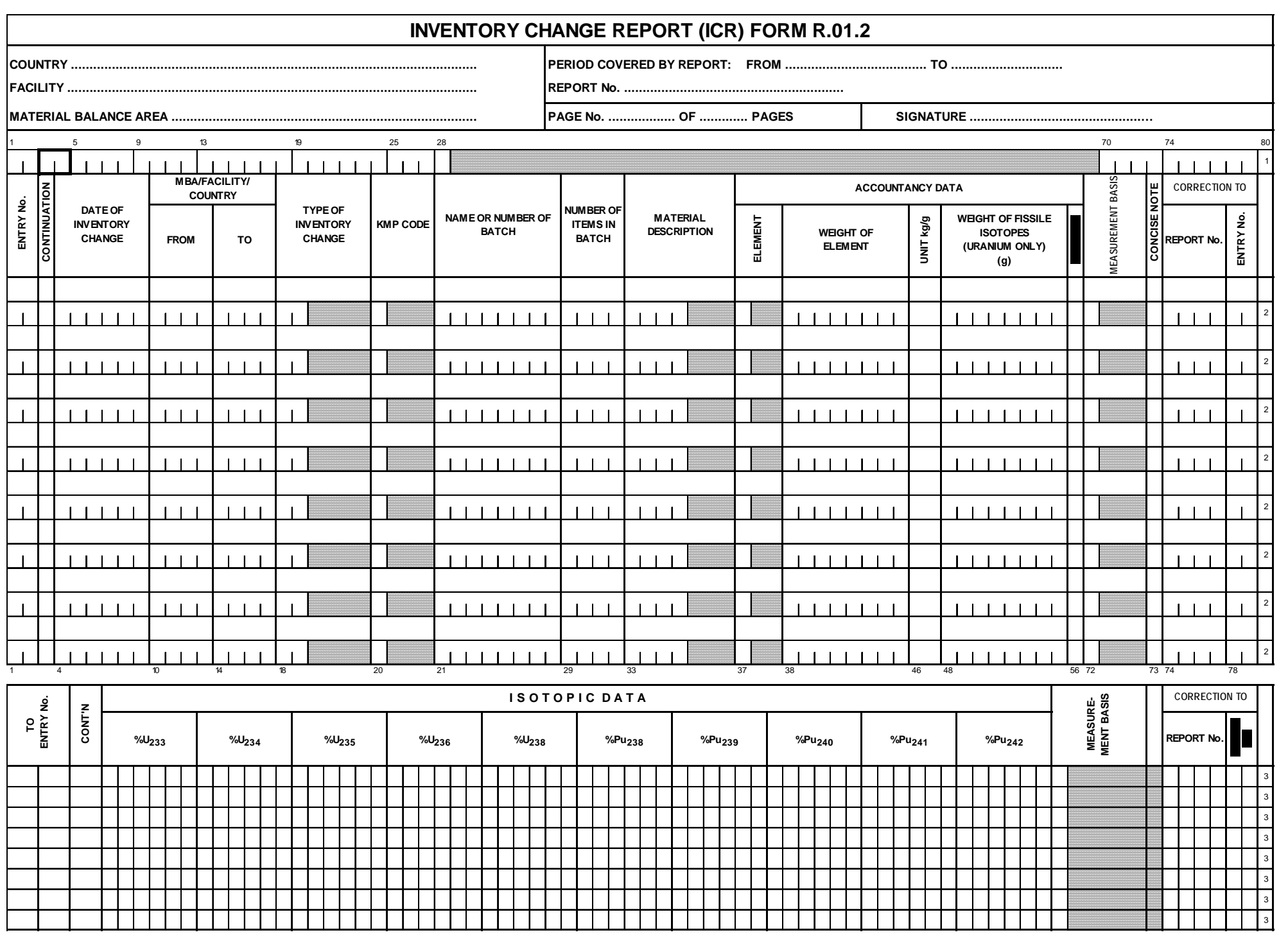

Figure B-2. Inventory Change Report form R.01.2. 
APPENDIX B-3. PHYSICAL INVENTORY LISTING FORM R.02/C

\begin{tabular}{|c|c|c|c|c|c|c|c|c|c|c|c|c|c|c|c|}
\hline & & & & PHYSI & CAL IN & /EN & VTORY LISTING ( & PIL) & FORM R.02/c & & & & & & \\
\hline $\begin{array}{l}\text { COUN } \\
\text { FAClL }\end{array}$ & $\begin{array}{l}\text { TRY. } \\
\text { ITY... }\end{array}$ & (n......... & $\ldots \ldots \ldots$ & & & & $\begin{array}{l}\text { DATE } \\
\text { REPORT NO. }\end{array}$ & $\ldots \ldots \ldots$ & ……… & & & & & & \\
\hline $\begin{array}{l}\text { MATE } \\
1\end{array}$ & RIAL & BAL & $\begin{array}{l}\text { ANCE AREA ................... } \\
59\end{array}$ & & 19 & & $\begin{array}{l}\text { PAGE NO. .......... OF ....... } \\
25 \quad 28\end{array}$ & $\begin{array}{ll}\ldots \ldots . . F \\
31\end{array}$ & $\begin{array}{l}\text { AGES } \\
4552\end{array}$ & & VAT & JRE: & 74 & & 80 \\
\hline & & & & & & & ACCOUN & TANC & Y DATA & & & & CORRECTI & ONTO & \\
\hline 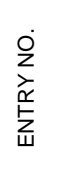 & 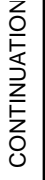 & 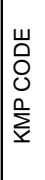 & $\begin{array}{c}\text { NAME OR NUMBER } \\
\text { OF BATCH }\end{array}$ & $\begin{array}{l}\text { NUMBER } \\
\text { OF TEMS } \\
\text { IN BATCH }\end{array}$ & 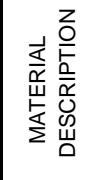 & 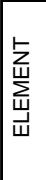 & WEGGHT OF ELEMENT & $\begin{array}{l}\frac{0}{9} \\
\frac{\sqrt{5}}{5} \\
\frac{2}{3}\end{array}$ & $\begin{array}{c}\text { WEGHT OF FISSILE } \\
\text { ISOTOPES } \\
\text { (URANIUM ONLY) } \\
\text { (G) }\end{array}$ & & 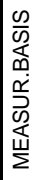 & 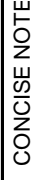 & $\begin{array}{l}\text { REPORT } \\
\text { NO. }\end{array}$ & 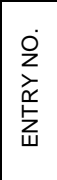 & \\
\hline 1 & 3 & 20 & 21 & 29 & 33 & 37 & 38 & 46 & 48 & 56 & 72 & 73 & 74 & 78 & 80 \\
\hline & & & & & & & & & & & & & & & 5 \\
\hline & & & & & & & & & & & & & & & 5 \\
\hline & & & & & & & & & & & & & & & 5 \\
\hline & & & & & & & & & & & & & & & 5 \\
\hline & & & & & & & & & & & & & & & 5 \\
\hline & & & & & & & & & & & & & & & 5 \\
\hline & & & & & & & & & & & & & & & 5 \\
\hline & & & & & & & & & & & & & & & 5 \\
\hline & & & & & & & & & & & & & & & 5 \\
\hline & & & & & & & & & & & & & & & 5 \\
\hline & & & & & & & & & & & & & & & 5 \\
\hline & & & & & & & & & & & & & & & 5 \\
\hline & & & & & & & & & & & & & & & 5 \\
\hline & & & & & & & & & & & & & & & 5 \\
\hline & & & & & & & & & & & & & & & 5 \\
\hline & & & & & & & & & & & & & & & 5 \\
\hline & & & & & & & & & & & & & & & 5 \\
\hline & & & & & & & & & & & & & & & 5 \\
\hline & & & & & & & & & & & & & & & 5 \\
\hline & & & & & & & & & & & & & & & 5 \\
\hline & & & & & & & & & & & & & & & 5 \\
\hline & & & & & & & & & & & & & & & 5 \\
\hline & & & & & & & & & & & & & & & 5 \\
\hline & & & & & & & & & & & & & & & 5 \\
\hline & & & & & & & & & & & & & & & 5 \\
\hline & & & & & & & & & & & & & & & 5 \\
\hline & & & & & & & & & & & & & & & 5 \\
\hline & & & & & & & & & & & & & & & 5 \\
\hline & & & & & & & & & & & & & & & 5 \\
\hline & & & & & & & & & & & & & & & 5 \\
\hline & & & & & & & & & & & & & & & 5 \\
\hline & & & & & & & & & & & & & & & 5 \\
\hline & & & & & & & & & & & & & & & 5 \\
\hline
\end{tabular}

Figure B-4. Physical Inventory Listing report form R.02/c. 


\section{APPENDIX B-4. MATERIAL BALANCE REPORT FORM R.03}

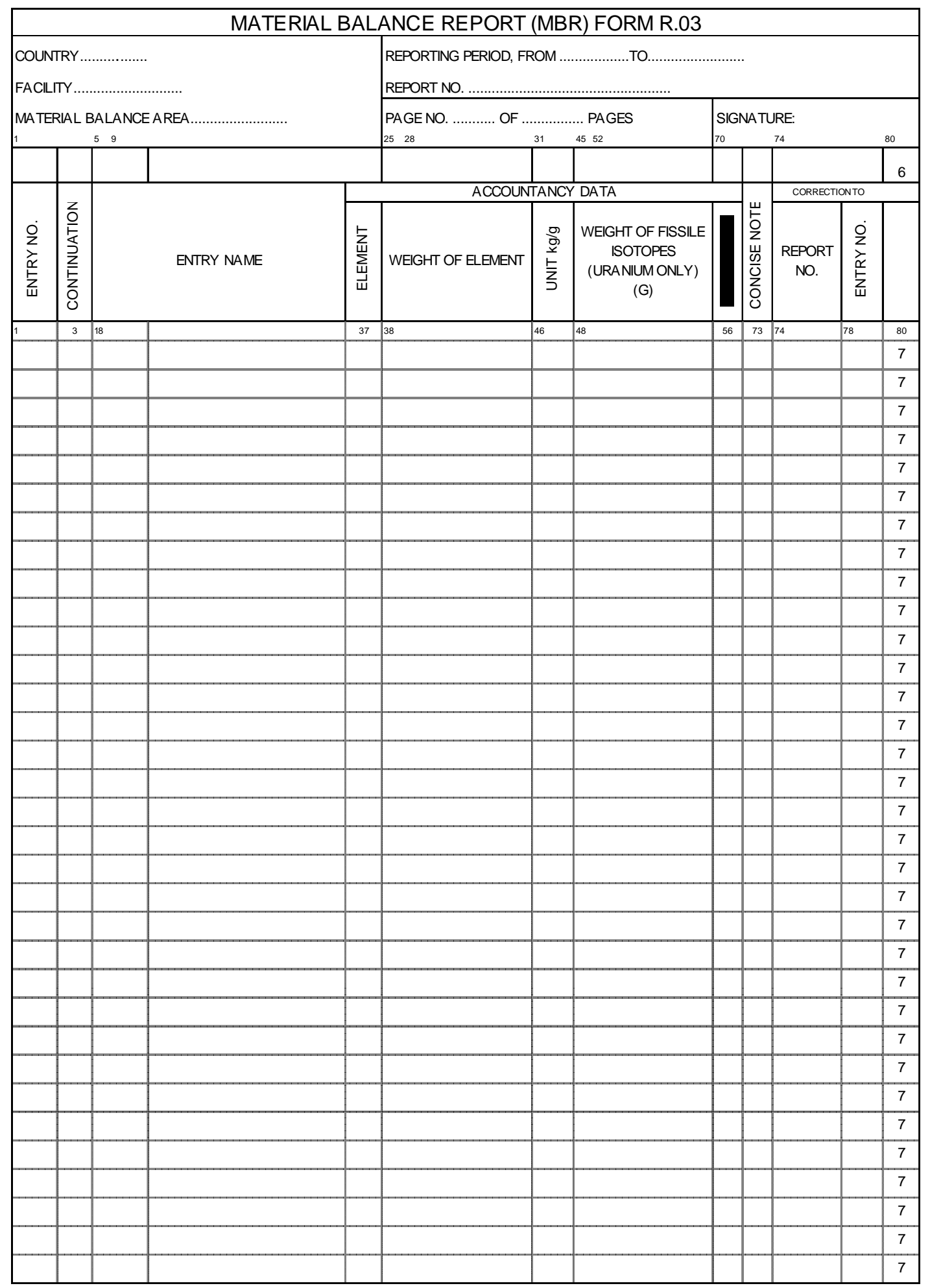

Figure B-4. Material Balance Report form R.03. 
APPENDIX B-5. CONCISE NOTE REPORTING FORM

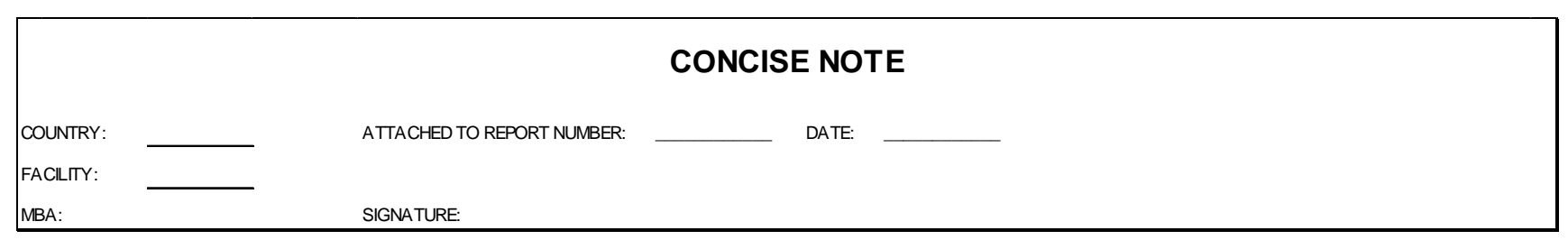

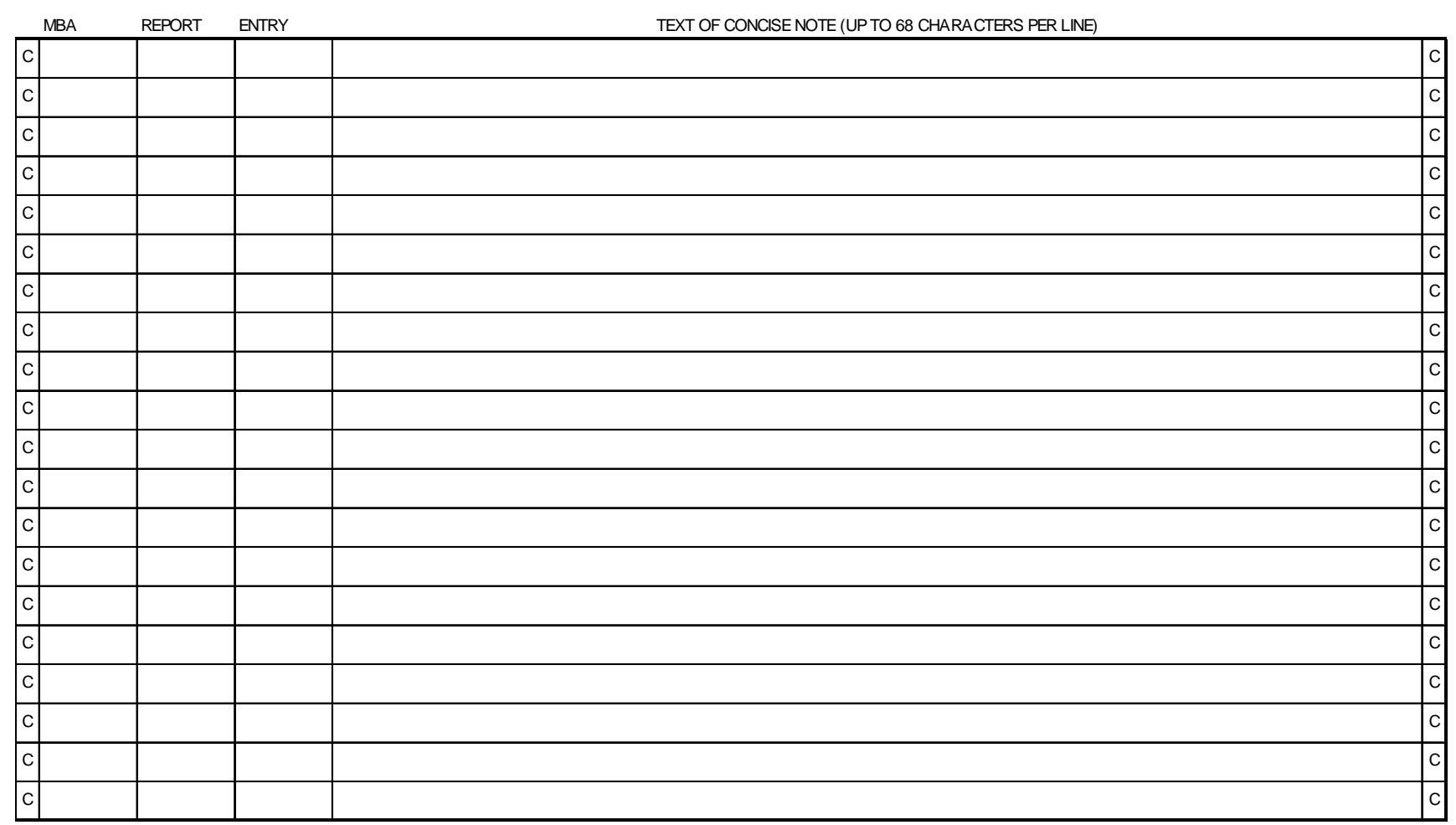

Figure B-5. Concise Note form. 



\section{APPENDIX C. FIXED FORMAT REPORTING CODES}





\section{APPENDIX C. FIXED FORMAT REPORTING CODES}

Table C-1. Inventory change codes (columns 19-20).

\begin{tabular}{|c|c|c|}
\hline Keyword & Code & $\begin{array}{ll}\text { Explanation } \\
\end{array}$ \\
\hline Receipt foreign & RF & Nuclear material imported into [Country]. \\
\hline Receipt domestic & RD & Domestic receipt of nuclear material from another MBA. \\
\hline Receipt at starting point & RS & $\begin{array}{l}\text { Domestic receipt of nuclear material at starting point of safeguards } \\
\text { pursuant to Article } 34 \text { (c) of the CSA. }\end{array}$ \\
\hline $\begin{array}{l}\text { Receipt from } \\
\text { nonsafeguarded activity }\end{array}$ & $\mathrm{RN}$ & $\begin{array}{l}\text { Domestic receipt of nuclear material from non-safeguarded (permitted } \\
\text { military) activity. }\end{array}$ \\
\hline Nuclear production & NP & Production of special fissionable materials in a reactor $\left(\mathrm{Pu}, \mathrm{U}_{233}\right)$. \\
\hline Deexemption, use & DU & $\begin{array}{l}\text { Reapplication of safeguards on nuclear material previously exempted } \\
\text { therefrom pursuant to Article } 37 \text { of the CSA. }\end{array}$ \\
\hline Deexemption, quantity & DQ & $\begin{array}{l}\text { Reapplication of safeguards on nuclear material previously exempted } \\
\text { therefrom pursuant to Article } 37 \text { of the CSA. }\end{array}$ \\
\hline Shipment foreign & SF & Nuclear material exported out of [Country]. \\
\hline Shipment domestic & SD & Domestic transfer of nuclear material to another MBA. \\
\hline $\begin{array}{l}\text { Shipment to } \\
\text { nonsafeguarded activity }\end{array}$ & SN & $\begin{array}{l}\text { Domestic transfer of nuclear material to nonsafeguarded (i.e., permitted } \\
\text { military) activity. }\end{array}$ \\
\hline Nuclear loss & LN & $\begin{array}{l}\text { Consumption of nuclear material due to its transformation into other } \\
\text { element(s) or isotope(s) as a result of a nuclear reaction. }\end{array}$ \\
\hline Measured discard & LD & $\begin{array}{l}\text { Operational loss (i.e., loss of a measured or estimated [on the basis of } \\
\text { measurement]) quantity of nuclear material from processing that has been } \\
\text { disposed of in such a way that it is not suitable for further nuclear use). }\end{array}$ \\
\hline $\begin{array}{l}\text { Transfer to retained } \\
\text { waste }\end{array}$ & TW & $\begin{array}{l}\text { Transfer to the retained waste category of measured nuclear material that is } \\
\text { deemed to be irrecoverable, to be stored at the MBA, and to be deleted } \\
\text { from the inventory of the MBA. }\end{array}$ \\
\hline $\begin{array}{l}\text { Transfer from retained } \\
\text { waste }\end{array}$ & FW & $\begin{array}{l}\text { Retransfer of material, which had been stored at the MBA as retained } \\
\text { waste, to the nuclear material inventory. This applies whenever material in } \\
\text { the retained waste category is removed from storage either for processing at } \\
\text { the MBA or for shipment from the MBA. }\end{array}$ \\
\hline Exemption, use & EU & $\begin{array}{l}\text { Exemption of nuclear material from safeguards pursuant to Article } 36 \text { of } \\
\text { the CSA. }\end{array}$ \\
\hline Exemption, quantity & EQ & $\begin{array}{l}\text { Exemption of nuclear material from safeguards pursuant to Article } 37 \text { of } \\
\text { the CSA. }\end{array}$ \\
\hline Termination & TU & $\begin{array}{l}\text { Termination of safeguards on nuclear material pursuant to Article } 35 \text { of the } \\
\text { CSA. }\end{array}$ \\
\hline Accidental loss & LA & $\begin{array}{l}\text { Irretrievable and inadvertent loss of a known quantity of nuclear material as } \\
\text { a result of an operational accident. }\end{array}$ \\
\hline Accidental gain & GA & $\begin{array}{l}\text { Nuclear material unexpectedly found to be present in the MBA, except } \\
\text { when detected in the course of a physical inventory taking. }\end{array}$ \\
\hline $\begin{array}{l}\text { Shipper/receiver } \\
\text { difference }\end{array}$ & DI & $\begin{array}{l}\text { The difference between the batch quantity reported as received (always on } \\
\text { shipper's data) and the quantity as measured by the operator of the } \\
\text { receiving MBA. }\end{array}$ \\
\hline Decrease in batch content & $\mathrm{RM}$ & $\begin{array}{l}\text { The quantity by which the batch mentioned in the entry is diminished. Used } \\
\text { for the application of batch follow-up in the MBA. }\end{array}$ \\
\hline Increase in batch content & $\mathrm{RP}$ & $\begin{array}{l}\text { The quantity of material added to the batch mentioned in the entry from } \\
\text { another batch. Used for the application of batch follow-up in the MBA. }\end{array}$ \\
\hline
\end{tabular}


Table C-2. Material description code—character (1): physical form (column 33).

Note: There are two possible sets of material description codes that can be specified in Code 10, and they are mutually exclusive. The older set of codes is still used by some States, so reference to the relevant Code 10 is necessary to determine which are to be used. The codes described below more completely define nuclear material batches, although both sets provide what is necessary for the implementation of IAEA safeguards.

\begin{tabular}{|l|c|l|}
\hline \multicolumn{1}{|c|}{ Keyword } & Code & \multicolumn{1}{c|}{ Explanation } \\
\hline Fuel elements & B & $\begin{array}{l}\text { Complete fuel elements for a given reactor system } \\
\text { (e.g., assemblies or bundles) }\end{array}$ \\
\hline Fuel components & D & Components of fuel elements (e.g., pins and plates) \\
\hline Powders & F & $\begin{array}{l}\text { Powders, nonceramic: any powdered material other than } \\
\text { ceramic grade oxides and carbides }\end{array}$ \\
\hline Powder, ceramic & G & $\begin{array}{l}\text { Powders, ceramic grade: high-fired oxide or carbide } \\
\text { specially prepared for ceramic fuel manufacture }\end{array}$ \\
\hline Formed, green & H & $\begin{array}{l}\text { Green pellets and particles: formed by pressing or } \\
\text { granulating mixtures of ceramic grade powder with a } \\
\text { binder, before sintering }\end{array}$ \\
\hline Ceramics & J & $\begin{array}{l}\text { Ceramic pellets and particles: as above, after debonding } \\
\text { and sintering }\end{array}$ \\
\hline Coated particles & K & $\begin{array}{l}\text { Ceramic particles that have been given a protective } \\
\text { coating (e.g., of SiC) }\end{array}$ \\
\hline Solids, other & $\varnothing$ & $\begin{array}{l}\text { Solid materials other than those specified above } \\
\text { (e.g., ingots, billets, extrusion pieces), but not mixed } \\
\text { materials }\end{array}$ \\
\hline Liquids & N & Aqueous solutions, organic, or other liquids \\
\hline Residues, scrap & R & $\begin{array}{l}\text { Residues and scrap arises from production process, } \\
\text { intended to be recycled or recovered }\end{array}$ \\
\hline Sealed sources & QS & $\begin{array}{l}\text { Sources of radiation consisting of permanently } \\
\text { encapsulated fissile materials }\end{array}$ \\
\hline Waste, solid & T & Solid wastes intended for disposal \\
\hline Waste, liquid & U & Liquid wastes intended for disposal \\
\hline $\begin{array}{l}\text { Small samples, } \\
\text { specimens }\end{array}$ & V & $\begin{array}{l}\text { Analytical samples or specimens, collected together into a } \\
\text { single batch }\end{array}$ \\
\hline & &
\end{tabular}


Table C-3. Material description code—character (2): chemical form (column 34).

\begin{tabular}{|c|c|c|}
\hline Keyword & Code & Explanation \\
\hline Elemental & $\mathrm{D}$ & Unalloyed metal \\
\hline Fluoride & $\mathrm{E}$ & Any fluoride except hexafluorides \\
\hline Hex & $\mathrm{G}$ & Hexafluoride \\
\hline Nitrate & $\mathrm{J}$ & Nitrate \\
\hline ADU & $\mathrm{K}$ & Ammonium diuranate \\
\hline Dioxide & $\mathrm{Q}$ & Dioxide \\
\hline Trioxide & $\mathrm{T}$ & Trioxide \\
\hline Oxide (3/8) & $\mathrm{U}$ & Oxide with formula $\mathrm{M}_{3} \mathrm{O}_{8}$ \\
\hline Other oxides & $\mathrm{R}$ & $\begin{array}{l}\text { Other oxides, including mixtures of different oxides of the } \\
\text { same element }\end{array}$ \\
\hline Carbide & $\mathrm{W}$ & Carbide \\
\hline Oxide/graphite & $\mathrm{X}$ & $\begin{array}{l}\text { Oxide/graphite mixture: (e.g., high-temperature reactor } \\
\text { [HTR] fuels) }\end{array}$ \\
\hline Carbide/graphite & $\mathrm{Y}$ & Carbide/graphite mixture: (e.g., HTR fuels) \\
\hline Nitride & $\mathrm{Z}$ & Nitride \\
\hline Organic & 1 & Organic compounds \\
\hline Other compounds & 2 & Other compounds, salts, and their mixtures \\
\hline $\mathrm{Al}$ alloys & 3 & Aluminum and Al-Si alloys \\
\hline Si alloys & 4 & Silicium alloys (except Al-Si alloys) and silicides \\
\hline Zr alloys & 5 & Zirconium alloys \\
\hline Mo and Ti alloys & 6 & Binary and ternary alloys with molybdenum and titanium \\
\hline Other alloys & 7 & Alloys other than those above \\
\hline Miscellaneous & $\varnothing$ & $\begin{array}{l}\text { Materials of various chemical forms collected together } \\
\text { into a single batch (e.g., analytical samples and } \\
\text { specimens) }\end{array}$ \\
\hline
\end{tabular}


Table C-4. Material description code—character (3): containment (column 35).

\begin{tabular}{|l|l|l|}
\hline \multicolumn{1}{|c|}{ Keyword } & Code & \multicolumn{1}{c|}{ Explanation } \\
\hline Uncontained & 1 & $\begin{array}{l}\text { Materials not in containers: free-standing items } \\
\text { including fuel elements and components, if } \\
\text { uncrated }\end{array}$ \\
\hline Fuel units & 2 & $\begin{array}{l}\text { Discrete fuel units and components, in shipping or } \\
\text { storage containers }\end{array}$ \\
\hline Flask & 3 & $\begin{array}{l}\text { Powders, nonceramic: any powdered material other } \\
\text { than ceramic-grade oxides and carbides }\end{array}$ \\
\hline In-core & 4 & Reactor, in-core fuel elements only \\
\hline Vessel, calibrated & 5 & Process vessels and tanks, calibrated \\
\hline Vessel, uncalibrated & 6 & Process vessels and tanks, uncalibrated; pipes \\
\hline Tray & 7 & Open trays, racks, skips \\
\hline Birdcage & 8 & Special, critically safe container \\
\hline “Container” and volume range & & (liters) \\
\hline $\begin{array}{l}\text { Sample bottles and other small } \\
\text { containers }\end{array}$ & A & $<0.5$ \\
\hline Bottles, fibrepacks, cans & E & $0.5-1$ \\
\hline Bottles, fibrepacks, cans & G & $>1-5$ \\
\hline $\begin{array}{l}\text { Bottles, fibrepacks, cans, and UF } \\
\text { cylinders }\end{array}$ & H & $>5-10$ \\
\hline Fibrepacks, cans & J & $>10-15$ \\
\hline Fibrepacks, drums & K & $>15-20$ \\
\hline Drums & L & $>20-50$ \\
\hline Drums & M & $>50-100$ \\
\hline Drums, barrels & N & $>100-200$ \\
\hline Drums, barrels & Q & $>200-500$ \\
\hline UF cylinders (2 t) & R & $>500-1,000$ \\
\hline Drums, barrels (10-14 t) & U & $>1,000-5,000$ \\
\hline Large containers (e.g., tank trucks) & V & $>5,000$ \\
\hline Other containers & $\varnothing$ & \\
\hline & & \\
\hline
\end{tabular}


Table C-5. Material description code—character (4): irradiation status and quality (column 36).

\begin{tabular}{|l|l|l|l|}
\hline \multirow{2}{*}{ Keyword } & \multicolumn{2}{c|}{ Code } & \multicolumn{1}{c|}{ Explanation } \\
\cline { 2 - 4 } & $\begin{array}{c}\text { Non- } \\
\text { irradiated }\end{array}$ & Irradiated & \\
\hline Fresh fuel & F & & Fresh fuel elements or assemblies \\
\hline Irradiated & & G & Irradiated fuel prior to reprocessing \\
\hline Manufactured & A & H & $\begin{array}{l}\text { Manufactured articles (other than complete fuel elements) } \\
\text { for which no sampling is possible, but which are suitable } \\
\text { for nondestructive measurement }\end{array}$ \\
\hline Pure, stable & B & J & $\begin{array}{l}\text { Homogeneous material that has been produced to } \\
\text { tight specifications governing purity and stability of both } \\
\text { physical and chemical form (e.g., product, intermediate } \\
\text { product, certain feed materials) }\end{array}$ \\
\hline Pure & C & K & $\begin{array}{l}\text { Materials conforming to high purity specifications that } \\
\text { may be slightly heterogeneous or less stable than the ones } \\
\text { categorized as "pure, stable” (e.g., certain intermediate } \\
\text { products, clean scrap and recycle, feed materials) }\end{array}$ \\
\hline Variable & D & L & $\begin{array}{l}\text { Heterogeneous materials of generally similar composition } \\
\text { that do not conform to purity specifications (e.g., most } \\
\text { scrap and recycle) }\end{array}$ \\
\hline & E & M & $\begin{array}{l}\text { Heterogeneous materials of variable and/or mixed } \\
\text { composition, possibly low in nuclear material content } \\
\text { (e.g., dirty scrap, leached hulls, waste) }\end{array}$ \\
\hline
\end{tabular}

Table C-6. Element code (column 37).

\begin{tabular}{|l|c|}
\hline \multicolumn{1}{|c|}{ Keyword } & Code \\
\hline Depleted uranium & $\mathrm{D}$ \\
\hline Natural uranium & $\mathrm{N}$ \\
\hline Enriched uranium & $\mathrm{E}$ \\
\hline Uranium, unified & $\mathrm{U}$ \\
\hline Plutonium & $\mathrm{P}$ \\
\hline Thorium & $\mathrm{T}$ \\
\hline
\end{tabular}

Table C-7. Elements and corresponding weight units (columns 46-47).

\begin{tabular}{|l|l|}
\hline \multicolumn{1}{|c|}{ Element } & \multicolumn{1}{c|}{ Unit } \\
\hline Plutonium & Grams \\
\hline $\begin{array}{l}\text { Total uranium for enriched } \\
\text { uranium }\end{array}$ & Grams \\
\hline Thorium & Kilograms (or, if desired, grams) \\
\hline Natural uranium & Kilograms (or, if desired, grams) \\
\hline Depleted uranium & Kilograms (or, if desired, grams) \\
\hline Unified uranium & Grams if the entry refers to enriched uranium \\
\hline Unified uranium & $\begin{array}{l}\text { Kilograms if the entry refers to depleted or } \\
\text { natural uranium. All unified uranium may, if } \\
\text { desired, be reported in grams. }\end{array}$ \\
\hline
\end{tabular}


Table C-8. Isotope codes (column 56).

\begin{tabular}{|l|c|}
\hline \multicolumn{1}{|c|}{ Description } & Code \\
\hline For fissile isotope content of $U_{235}$ only & $\mathrm{G}$ \\
\hline For fissile isotope content of $U_{233}$ plus $U_{235}$ & $\mathrm{~J}$ \\
\hline For fissile isotope content of $U_{233}$ only & $\mathrm{K}$ \\
\hline
\end{tabular}

Table C-9. Measurement basis code (column 72).

\begin{tabular}{|l|c|l|}
\hline \multicolumn{1}{|c|}{ Keyword } & Code & \multicolumn{1}{c|}{ Explanation } \\
\hline Measured & $\mathrm{M}$ & $\begin{array}{l}\text { The batch data are based on measurements made at the MBA, including KMPs on its } \\
\text { boundary. }\end{array}$ \\
\hline $\begin{array}{l}\text { Measured } \\
\text { elsewhere }\end{array}$ & $\mathrm{N}$ & \begin{tabular}{l} 
The batch data are based on measurements made at another MBA. \\
\hline Tagged
\end{tabular} \\
\hline Labeled & $\mathrm{T}$ & $\begin{array}{l}\text { The batch data are based on measurements previously made at the same MBA and } \\
\text { have been reported for that MBA in an ICR or PIL, and the measurements have not } \\
\text { been repeated. }\end{array}$ \\
$\begin{array}{l}\text { The batch data are based on measurements previously made at another MBA and } \\
\text { have been reported for the present MBA in an ICR or PIL without remeasurement. }\end{array}$ \\
\hline
\end{tabular}


Table C-10. MBR entry name.

\begin{tabular}{|c|c|c|}
\hline Keyword & Code & Explanation \\
\hline $\begin{array}{l}\text { Physical beginning } \\
\text { inventory }\end{array}$ & $\mathrm{PB}$ & $\begin{array}{l}\text { PB should be equal to the PE of the previous MBR relating to the same } \\
\text { category of material. }\end{array}$ \\
\hline $\begin{array}{l}\text { Inventory changes: for } \\
\text { keywords and codes } \\
\text { relating to various types } \\
\text { of inventory change, see } \\
\text { Appendix C, Table C-1. }\end{array}$ & & $\begin{array}{l}\text { For each type of inventory change, as applicable for the MBA in question, } \\
\text { one consolidated entry should be made for the entire material balance period; } \\
\text { list increases in the inventory first and then decreases therein; receipts of } \\
\text { nuclear material at the facility should be entered on shipper's data. Category } \\
\text { changed as a result of blending, enrichment, or irradiation should be reported } \\
\text { as indicated in Section } 3.5 .3 \text { of this document. }\end{array}$ \\
\hline Ending book inventory & $\mathrm{BE}$ & $\begin{array}{l}\text { The algebraic sum of the PB and the inventory changed, not including any } \\
\text { rounding adjustments reported in the MBR. }\end{array}$ \\
\hline $\begin{array}{l}\text { Shipper/receiver } \\
\text { difference }\end{array}$ & DI & $\begin{array}{l}\text { One consolidated entry should be made for all shipper/receiver differences } \\
\text { over the entire reporting period, if applicable. }\end{array}$ \\
\hline $\begin{array}{l}\text { Adjusted ending book } \\
\text { inventory }\end{array}$ & BA & $\begin{array}{l}\text { The algebraic sum of the PB and of the inventory changed over the period, } \\
\text { adjusted to take account of the shipper/receiver differences. }\end{array}$ \\
\hline $\begin{array}{l}\text { Physical ending } \\
\text { inventory }\end{array}$ & $\mathrm{PE}$ & $\begin{array}{l}\text { The sum of all measured and derived batch quantities of nuclear material on } \\
\text { hand at the date of the physical inventory taking. }\end{array}$ \\
\hline MUF & $\mathrm{MF}$ & $\begin{array}{l}\text { Material unaccounted for: calculated as the difference between adjusted } \\
\text { ending book inventory and the physical inventory. }\end{array}$ \\
\hline $\begin{array}{l}\text { Rounding adjustment to } \\
\text { entry XX }\end{array}$ & RAXX & $\begin{array}{l}\text { The quantity to be added to the rounded sum to make it equal to the sum of } \\
\text { the rounded terms. A rounding adjustment is made to an entry in the MBR on } \\
\text { which the IAEA has been informed differently through ICRs and PILs, to } \\
\text { bring the MBR entry into agreement with the corresponding figures } \\
\text { established on the basis of ICRs and PILs. } \\
\text { The rounding adjustments should be coded RAXX, where XX stands for the } \\
\text { code of the entry to which the rounding adjustment pertains (e.g., RALN } \\
\text { means a rounding adjustment to the consolidated entry on the nuclear loss). } \\
\text { In the case of a rounding adjustment to the ending book inventory, adjusted } \\
\text { ending book inventory, or MUF, the following formulae should be used, } \\
\text { respectively: } \\
\text { RABE = PB + IC } \\
\text { RABA }=\text { PB + IC BE } \\
\text { RAMF = BA - PE - MF - BA } \\
\text { Where IC } \\
\text { reported in the MBR, taken with the appropriate sign indicating increases or } \\
\text { decreases. }\end{array}$ \\
\hline
\end{tabular}



APPENDIX D. FIXED FORMAT REPORT EXAMPLES 



\section{APPENDIX D-1. INVENTORY CHANGE REPORT EXAMPLES}

Example 1-Fixed format receipt domestic of spent fuel.

\begin{tabular}{|c|c|c|c|c|c|c|c|c|c|c|c|c|c|c|c|c|c|c|c|}
\hline \multicolumn{20}{|c|}{ INVENTORY CHANGE REPORT (ICR) FORM R.01.1/c } \\
\hline \multirow{2}{*}{\multicolumn{9}{|c|}{ 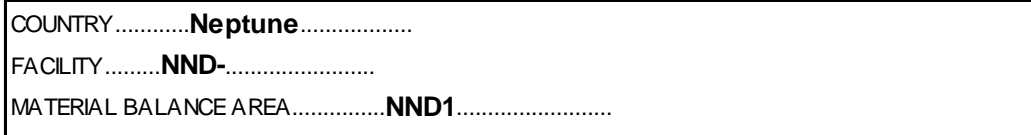 }} & \multicolumn{11}{|c|}{ 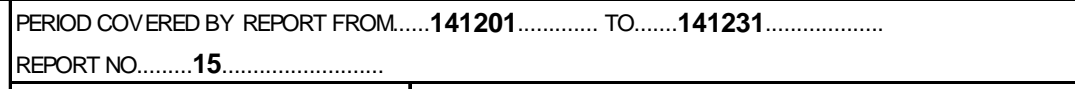 } \\
\hline & & & & & & & & & \multirow{2}{*}{\multicolumn{3}{|c|}{ PAGENO...1... OF ...1...PAGES }} & \multirow{2}{*}{\multicolumn{8}{|c|}{ SIGNATURE }} \\
\hline & & & & & & & 25 & 2831 & & & & & & & & & & & \\
\hline \multirow[b]{3}{*}{$\begin{array}{l}\text { ENTRY } \\
\text { No. }\end{array}$} & \multirow[b]{3}{*}{ 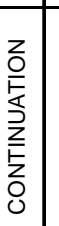 } & \multirow[b]{3}{*}{$\begin{array}{l}\text { DATEOF } \\
\text { INVENTORY } \\
\text { CHANGE }\end{array}$} & \multirow{2}{*}{\multicolumn{2}{|c|}{ MBA/COUNTRY }} & \multirow[b]{3}{*}{ 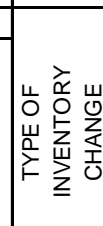 } & \multirow[b]{3}{*}{$\mid \begin{array}{l}u \\
0 \\
0 \\
0 \\
\sum \\
\Sigma \\
\Sigma\end{array}$} & \multirow[b]{3}{*}{$\begin{array}{l}\text { NAME OR NUMBER OF } \\
\text { BATCH }\end{array}$} & \multirow[b]{3}{*}{$=\begin{array}{l}\text { NUMBER } \\
\text { OF TEMS } \\
\text { IN BATCH }\end{array}$} & \multirow[b]{3}{*}{ 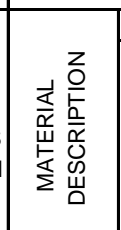 } & \multirow{2}{*}{\multicolumn{5}{|c|}{ ACCOUNTANCY DATA }} & \multirow[b]{3}{*}{ 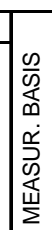 } & \multirow[b]{3}{*}{ 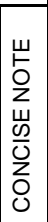 } & \multirow{2}{*}{\multicolumn{3}{|c|}{ CORRECTION TO }} \\
\hline & & & & & & & & & & & & & & & & & & & \\
\hline & & & FROM & Tо & & & & & & 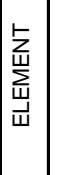 & WEGHT OF EEMMENT & 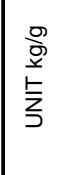 & $\begin{array}{c}\text { WEGGHT OF FISSILE } \\
\text { ISOTOPES (URANIUM } \\
\text { ONLY) (g) }\end{array}$ & & & & $\begin{array}{c}\text { REPORT } \\
\text { NO. }\end{array}$ & \begin{tabular}{|c|} 
ENTRY \\
no.
\end{tabular} & \\
\hline 1 & 3 & & 10 & 14 & 18 & 20 & 21 & 29 & 33 & $377^{3}$ & 8 & 46 & 48 & 56 & 72 & 737 & 74 & 78 & 80 \\
\hline 1 & & 141215 & NN-B & NND1 & RD & 3 & $045 \mathrm{C} 8$ & 1 & BQ1G & $\mathrm{E}$ & 163257 & G & 1306 & G & $\mathbf{N}$ & & & & 2 \\
\hline 2 & C & 141215 & NN-B & NND2 & RD & 3 & $045 \mathrm{C} 8$ & 0 & & $\mathbf{P}$ & 1498 & G & & & $\mathbf{N}$ & & & & 2 \\
\hline & & & & & & & & & & & & & & & & & & & 2 \\
\hline & & & & & & & & & & & & & & & & & & & 2 \\
\hline & & & & & & & & & & & & & & & & & & & 2 \\
\hline & & & & & & & & & & & & & & & & & & & 2 \\
\hline & & & & & & & & & & & & & & & & & & & 2 \\
\hline & & & & & & & & & & & & & & & & & & & 2 \\
\hline & & & & & & & & & & & & & & & & & & & 2 \\
\hline & & & & & & & & & & & & & & & & & & & 2 \\
\hline
\end{tabular}


Example 2-Addition of an entry to a previous report: Report 64, entry 1 is added as entry 24 to report 63.

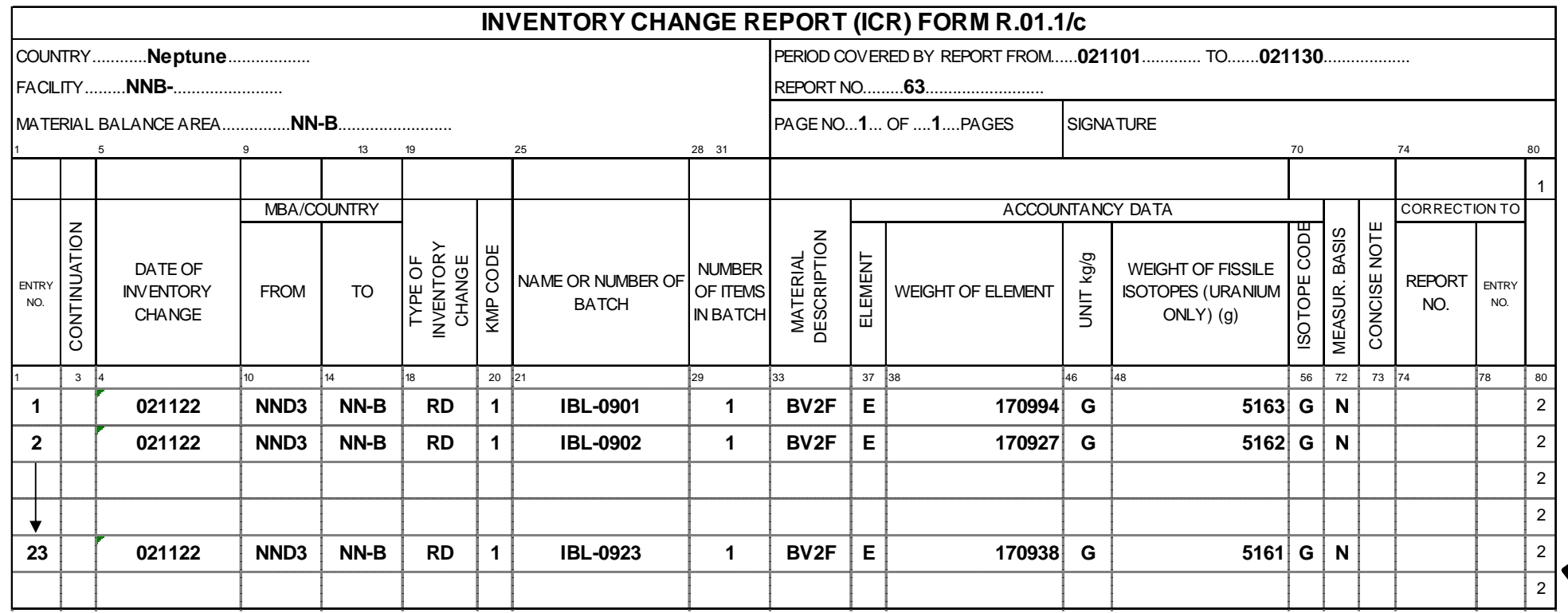

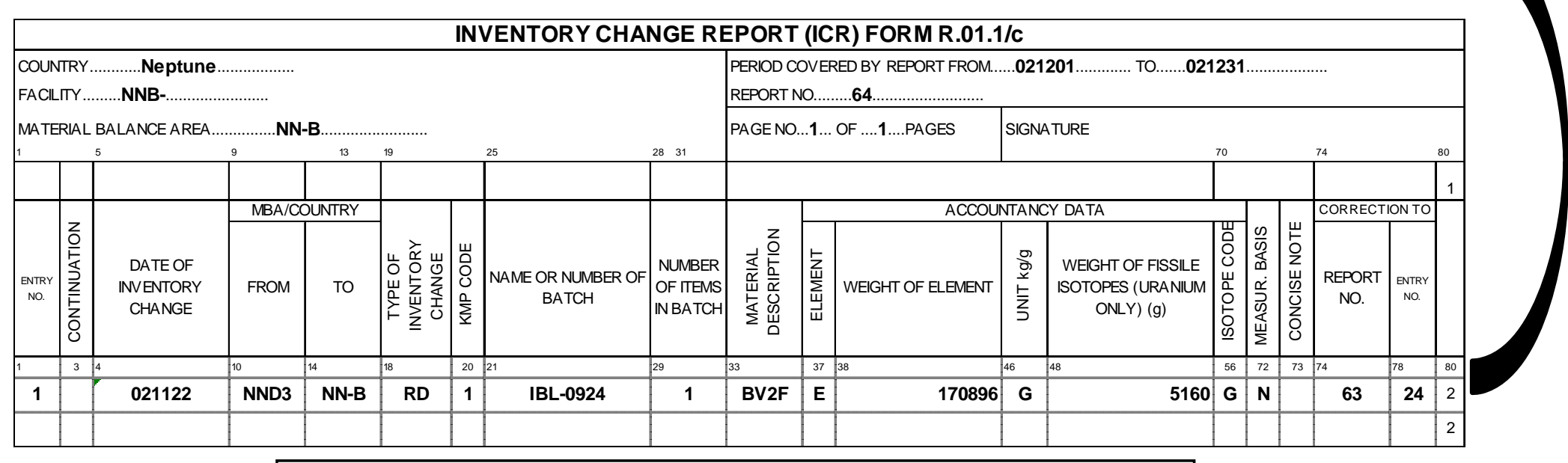

Entry 1 of report 64 is used by the IAEA as entry 24 of report 63.

This addition process also applies to PILs and MBRs. 
Example 3-Correction of an entry in a previous report: Report 127, entry 1 corrects entry 18 in to report 126.

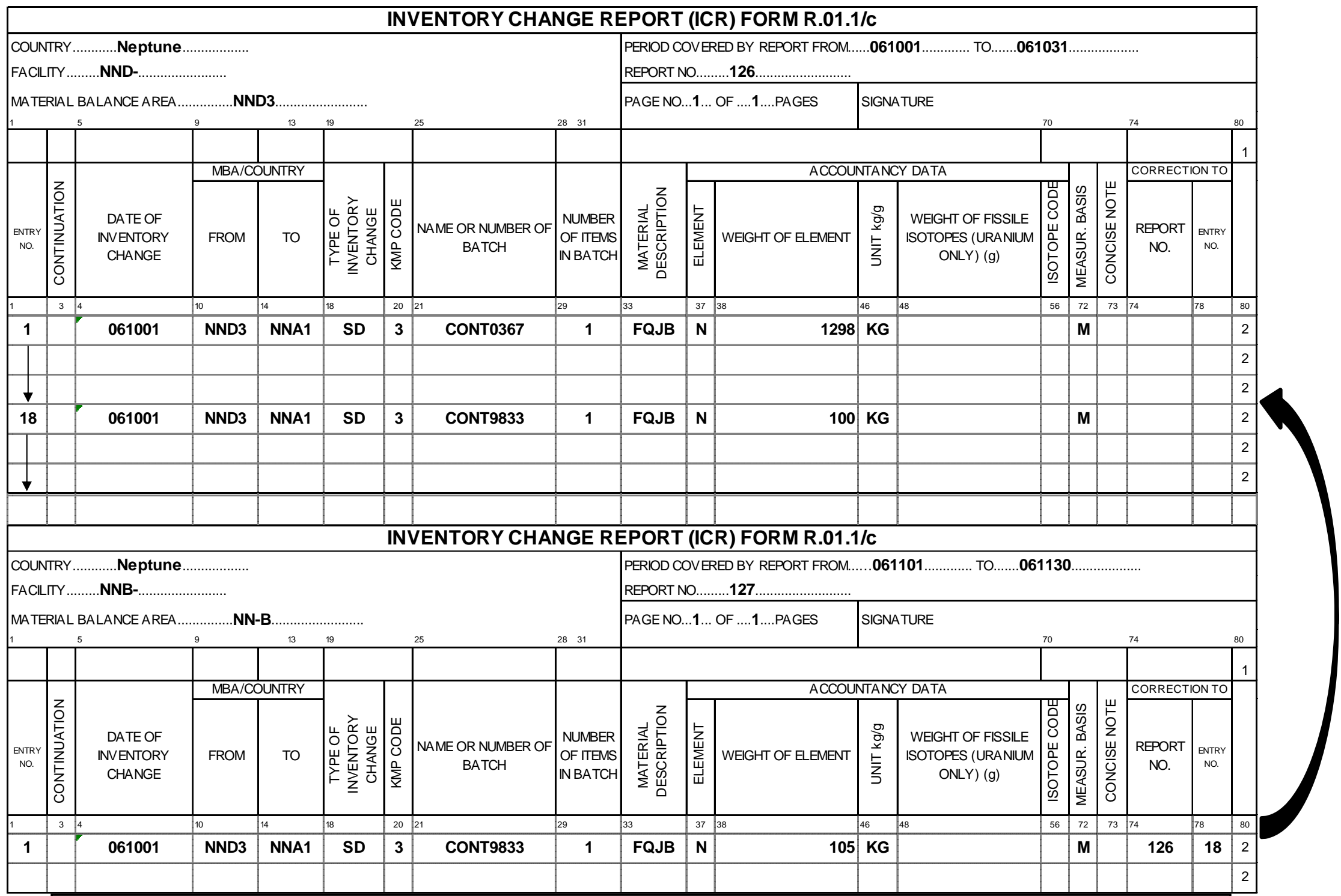

Entry 1 of report 127 corrects the weight reported in report 126, entry 18. All data fields, including those that have not changed, must be reported. This correction process also applies to PILs and MBRs. 
Example 4-Deletion of an entry in a previous report: Report 182, entry 1 deletes (deactivates) entry 17 in report 181.

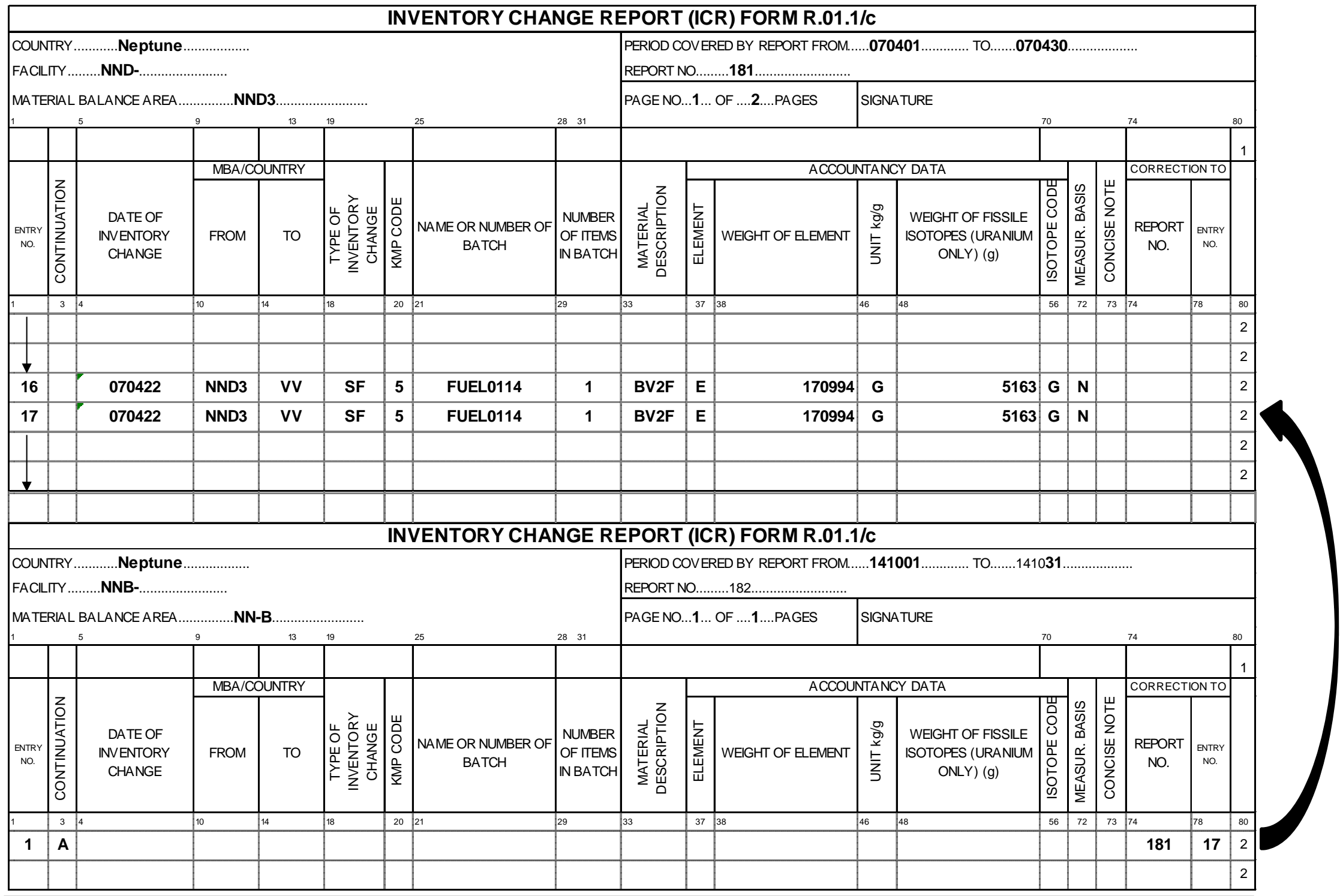

Entry 1 of report 182 deletes (deactivates) one of the duplicate entries reporting batch FUEL0114 in report 182. Either one of the duplicate entries (16 or 17) could be deactivated. Deactivation is indicated by an A in position 3 (Continuation). This deletion process also applies to PILs and MBRs. 
Example 5-Category change from natural uranium to enriched uranium.

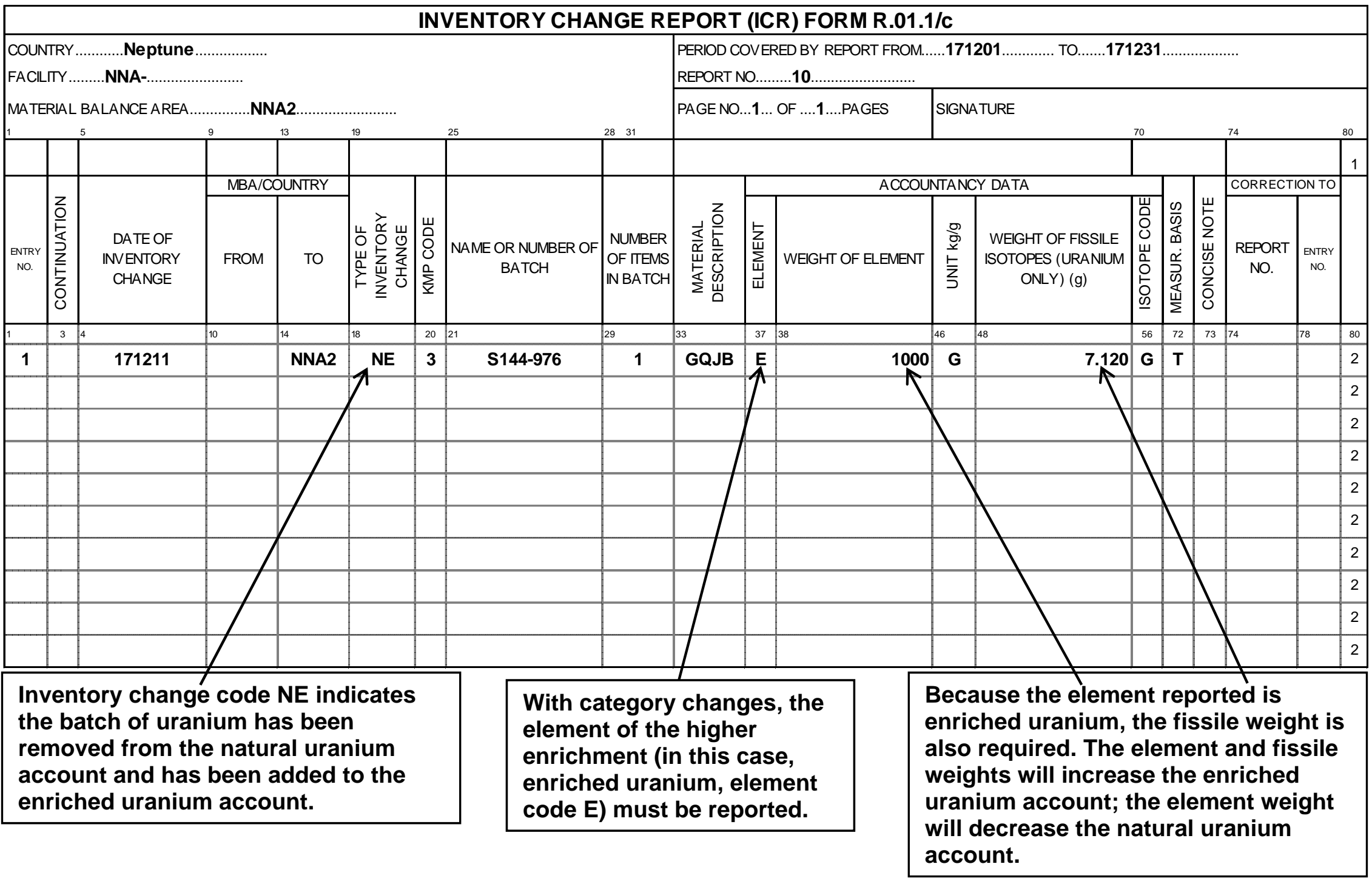




\section{APPENDIX D-2. PHYSICAL INVENTORY LISTING EXAMPLES}

Example 1-Physical inventory listing.

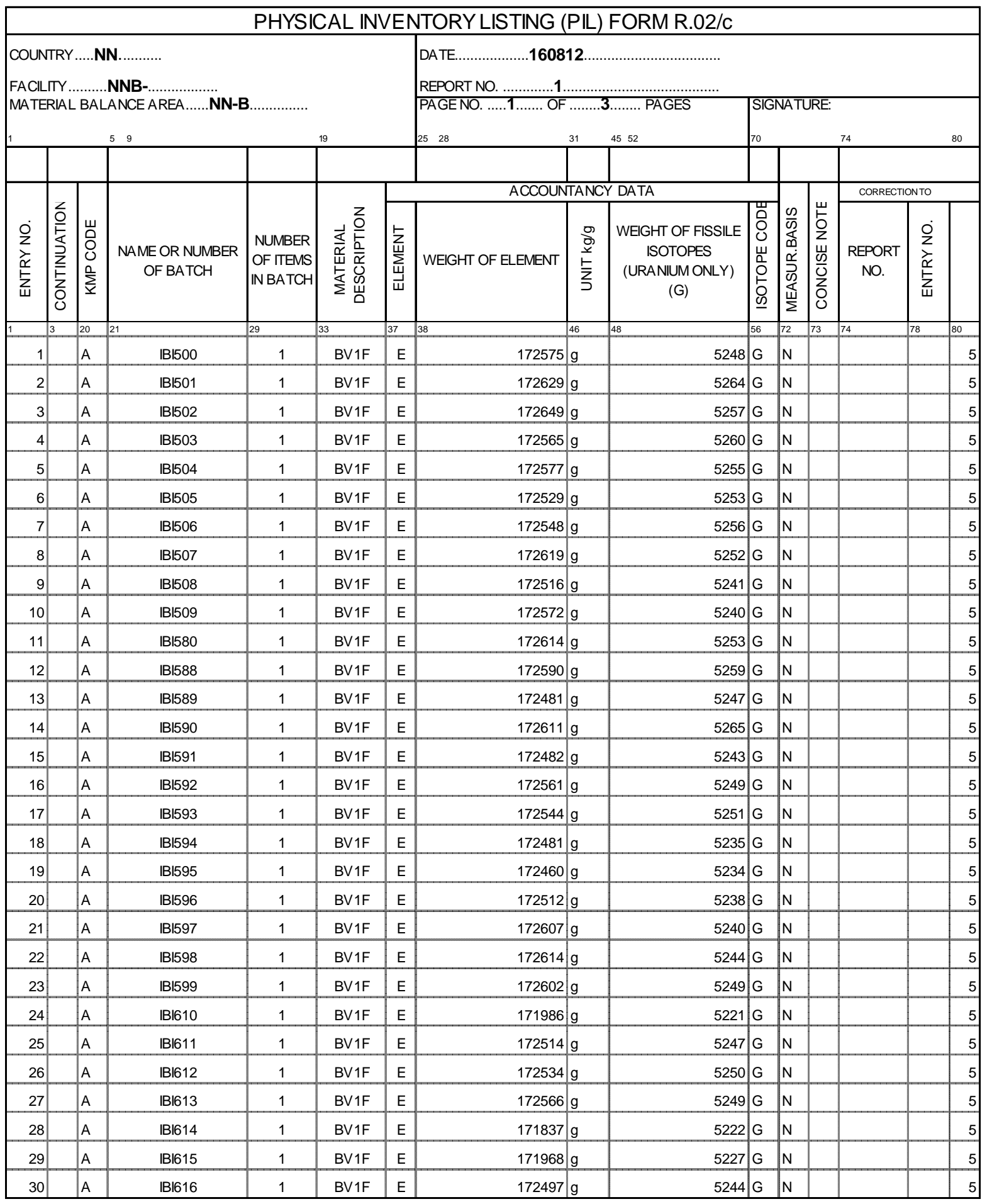


Example 2-Reporting a PIL where no batches of nuclear material are in an MBA (i.e., a null PIL).

\begin{tabular}{|c|c|c|c|c|c|c|c|c|c|c|c|c|c|c|c|}
\hline & & & & PHYSIC & CAL IN & EN & NTORY LISTING ( & PIL) & FORM R.02/c & & & & & & \\
\hline & TRY. & $\ldots . . \mathrm{N}$ & IN N.......... & & & & DATE $\ldots . .171001 \ldots \ldots \ldots$ & .......... & $\ldots \ldots \ldots \ldots \ldots \ldots \ldots \ldots$ & & & & & & \\
\hline $\mathrm{FACl}$ & $\Pi \pi Y .$. & $\ldots . . . N$ & JNA- & & & & REPORT NO .....37........... & ......... & 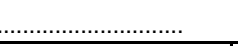 & & & & & & \\
\hline & RIAL & BAL & . ANCE AREA......NNA2 & & & & PAGENO $\ldots . .1 \ldots$ OF $\ldots$ &. $.1 \ldots$ & PAGES & SIGN & ATU & & & & \\
\hline & & & 59 & & 19 & & $25 \quad 28$ & 31 & 4552 & 70 & & & 74 & & 80 \\
\hline & & & & & & & $A C C O U N$ & TANC & Y DATA & & & & CORRECTIS & & \\
\hline & & & & & & & ACCOUN & TAIVC & Y DATA & & & & CORRECTIC & & \\
\hline 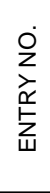 & 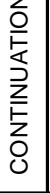 & 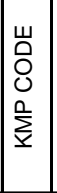 & $\begin{array}{l}\text { NAME OR NUMBER } \\
\text { OF BATCH }\end{array}$ & \begin{tabular}{|} 
NUMBER \\
OF ITEMS \\
IN BATCH
\end{tabular} & 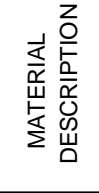 & 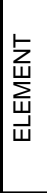 & WEGHT OF EEMENT & 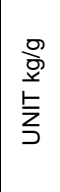 & $\begin{array}{c}\text { WEGHT OF FISSILE } \\
\text { ISOTOPES } \\
\text { (URANIUM ONLY) } \\
(\mathrm{G})\end{array}$ & & 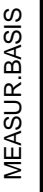 & 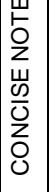 & $\begin{array}{c}\text { REPORT } \\
\text { NO. }\end{array}$ & 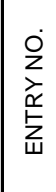 & \\
\hline 1 & 3 & 20 & 21 & 29 & 33 & 37 & 38 & 46 & 48 & 56 & 72 & 73 & 74 & 78 & 80 \\
\hline 1 & A & & & & & & & & & & & & & & 5 \\
\hline & & & & & & & & & & & & & & & 5 \\
\hline & & & & & & & & & & & & & & & 5 \\
\hline & & & & & & & & & & & & & & & 5 \\
\hline & & & & & & & & & & & & & & & 5 \\
\hline & & & & & & & & & & & & & & & 5 \\
\hline & & & & & & & & & & & & & & & 5 \\
\hline & & & & & & & & & noition ? Th & & & & & & 5 \\
\hline & & & inding & Iy can & De re & poi & ted, witn an $A$ & In & . & & & & & & 5 \\
\hline & & & renort must & have a & t leas & d & entry & CII & Cha that a & & & & & & 5 \\
\hline & & & & & & & 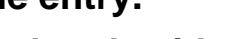 & & & & & & & & 5 \\
\hline & & & It is not corre & ect to r & eport & on & e batch with a & we & ight of zero, & & & & & & 5 \\
\hline & & & Decause tnat & timpire & es nuc & I & Ir material (e.g & ., $\mathbf{a}$ & small amoun & & & & & & 5 \\
\hline & & & that rounds $t$ & to zero & ) IS ol & & e inventory. & & & & & & & & 5 \\
\hline & & & & & & & & & & & & & & & 5 \\
\hline & & & & & & & & & & & & & & & 5 \\
\hline & & & & & & & & & & & & & & & 5 \\
\hline & & & & & & & & & & & & & & & 5 \\
\hline & & & & & & & & & & & & & & & 5 \\
\hline & & & & & & & & & & & & & & & 5 \\
\hline & & & & & & & & & & & & & & & 5 \\
\hline & & & & & & & & & & & & & & & 5 \\
\hline & & & & & & & & & & & & & & & 5 \\
\hline & & & & & & & & & & & & & & & 5 \\
\hline & & & & & & & & & & & & & & & 5 \\
\hline & & & & & & & & & & & & & & & 5 \\
\hline & & & & & & & & & & & & & & & 5 \\
\hline & & & & & & & & & & & & & & & 5 \\
\hline & & & & & & & & & & & & & & & 5 \\
\hline & & & & & & & & & & & & & & & 5 \\
\hline
\end{tabular}




\section{APPENDIX D-3. MATERIAL BALANCE REPORT EXAMPLES}

Example 1-Material balance report.

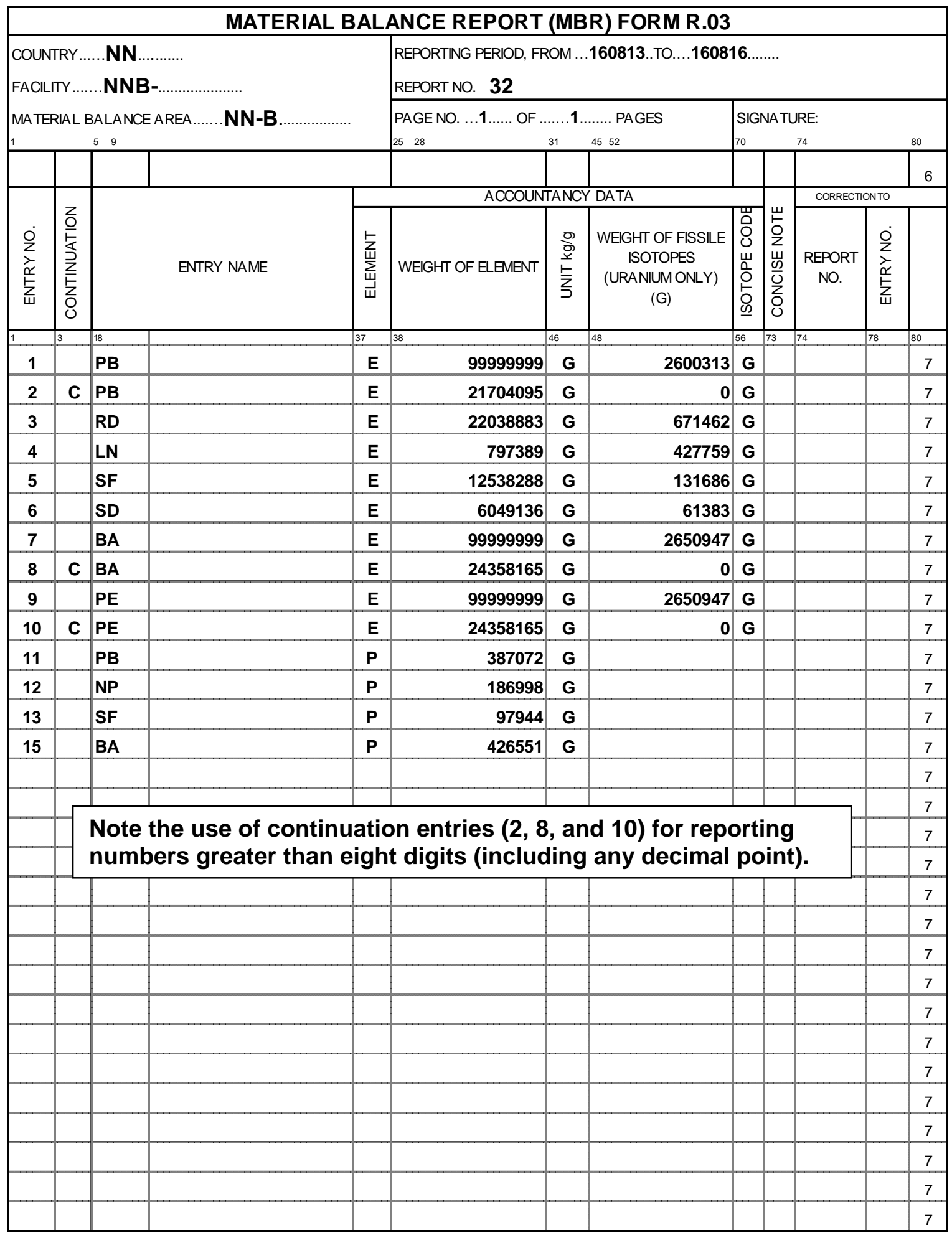


Example 2-Reporting an MBR where no batches of nuclear material are on the physical beginning inventory, none are on the physical ending inventory, and no transactions (i.e., ICRs) have occurred during the material balance period (i.e., a null MBR).

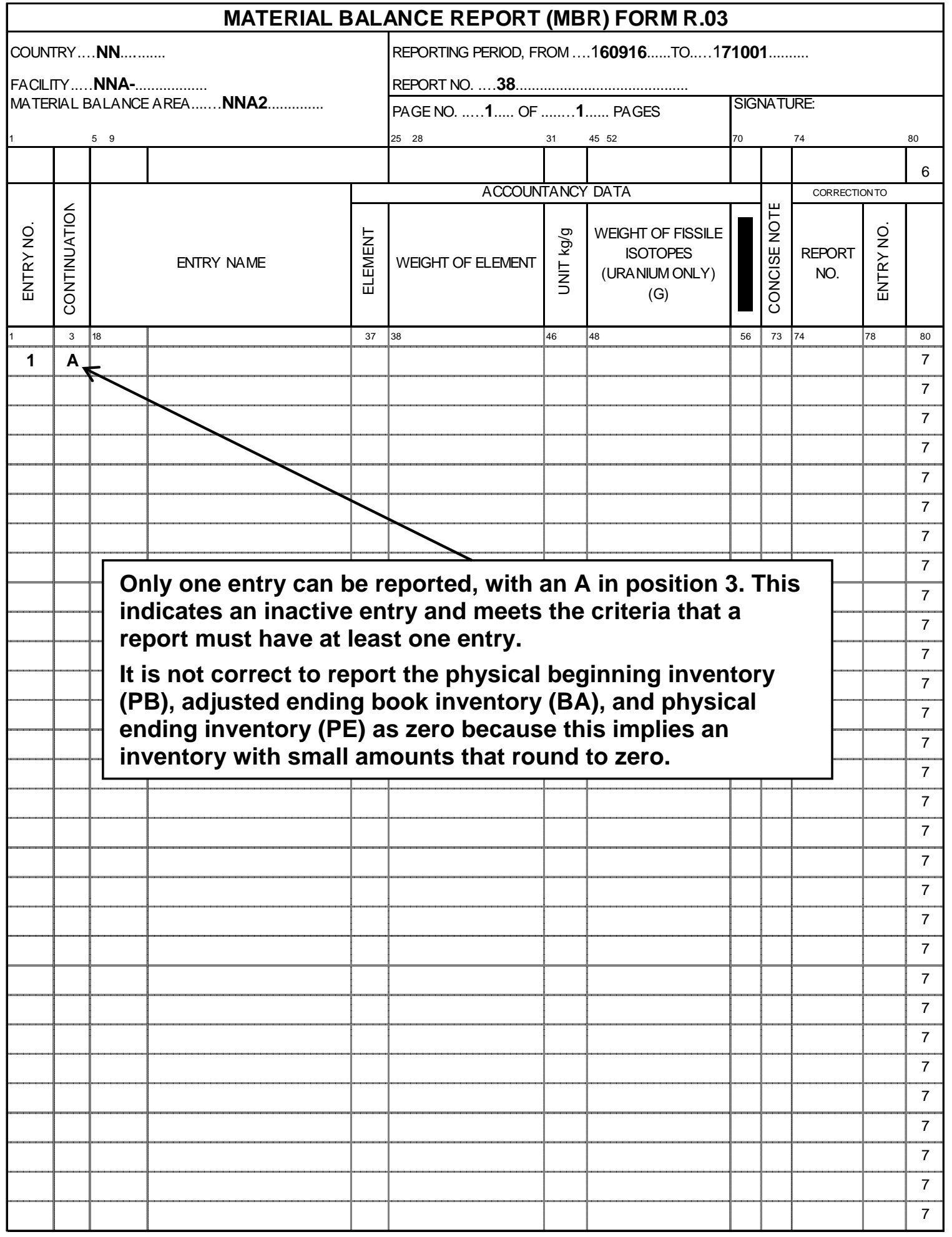


Example 3-Category change reporting in an MBR.

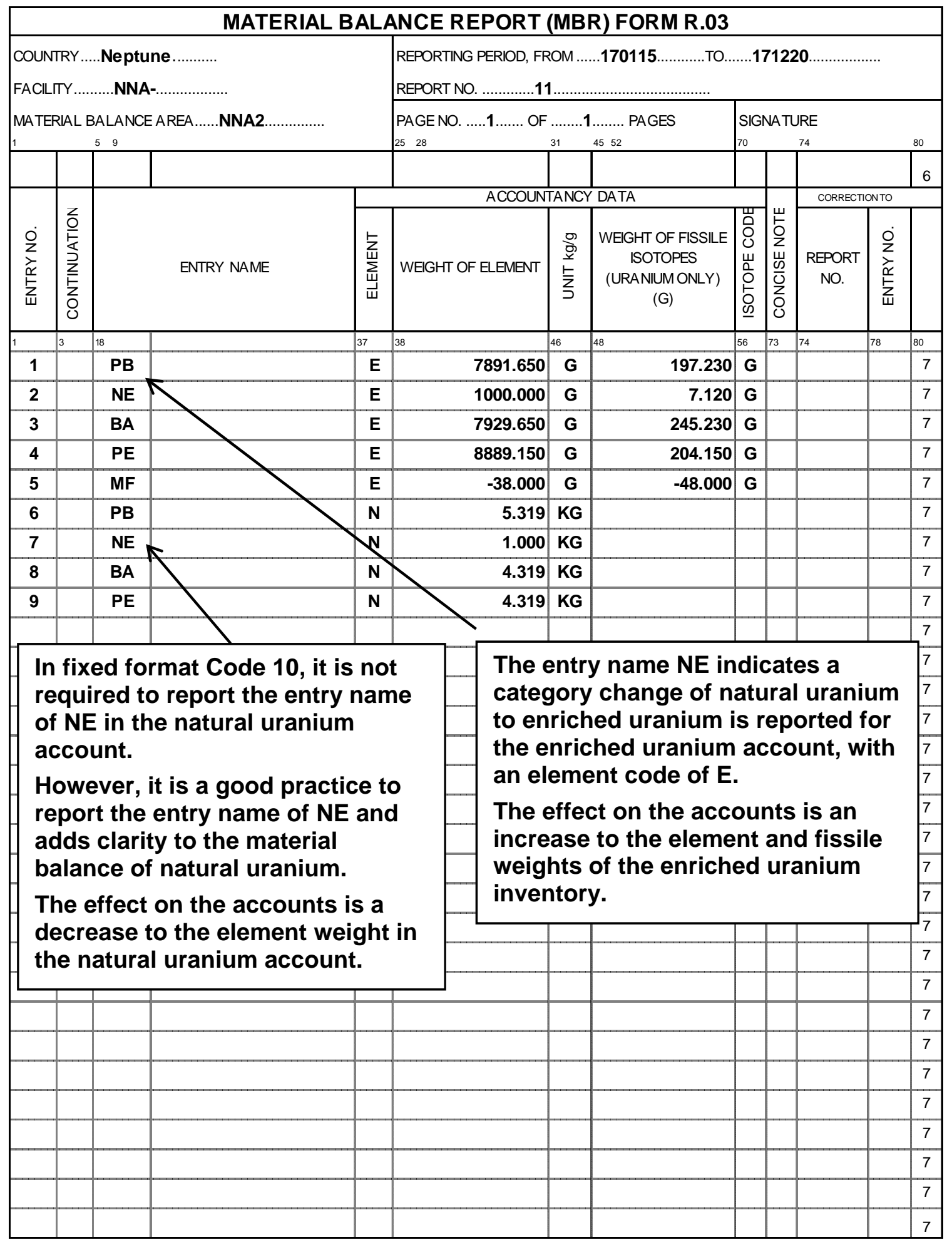


APPENDIX D-4. CONCISE NOTE EXAMPLE

\begin{tabular}{|c|c|c|c|c|c|}
\hline \multirow{4}{*}{$\begin{array}{l}\text { COUNTRY: } \\
\text { FACILITY: } \\
\text { MBA: }\end{array}$} & \multicolumn{5}{|c|}{ CONCISE NOTE } \\
\hline & NN & \multirow[t]{2}{*}{ ATTACHED TO REPORT NUMBER: } & 112 & \multirow[t]{3}{*}{ DATE: } & \multirow[t]{3}{*}{20171015} \\
\hline & NNH- & & & & \\
\hline & NN-H & SIGNATURE: & & & \\
\hline
\end{tabular}

\begin{tabular}{|c|c|c|c|c|c|}
\hline \multicolumn{2}{|c|}{ MBA } & \multirow{2}{*}{$\begin{array}{r}\text { REPORT } \\
13\end{array}$} & \multirow{2}{*}{$\begin{array}{r}\text { ENTRY } \\
1\end{array}$} & \multicolumn{2}{|l|}{ TEXT OF CONCISE NOTE (UP TO 68 CHARACTERS PER LINE) } \\
\hline c & NN-H & & & This is a Concise Note that refers to a specific line entry in report 112 for MBA NN-H & c \\
\hline c & & & & (The Concise Note indicator in entry 1 of report 13 should contain 'Y') & c \\
\hline c & & & & & c \\
\hline c & & & & & c \\
\hline C & NN-H & 13 & & By leaving the entry number blank means this Concise Note applies to all entries of report 112 for MBA NN-H & c \\
\hline c & & & & (Note that the Concise Note indicator is not set in the individual line entries for this Concise Note) & c \\
\hline C & & & & & c \\
\hline c & & & & & c \\
\hline $\mathrm{c}$ & $\mathrm{NN}-\mathrm{H}$ & & & For a Concise Note that refers to the MBA in general and not to a specific report and/or entry, leave the report anc & \\
\hline c & & & & (Note that the Concise Note indicator is not set in any line entries for this Concise Note) & c \\
\hline c & & & & & c \\
\hline C & & & & & $c$ \\
\hline C & & & & & $c$ \\
\hline C & & & & & $c$ \\
\hline C & & & & & C \\
\hline C & & & & & $\mathrm{c}$ \\
\hline C & & & & & $c$ \\
\hline C & & & & & $c$ \\
\hline c & & & & & c \\
\hline$c$ & & & & & $c$ \\
\hline
\end{tabular}





\section{APPENDIX E. LABELED FORMAT REPORTING CODES}





\section{APPENDIX E-1. TYPE OF INVENTORY CHANGES}

Table E-1. Type of inventory changes (label 411)

\begin{tabular}{|c|c|c|}
\hline Keyword & Code & $\begin{array}{l}\text { Explanation } \\
\end{array}$ \\
\hline Receipt foreign & RF & Nuclear material imported into [Country]. \\
\hline Receipt domestic & RD & Domestic receipt of nuclear material from another MBA. \\
\hline Receipt at starting point & RS & $\begin{array}{l}\text { Domestic receipt of nuclear material at starting point of safeguards pursuant } \\
\text { to Article } 34 \text { (c) of the CSA. }\end{array}$ \\
\hline $\begin{array}{l}\text { Receipt from } \\
\text { nonsafeguarded activity }\end{array}$ & RN & $\begin{array}{l}\text { Domestic receipt of nuclear material from nonsafeguarded (i.e., permitted } \\
\text { military) activity. }\end{array}$ \\
\hline Nuclear production & NP & Production of special fissionable materials in a reactor $\left(\mathrm{Pu}, \mathrm{U}_{233}\right)$. \\
\hline Deexemption, use & DU & $\begin{array}{l}\text { Reapplication of safeguards on nuclear material previously exempted } \\
\text { therefrom pursuant to Article } 37 \text { of the CSA. }\end{array}$ \\
\hline Deexemption, quantity & DQ & $\begin{array}{l}\text { Reapplication of safeguards on nuclear material previously exempted } \\
\text { therefrom pursuant to Article } 37 \text { of the CSA. }\end{array}$ \\
\hline Shipment foreign & SF & Nuclear material exported out of [Country]. \\
\hline Shipment domestic & SD & Domestic transfer of nuclear material to another MBA. \\
\hline $\begin{array}{l}\text { Shipment to } \\
\text { nonsafeguarded activity }\end{array}$ & SN & $\begin{array}{l}\text { Domestic transfer of nuclear material to nonsafeguarded (i.e., permitted } \\
\text { military) activity. }\end{array}$ \\
\hline Nuclear loss & $\mathrm{LN}$ & $\begin{array}{l}\text { Consumption of nuclear material due to its transformation into other } \\
\text { element(s) or isotope(s) as a result of a nuclear reaction. }\end{array}$ \\
\hline Measured discard & LD & $\begin{array}{l}\text { Operational loss (i.e., loss of a measured or estimates [on the basis of } \\
\text { measurement] quantity of nuclear material from processing that has been } \\
\text { disposed of in such a way that it is not suitable for further nuclear use). }\end{array}$ \\
\hline $\begin{array}{l}\text { Transfer to retained } \\
\text { waste }\end{array}$ & TW & $\begin{array}{l}\text { Transfer to the retained waste category of measured nuclear material, which is } \\
\text { deemed to be irrecoverable, to be stored at the MBA and to be deleted from } \\
\text { the inventory of the MBA. }\end{array}$ \\
\hline $\begin{array}{l}\text { Transfer from retained } \\
\text { waste }\end{array}$ & FW & $\begin{array}{l}\text { Retransfer of material, which had been stored at the MBA as retained waste, } \\
\text { to the nuclear material inventory. This applies whenever material in the } \\
\text { retained waste category is removed from storage either for processing at the } \\
\text { MBA or for shipment from the MBA. }\end{array}$ \\
\hline Exemption, use & EU & $\begin{array}{l}\text { Exemption of nuclear material from safeguards pursuant to Article } 36 \text { of the } \\
\text { CSA. }\end{array}$ \\
\hline Exemption, quantity & EQ & $\begin{array}{l}\text { Exemption of nuclear material from safeguards pursuant to Article } 37 \text { of the } \\
\text { CSA. }\end{array}$ \\
\hline Termination & $\mathrm{TU}$ & $\begin{array}{l}\text { Termination of safeguards on nuclear material pursuant to Article } 35 \text { of the } \\
\text { CSA. }\end{array}$ \\
\hline Accidental loss & LA & $\begin{array}{l}\text { Irretrievable and inadvertent loss of a known quantity of nuclear material as a } \\
\text { result of an operational accident. }\end{array}$ \\
\hline Accidental gain & GA & $\begin{array}{l}\text { Nuclear material unexpectedly found to be present in the MBA, except when } \\
\text { detected in the course of a physical inventory taking. }\end{array}$ \\
\hline $\begin{array}{l}\text { Category change (with } \\
\text { the appropriate code as } \\
\text { shown) }\end{array}$ & $\begin{array}{l}\text { EN } \\
\text { ED } \\
\text { NE } \\
\text { ND } \\
\text { DE } \\
\text { DN }\end{array}$ & $\begin{array}{l}\text { The quantity of uranium that has changed category as a result of blending, } \\
\text { enrichment, depletion, or burn-up. The first letter denotes the original, the } \\
\text { second letter the resulting category: ( } E=\text { enriched, } N=\text { natural, } D=\text { depleted } \\
\text { uranium). } \\
\text { The material description codes (labels } 430 \text { and, if appropriate, } 435 \text { ) should be } \\
\text { those for the resulting material. The weight data (in labels } 610,620,630,640 \text {, } \\
660,670,770 \text {, and } 780 \text {, as appropriate) should be provided for both the } \\
\text { originating and the resulting categories. These entries should be consolidated } \\
\text { into the material balance for both categories. }\end{array}$ \\
\hline
\end{tabular}


Table E-1. Type of inventory changes (label 411) (continued)

\begin{tabular}{|l|c|l|}
\hline \multicolumn{1}{|c|}{ Keyword } & Code & \multicolumn{1}{c|}{ Explanation } \\
\hline $\begin{array}{l}\text { Shipper/receiver } \\
\text { difference }\end{array}$ & DI & $\begin{array}{l}\text { The difference between the batch quantity report as received (always on } \\
\text { shipper's data) and the quantity of the same batch as measured by the operator } \\
\text { of the receiving MBA. }\end{array}$ \\
\hline Decrease in batch content & RM & $\begin{array}{l}\text { The quantity by which the batch mentioned in the entry is diminished due to } \\
\text { rebatching. }\end{array}$ \\
\hline Increase in batch content & RP & $\begin{array}{l}\text { The quantity of material by which the batch mentioned in the entry is } \\
\text { increased due to rebatching. }\end{array}$ \\
\hline
\end{tabular}




\section{APPENDIX E-2. MATERIAL DESCRIPTION CODE}

Note: There are two possible sets of material description codes that can be specified in Code 10, and they are mutually exclusive. The older set of codes is still used by some States, so reference to the relevant Code 10 is necessary to determine which are to be used. The codes described below more completely define nuclear material batches, although both sets provide what is necessary for the implementation of IAEA safeguards.

Table E-2. Physical form (label 430, first subfield)

\begin{tabular}{|l|c|l|}
\hline \multicolumn{1}{|c|}{ Keyword } & Code & \multicolumn{1}{c|}{ Explanation } \\
\hline Fuel elements & B & Complete fuel elements for a given reactor system (e.g., assemblies or bundles) \\
\hline Fuel components & D & Components of fuel elements (e.g., pins and plates) \\
\hline Powders & F & $\begin{array}{l}\text { Powders, nonceramic: any powdered material other than ceramic-grade oxides and } \\
\text { carbides }\end{array}$ \\
\hline Powder, ceramic & G & $\begin{array}{l}\text { Powders, ceramic grade: high-fired oxide or carbide specially prepared for ceramic } \\
\text { fuel manufacture }\end{array}$ \\
\hline Formed, green & H & $\begin{array}{l}\text { Green pellets and particles: formed by pressing or granulating mixtures of ceramic- } \\
\text { grade powder with a binder, before sintering }\end{array}$ \\
\hline Ceramics & J & Ceramic pellets and particles: as above, after debonding and sintering \\
\hline Coated particles & K & Ceramic particles that have been given a protective coating (e.g., of SiC) \\
\hline Solids, other & $\varnothing$ & $\begin{array}{l}\text { Solid materials other than those specified above (e.g., ingots, billets, extrusion } \\
\text { pieces), but not mixed materials }\end{array}$ \\
\hline Liquids & N & Aqueous solutions, organic, or other liquids \\
\hline Residues, scrap & R & $\begin{array}{l}\text { Residues and scrap arising from the production process, intended to be recycled or } \\
\text { recovered }\end{array}$ \\
\hline Sealed sources & QS & Sources of radiation consisting of permanently encapsulated fissile materials \\
\hline Waste, solid & T & Solid wastes intended for disposal \\
\hline Waste, liquid & U & Liquid wastes intended for disposal \\
\hline $\begin{array}{l}\text { Small samples, } \\
\text { specimens }\end{array}$ & V & Analytical samples or specimens, collected together into a single batch \\
\hline
\end{tabular}


Table E-3. Chemical form (label 430, second subfield)

\begin{tabular}{|l|c|l|}
\hline \multicolumn{1}{|c|}{ Keyword } & Code & \\
\hline Elemental & D & Unalloyed metal \\
\hline Fluoride & E & Any fluoride except hexafluorides \\
\hline Hex & G & Hexafluoride \\
\hline Nitrate & J & Nitrate \\
\hline ADU & K & Ammonium diuranate \\
\hline Dioxide & Q & Dioxide \\
\hline Trioxide & T & Trioxide \\
\hline Oxide (3/8) & U & Oxide with formula $\mathrm{M}_{3} \mathrm{O}_{8}$ \\
\hline Other oxides & R & Other oxides, including mixtures of different oxides of the same element \\
\hline Carbide & W & Carbide \\
\hline Oxide/graphite & X & Oxide/graphite mixture: (e.g., HTR fuels) \\
\hline Carbide/graphite & Y & Carbide/graphite mixture: (e.g., HTR fuels) \\
\hline Nitride & Z & Nitride \\
\hline Organic & 1 & Organic compounds \\
\hline Other compounds & 2 & Other compounds, salts, and their mixtures \\
\hline Al alloys & 3 & Aluminum and Al-Si alloys \\
\hline Si alloys & 4 & Silicium alloys (except Al-Si alloys) and silicides \\
\hline Zr alloys & 5 & Zirconium alloys \\
\hline Mo and Ti alloys & 6 & Binary and ternary alloys with molybdenum and titanium \\
\hline Other alloys & 7 & Alloys other than those above \\
\hline Miscellaneous & $\varnothing$ & $\begin{array}{l}\text { Materials of various chemical forms collected together into a single batch } \\
\text { (e.g., analytical samples and specimens) }\end{array}$ \\
\hline
\end{tabular}


Table E-4. Containment (label 430, third subfield)

\begin{tabular}{|l|c|l|}
\hline \multicolumn{1}{|c|}{ Keyword } & Code & \multicolumn{1}{|c|}{ Explanation } \\
\hline Uncontained & 1 & $\begin{array}{l}\text { Materials not in containers: free-standing items including } \\
\text { fuel elements and components, if uncrated }\end{array}$ \\
\hline Fuel units & 2 & $\begin{array}{l}\text { Discrete fuel units and components, in shipping or storage } \\
\text { containers }\end{array}$ \\
\hline Flask & 3 & $\begin{array}{l}\text { Powders, non-ceramic: any powdered material other than } \\
\text { ceramic-grade oxides and carbides }\end{array}$ \\
\hline In-core & 4 & Reactor, in-core fuel elements only \\
\hline Vessel, calibrated & 5 & Process vessels and tanks, calibrated \\
\hline Vessel, uncalibrated & 6 & Process vessels and tanks, uncalibrated; pipes \\
\hline Tray & 7 & Open trays, racks, skips \\
\hline Birdcage & 8 & Special, critically safe container \\
\hline “Container” and volume range & & (liters) \\
\hline Sample bottles and other small containers & A & $<0.5$ \\
\hline Bottles, fibrepacks, cans & E & $0.5-1$ \\
\hline Bottles, fibrepacks, cans & G & $>1-5$ \\
\hline $\begin{array}{l}\text { Bottles, fibrepacks, cans, and UF } \\
\text { cylinders }\end{array}$ & H & $>5-10$ \\
\hline Fibrepacks, cans & J & $>10-15$ \\
\hline Fibrepacks, drums & K & $>15-20$ \\
\hline Drums & L & $>20-50$ \\
\hline Drums & M & $>50-100$ \\
\hline Drums, barrels & N & $>100-200$ \\
\hline Drums, barrels & Q & $>200-500$ \\
\hline UF 6 cylinders (2 t) & R & $>500-1,000$ \\
\hline Drums, barrels (10-14 t) & U & $>1,000-5,000$ \\
\hline Large containers (e.g., tank trucks) & V & $>5,000$ \\
\hline Other containers & $\varnothing$ & \\
\hline & & \\
\hline
\end{tabular}


Table E-5. Irradiation status and quality (label 430, fourth subfield)

\begin{tabular}{|l|c|c|l|}
\hline \multirow{2}{*}{ Keyword } & \multicolumn{2}{|c|}{ Code } & \multirow{2}{*}{ Explanation } \\
\cline { 2 - 4 } & $\begin{array}{c}\text { Non- } \\
\text { irradiated }\end{array}$ & Irradiated & \\
\hline Fresh fuel & F & & Fresh fuel elements or assemblies \\
\hline irradiated & A & G & Irradiated fuel prior to reprocessing \\
\hline Manufactured & H & $\begin{array}{l}\text { Manufactured articles (other than complete fuel elements) for which } \\
\text { no sampling is possible, but which are suitable for nondestructive } \\
\text { measurement }\end{array}$ \\
\hline Pure, stable & J & K & $\begin{array}{l}\text { Homogeneous material that has been produced to } \\
\text { tight specifications governing purity and stability of both physical and } \\
\text { chemical form (e.g., product, intermediate product, certain feed } \\
\text { materials) }\end{array}$ \\
\hline Pure & $\begin{array}{l}\text { Materials conforming to high purity specifications, which may be } \\
\text { slightly heterogeneous or less stable than the ones categorized as } \\
\text { "pure, stable" (e.g., certain intermediate products, clean scrap and } \\
\text { recycle, feed materials) }\end{array}$ \\
\hline Heterogeneous & D & L & $\begin{array}{l}\text { Heterogeneous materials of generally similar composition that do not } \\
\text { conform to purity specifications (e.g., most scrap and recycle) }\end{array}$ \\
\hline Variable & E & M & $\begin{array}{l}\text { Heterogeneous materials of variable and/or mixed } \\
\text { composition, possibly low in nuclear material content (e.g., dirty } \\
\text { scrap, leached hulls, waste) }\end{array}$ \\
\hline
\end{tabular}




\section{APPENDIX E-3. WEIGHT DATA LABELS}

Table E-6. Individual numeric labels for weight data

\begin{tabular}{|l|l|l|}
\hline \multicolumn{1}{|c|}{ Label } & \multicolumn{1}{|c|}{ Data field name } & \multicolumn{1}{c|}{ Numeric data } \\
\hline 600 & Unified uranium & Weight of element \\
\hline 610 & Natural uranium & Weight of element \\
\hline 620 & Depleted uranium & Weight of element \\
\hline 630 & Enriched uranium & Weight of element \\
\hline 640 & Enriched/unified uranium $\mathrm{U}_{233}$ content & Weight of isotope \\
\hline 650 & Enriched/unified uranium $\mathrm{U}_{234}$ content & Weight of isotope \\
\hline 660 & Enriched/unified uranium $\mathrm{U}_{233}+\mathrm{U}_{235}$ content & Weight of isotopes \\
\hline 670 & Enriched/unified uranium $\mathrm{U}_{235}$ content & Weight of isotope \\
\hline 680 & Enriched/unified uranium $\mathrm{U}_{236}$ content & Weight of isotope \\
\hline 690 & Enriched/unified uranium $\mathrm{U}_{238}$ content & Weight of isotope \\
\hline 700 & Plutonium & Weight of element \\
\hline 710 & Plutonium $\mathrm{Pu}_{238}$ content & Weight of isotope \\
\hline 720 & Plutonium $\mathrm{Pu}_{239}$ content & Weight of isotope \\
\hline 730 & Plutonium $\mathrm{Pu}_{240}$ content & Weight of isotope \\
\hline 740 & Plutonium $\mathrm{Pu}_{241}$ content & Weight of isotope \\
\hline 750 & Plutonium $\mathrm{Pu}_{242}$ content & Weight of isotope \\
\hline 760 & Plutonium $\mathrm{Pu}_{239}+$ Pu 241 content & Weight of isotopes \\
\hline 770 & Natural uranium fissile content & Weight of isotope \\
\hline 780 & Depleted uranium fissile content & Weight of isotope \\
\hline 800 & Thorium & Weight of element \\
\hline
\end{tabular}




\section{APPENDIX E-4. MATERIAL BALANCE REPORT ENTRY NAMES}

Table E-7. Entry names that only appear in material balance reports

\begin{tabular}{|c|c|c|}
\hline Keyword & Code & Explanation \\
\hline $\begin{array}{l}\text { Physical beginning } \\
\text { inventory }\end{array}$ & $\mathrm{PB}$ & $\begin{array}{l}\text { PB should be equal to the PE of the previous MBR relating to the same category } \\
\text { of material. }\end{array}$ \\
\hline Inventory changes & & $\begin{array}{l}\text { For each type of inventory change as applicable for the MBA in question, one } \\
\text { consolidated entry should be made for the entire material balance period. }\end{array}$ \\
\hline $\begin{array}{l}\text { Ending book } \\
\text { inventory }\end{array}$ & $\mathrm{BE}$ & $\begin{array}{l}\text { The algebraic sum of the PB and the inventory changes, not including any } \\
\text { rounding adjustments reporting in the MBR. }\end{array}$ \\
\hline $\begin{array}{l}\text { Shipper/receiver } \\
\text { difference }\end{array}$ & DI & $\begin{array}{l}\text { One consolidated entry should be made for all shipper/receiver differences over } \\
\text { the entire reporting period, if applicable. }\end{array}$ \\
\hline $\begin{array}{l}\text { Adjusted ending } \\
\text { book inventory }\end{array}$ & BA & $\begin{array}{l}\text { The algebraic sum of the PB and of the inventory changed over the period, } \\
\text { adjusted to take account of the shipper/receiver differences. }\end{array}$ \\
\hline $\begin{array}{l}\text { Physical ending } \\
\text { inventory }\end{array}$ & $\mathrm{PE}$ & $\begin{array}{l}\text { The sum of all measured and derived batch quantities of nuclear material on hand } \\
\text { at the date of the physical inventory taking. }\end{array}$ \\
\hline MUF & MF & $\begin{array}{l}\text { Material unaccounted for: calculated as the difference between the adjusted } \\
\text { ending book inventory and the PE. }\end{array}$ \\
\hline $\begin{array}{l}\text { Rounding } \\
\text { adjustment to entry } \\
\text { XX }\end{array}$ & RAXX & $\begin{array}{l}\text { The quantity to be added to the rounded sum to make it equal to the sum of the } \\
\text { rounded terms. A rounding adjustment is made to an entry in the MBR on which } \\
\text { the IAEA has been informed differently through ICRs and PILs, to bring the } \\
\text { MBR entry into agreement with the corresponding figures established on the } \\
\text { basis of ICRs and PILs. } \\
\text { The rounding adjustments should be coded RAXX, where XX stands for the code } \\
\text { of the entry to which the rounding adjustment pertains (e.g., RALN means a } \\
\text { rounding adjustment to the consolidated entry on the nuclear loss). } \\
\text { In the case of a rounding adjustment to the ending book inventory, adjusted } \\
\text { ending book inventory, or MUF, the following formulae should be used, } \\
\text { respectively: } \\
\text { RABE = PB + IC } \text { MBR - BE } \\
\text { RABA = PB + ICMBR - DI - BA } \\
\text { RAMF = BA - PE - MF } \\
\text { Where ICMBR represents the sum of the consolidated inventory changes as } \\
\text { reported in the MBR, taken with the appropriate sign indicating increases or } \\
\text { decreases. }\end{array}$ \\
\hline
\end{tabular}


APPENDIX F. LABELED FORMAT REPORT EXAMPLES 

Example 1-Labeled format receipt domestic,

(See the following page for the data string that reports this inventory change.)

LABEL

\begin{tabular}{|c|c|c|c|}
\hline 001: & $\therefore \quad$ Ol $\quad I \quad \mathrm{NN}$ & ; 000015 & \\
\hline 002: & 1 & $\begin{array}{ll}1 & 1\end{array}$ & L \\
\hline 003: & 20150124 & & \\
\hline 006: & NAME, I & & \\
\hline 010: & I & & \\
\hline 015: & 20141201 & /20141231 & \\
\hline 099: & & $I$ & \\
\hline 207: & NND- & & \\
\hline $307:$ & NND1 & & \\
\hline 309: & $: \mathbf{N} I$ & ; & $I$ \\
\hline 310: & & & \\
\hline 370: & $:$ NN I NN-B & & \\
\hline 372: & $: \begin{array}{lll}\text { NN } \quad \text { NND1 } \\
\end{array}$ & & \\
\hline 390: & & & \\
\hline 391: & & & \\
\hline 407: & 3 & & \\
\hline 411: & RD & & \\
\hline 412: & 20141215 & & \\
\hline 430: & $: \mathbf{B} / \mathbf{Q} / \mathbf{1} / \mathbf{G}$ & & \\
\hline 435: & & $I$ & \\
\hline 36 & & & \\
\hline 445 & & & \\
\hline 446: & $045 \mathrm{C} 8$ & & \\
\hline 447 & & & \\
\hline 469: & $\mathrm{N} I$ & & $I$ \\
\hline
\end{tabular}

\section{ICR DATA ELEMENT}

REFERENCE NUMBER

ENTRY NUMBER / TOTAL NUMBER OF ENTRIES

REPORT DATE

ENCODER'S NAME

REPORT TYPE

REPORTING PERIOD

CONCISE NOTE REFERENCE

FACILITY CODE

MBA CODE

ENTRY STATUS AND CROSS REFERENCE CODE

STATE ACCOUNTABILITY SYSTEM RECORD IDENTIFICATION

SHIPPER OF NUCLEAR MATERIAL

RECEIVER OF NUCLEAR MATERIAL

CONCISE NOTE INDICATOR

TEXT OF CONCISE NOTE

KEY MEASUREMENT POINT CODE

TYPE OF INVENTORY CHANGE, TYPE OF ACCOUNTING ENTRY

DATE OF INVENTORY CHANGE

MATERIAL DESCRIPTION CODE

OPERATOR'S MATERIAL DESCRIPTION CODE

OPERATOR'S MATERIAL DESCRIPTION (TEXT)

NON-LATIN ALPHABET IDENTIFICATION

BATCH NAME

SHIPPER'S BATCH NAME

MEASUREMENT IDENTIFICATION CODE

NUMBER OF ITEMS IN BATCH

WEIGHT DATA:
600: $\quad \#$ 650: $\quad$ 610:
\# 620:
700: 1 1498G \# 710:
750: \# 760

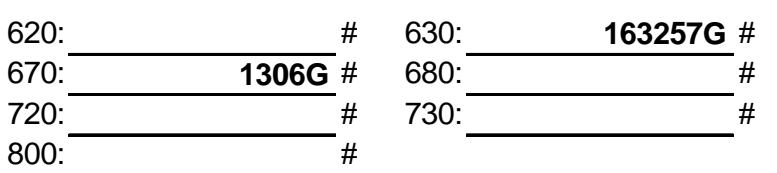
640:
690:
$740:$ \# \# 800:

Note that only one entry is necessary to report two elements (uranium and plutonium), whereas in fixed format two separate entries are required. Labels 630 and 670 are for the uranium element and isotope weights; label 700 reports the plutonium weight. 
Example 2-Data string that reports the inventory change shown in Example 1.

001:OI/NN;15\#002:1/1\#003:20150124\#006:NAME, I \#010:I\#015:20141201/20141231\#207:NND-\#307:NND1 \#309:N\#370:NN/NN-B\#372:NN/NND1\#407:3\#411:RD \#412:20141215\#430:B/Q/1/G\#446:045C8\#469:N \#470:1\#630:163275G\#670:1306G\#700:1498G\# 
Example 3-Addition of an entry to a previous report.

LABEL

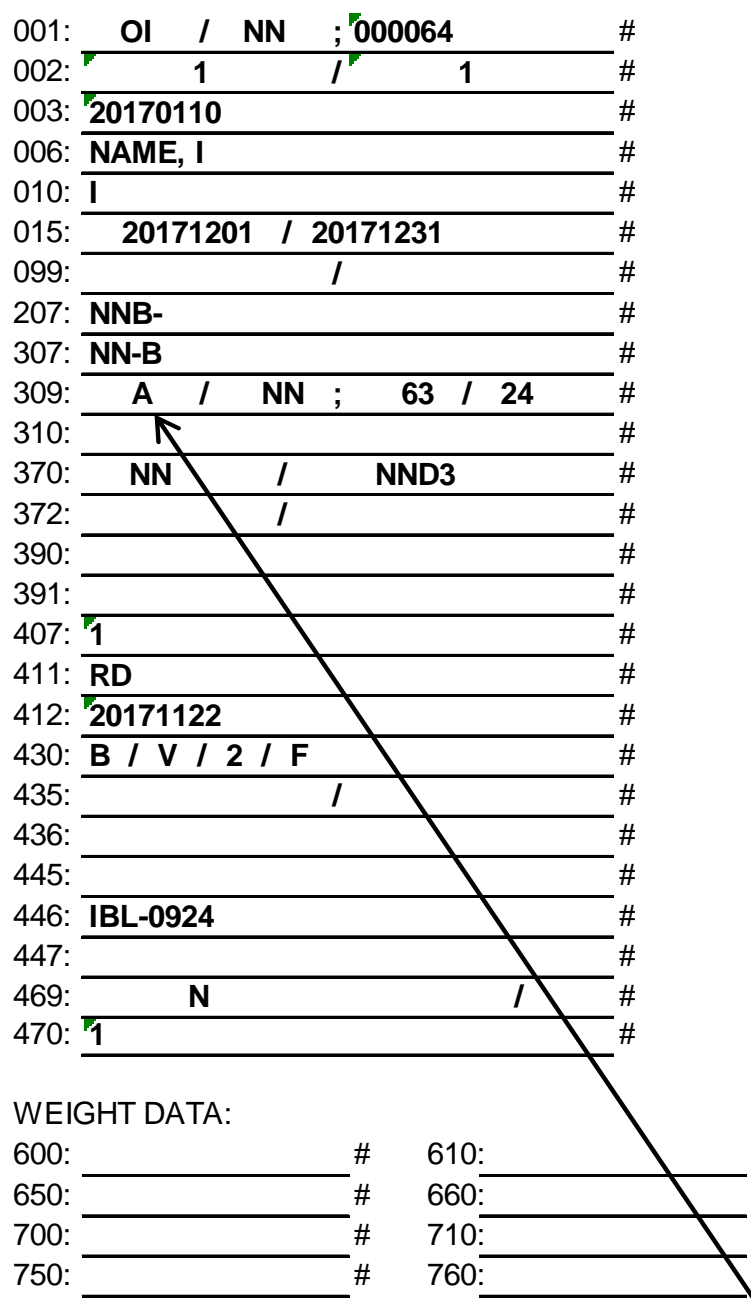

\section{ICR DATA ELEMENT}

REFERENCE NUMBER

ENTRY NUMBER / TOTAL NUMBER OF ENTRIES

REPORT DATE

ENCODER'S NAME

REPORT TYPE

REPORTING PERIOD

CONCISE NOTE REFERENCE

FACILITY CODE

MBA CODE

ENTRY STATUS AND CROSS REFERENCE CODE

STATE ACCOUNTABILITY SYSTEM RECORD IDENTIFICATION

SHIPPER OF NUCLEAR MATERIAL

RECEIVER OF NUCLEAR MATERIAL

CONCISE NOTE INDICATOR

TEXT OF CONCISE NOTE

KEY MEASUREMENT POINT CODE

TYPE OF INVENTORY CHANGE, TYPE OF ACCOUNTING ENTRY

DATE OF INVENTORY CHANGE

MATERIAL DESCRIPTION CODE

OPERATOR'S MATERIAL DESCRIPTION CODE

OPERATOR'S MATERIAL DESCRIPTION (TEXT)

NON-LATIN ALPHABET IDENTIFICATION

BATCH NAME

SHIPPER'S BATCH NAME

MEASUREMENT IDENTIFICATION CODE

NUMBER OF ITEMS IN BATCH
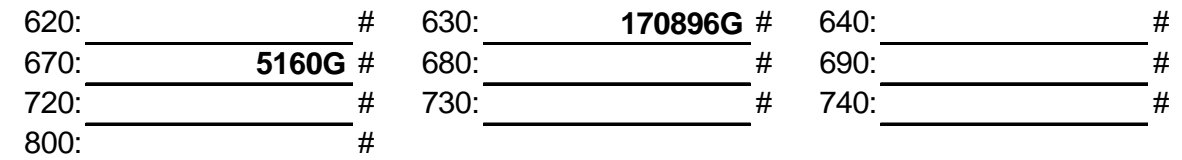

Entry 1 in report 64 is being added as entry 24 in report 63 (not shown). Because entry 24 is being added, this means report 64 has 23 entries prior to this addition. After this addition is applied, report 63 will have 24 entries, and if another entry is added to report 63, the next added entry would be number 25 . An addition entry must contain all data fields. This addition process also applies to PILs and MBRs. 
Example 4-Correction of an entry in a previous report.

\section{LABEL}

\begin{tabular}{|c|c|c|}
\hline Ol & NN & ; '000127 \\
\hline 002: & 1 & $l^{2}$ \\
\hline
\end{tabular}

006: NAME, I

010:

015: $\frac{20061101 / 20061130}{1}$

207: NND- \#

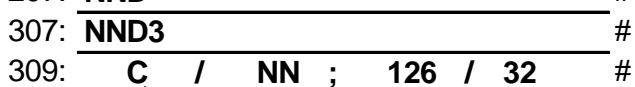

310:

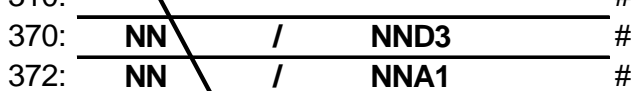

372: \begin{tabular}{l|ll} 
NN & $l$ & NNA1
\end{tabular} \#

407: 3

\section{ICR DATA ELEMENT}

REFERENCE NUMBER

ENTRY NUMBER / TOTAL NUMBER OF ENTRIES

REPORT DATE

ENCODER'S NAME

REPORT TYPE

REPORTING PERIOD

CONCISE NOTE REFERENCE

FACILITY CODE

MBA CODE

ENTRY STATUS AND CROSS REFERENCE CODE

STATE ACCOUNTABILITY SYSTEM RECORD IDENTIFICATION

SHIPPER OF NUCLEAR MATERIAL

RECEIVER OF NUCLEAR MATERIAL

CONCISE NOTE INDICATOR

TEXT OF CONCISE NOTE

KEY MEASUREMENT POINT CODE

TYPE OF INVENTORY CHANGE, TYPE OF ACCOUNTING ENTRY

DATE OF INVENTORY CHANGE

MATERIAL DESCRIPTION CODE

OPERATOR'S MATERIAL DESCRIPTION CODE

OPERATOR'S MATERIAL DESCRIPTION (TEXT)

NON-LATIN ALPHABET IDENTIFICATION

BATCH NAME

SHIPPER'S BATCH NAME

MEASUREMENT IDENTIFICATION CODE

NUMBER OF ITEMS IN BATCH

WEIGHT DATA

600:

650:

700:

750:

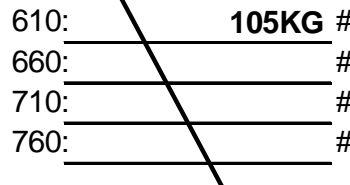

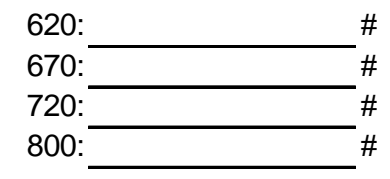

$\begin{array}{lll}\text { 630: } & \# & 640: \\ \text { 680: } & \# \text { 690: } \\ 730: & \#\end{array}$

Entry 1 of report 127 corrects the weight reported in report 126, entry 18. All data fields, including those that have not changed, must be reported. This correction process also applies to PILs and MBRs. 
Example 5-Deletion of a previously reported record.

LABEL

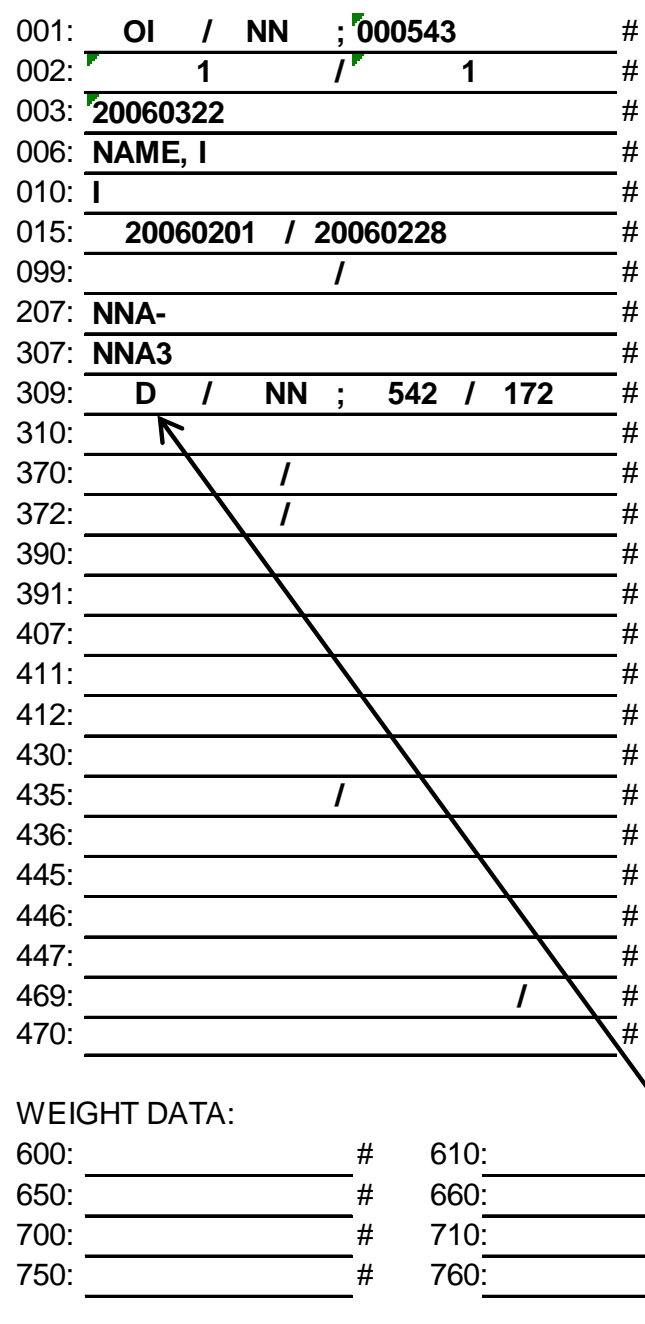

\section{ICR DATA ELEMENT}

REFERENCE NUMBER

ENTRY NUMBER / TOTAL NUMBER OF ENTRIES

REPORT DATE

ENCODER'S NAME

REPORT TYPE

REPORTING PERIOD

CONCISE NOTE REFERENCE

FACILITY CODE

MBA CODE

ENTRY STATUS AND CROSS REFERENCE CODE

STATE ACCOUNTABILITY SYSTEM RECORD IDENTIFICATION

SHIPPER OF NUCLEAR MATERIAL

RECEIVER OF NUCLEAR MATERIAL

CONCISE NOTE INDICATOR

TEXT OF CONCISE NOTE

KEY MEASUREMENT POINT CODE

TYPE OF INVENTORY CHANGE, TYPE OF ACCOUNTING ENTRY

DATE OF INVENTORY CHANGE

MATERIAL DESCRIPTION CODE

OPERATOR'S MATERIAL DESCRIPTION CODE

OPERATOR'S MATERIAL DESCRIPTION (TEXT)

NON-LATIN ALPHABET IDENTIFICATION

BATCH NAME

SHIPPER'S BATCH NAME

MEASUREMENT IDENTIFICATION CODE

NUMBER OF ITEMS IN BATCH

Entry 172 in report 542 (not shown) is being deleted by entry number 1 in report 543 for MBA NNA3. The D in the first subfield of label 309 indicates the deletion, and the other subfields show the country code and the report/entry to be deleted. This deletion process also applies to PILs and MBRs. 
Example 6-Category change in an ICR.

\section{LABEL}

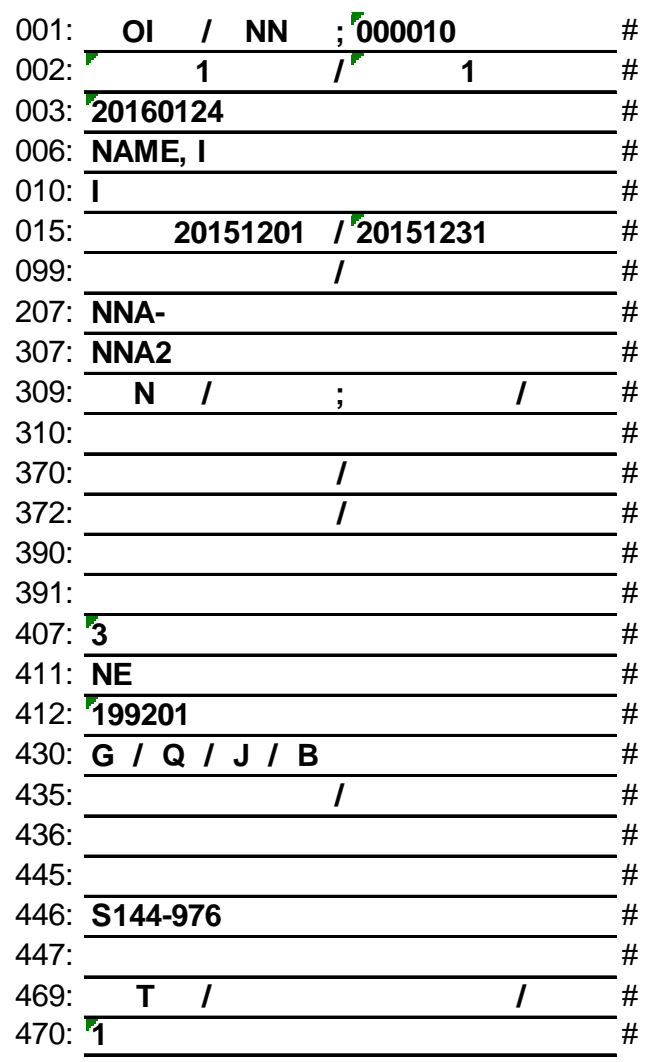

\section{ICR DATA ELEMENT}

REFERENCE NUMBER

ENTRY NUMBER / TOTAL NUMBER OF ENTRIES

REPORT DATE

ENCODER'S NAME

REPORT TYPE

REPORTING PERIOD

CONCISE NOTE REFERENCE

FACILITY CODE

MBA CODE

ENTRY STATUS AND CROSS REFERENCE CODE

STATE ACCOUNTABILITY SYSTEM RECORD IDENTIFICATION

SHIPPER OF NUCLEAR MATERIAL

RECEIVER OF NUCLEAR MATERIAL

CONCISE NOTE INDICATOR

TEXT OF CONCISE NOTE

KEY MEASUREMENT POINT CODE

TYPE OF INVENTORY CHANGE, TYPE OF ACCOUNTING ENTRY

DATE OF INVENTORY CHANGE

MATERIAL DESCRIPTION CODE

OPERATOR'S MATERIAL DESCRIPTION CODE

OPERATOR'S MATERIAL DESCRIPTION (TEXT)

NON-LATIN ALPHABET IDENTIFICATION

BATCH NAME

SHIPPER'S BATCH NAME

MEASUREMENT IDENTIFICATION CODE

NUMBER OF ITEMS IN BATCH

WEIGHT DATA:

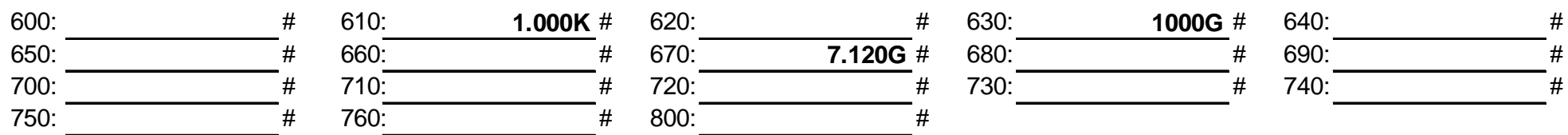

The inventory change code NE (label 411) indicates the batch of uranium has been removed from the natural uranium account and has been added to the enriched uranium account.

In labeled format Code 10, the amount leaving the natural uranium account (label 610) and the amounts being added to the enriched and fissile accounts (labels 630 and 670) must be reported. 
Example 7-Labeled format PIL (one entry, which shows one batch of nuclear material).

\section{LABEL}

\begin{tabular}{|c|c|c|c|c|c|c|c|c|}
\hline 001: & Ol & I & NN & ; & 14 & & & $\neq$ \\
\hline 002: & & 1 & & $T$ & & & & $\neq$ \\
\hline 003: & 201609 & & & & & & & ; \\
\hline 006: & NAME, & & & & & & & 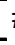 \\
\hline 010: & $P$ & & & & & & & 7 \\
\hline 015: & 201608 & & & $I$ & & & & z \\
\hline 099: & & & & $I$ & & & & - \\
\hline 207: & NNB- & & & & & & & 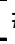 \\
\hline 307: & NN-B & & & & & & & 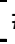 \\
\hline 309: & $\mathbf{N}$ & $I$ & & ; & & & & 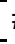 \\
\hline 390: & & & & & & & & - \\
\hline 391: & & & & & & & & - \\
\hline 407: & $A$ & & & & & & & . \\
\hline 430: & $\mathrm{B}$ & $I$ & V & $I$ & 1 & $I$ & $\mathbf{F}$ & 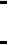 \\
\hline 435: & & & & $I$ & & & & - \\
\hline 436: & & & & & & & & _. \\
\hline 45: & & & & & & & & _ \\
\hline 446: & IBL960 & & & & & & & \\
\hline 447: & & & & & & & & \\
\hline 469: & $\mathrm{L}$ & $I$ & & & & & $I$ & \\
\hline
\end{tabular}

\section{PIL DATA ELEMENT}

REFERENCE NUMBER

ENTRY NUMBER / TOTAL NUMBER OF ENTRIES

REPORT DATE

ENCODER'S NAME

REPORT TYPE

REPORTING PERIOD

CONCISE NOTE REFERENCE

FACILITY CODE

MBA CODE

ENTRY STATUS AND CROSS REFERENCE CODE

CONCISE NOTE INDICATOR

TEXT OF CONCISE NOTE

KEY MEASUREMENT POINT CODE

MATERIAL DESCRIPTION CODE

OPERATOR'S MATERIAL DESCRIPTION CODE

OPERATOR'S MATERIAL DESCRIPTION (TEXT)

NON-LATIN ALPHABET IDENTIFICATION

BATCH NAME

SHIPPER'S BATCH NAME

MEASUREMENT IDENTIFICATION CODE

NUMBER OF ITEMS IN BATCH

\section{WEIGHT DATA:}

$\begin{array}{ll}\text { 600: } & \# \quad 610: \\ \text { 650: } & \# \text { 660: } \\ 700: & 710:\end{array}$

620:

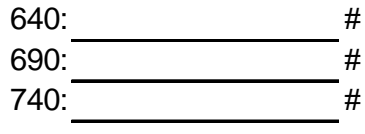


Example 8-Reporting a PIL where no batches of nuclear material are in an MBA (i.e., a null PIL).

\section{LABEL}

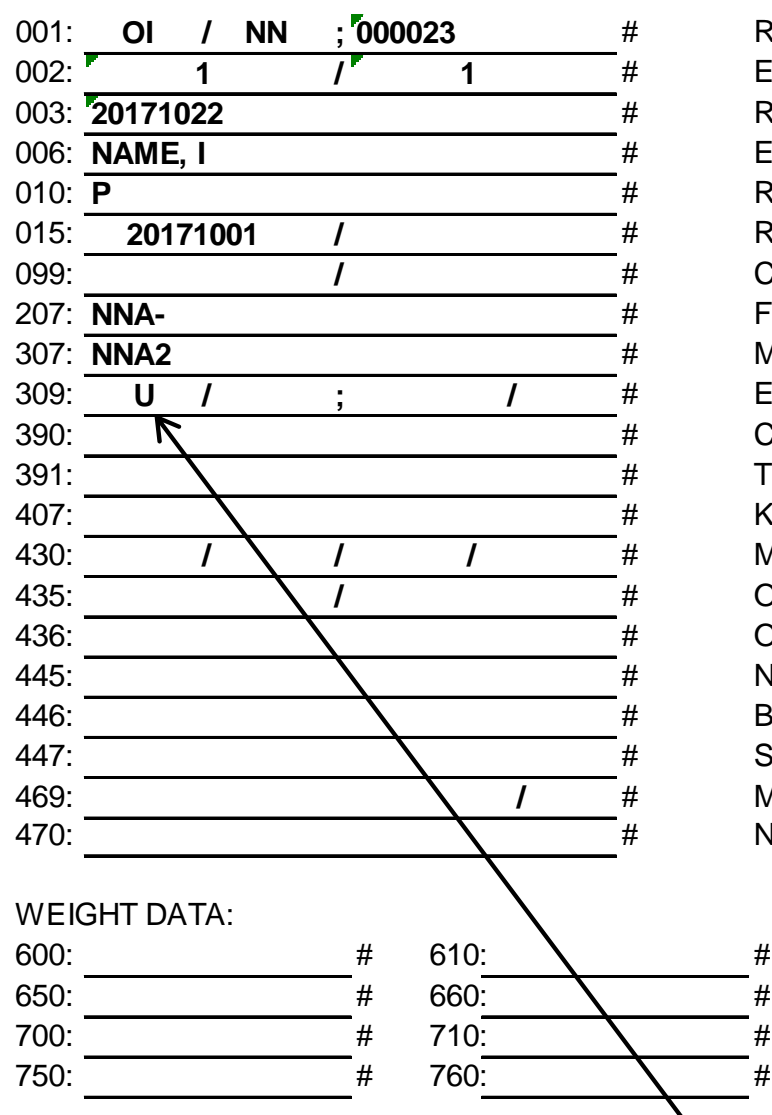

\section{PIL DATA ELEMENT}

REFERENCE NUMBER

ENTRY NUMBER / TOTAL NUMBER OF ENTRIES

REPORT DATE

ENCODER'S NAME

REPORT TYPE

REPORTING PERIOD

CONCISE NOTE REFERENCE

FACILITY CODE

MBA CODE

ENTRY STATUS AND CROSS REFERENCE CODE

CONCISE NOTE INDICATOR

TEXT OF CONCISE NOTE

KEY MEASUREMENT POINT CODE

MATERIAL DESCRIPTION CODE

OPERATOR'S MATERIAL DESCRIPTION CODE

OPERATOR'S MATERIAL DESCRIPTION (TEXT)

NON-LATIN ALPHABET IDENTIFICATION

BATCH NAME

SHIPPER'S BATCH NAME

MEASUREMENT IDENTIFICATION CODE

NUMBER OF ITEMS IN BATCH
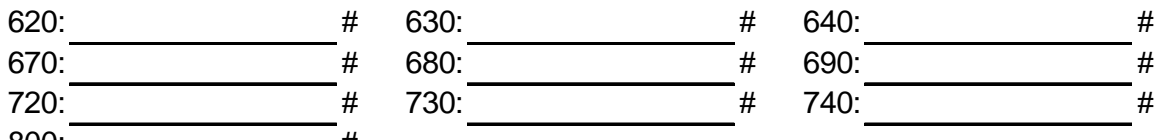

Only one entry can be reported, with a $U$ in the first subfield of label 309. This indicates an inactive entry and meets the criteria that a report must have at least one entry.

It is not correct to report one batch with a weight of zero, because that implies nuclear material (e.g., a small amount that rounds to zero) is on the inventory. 
Example 9-Labeled format MBR.

LABEL

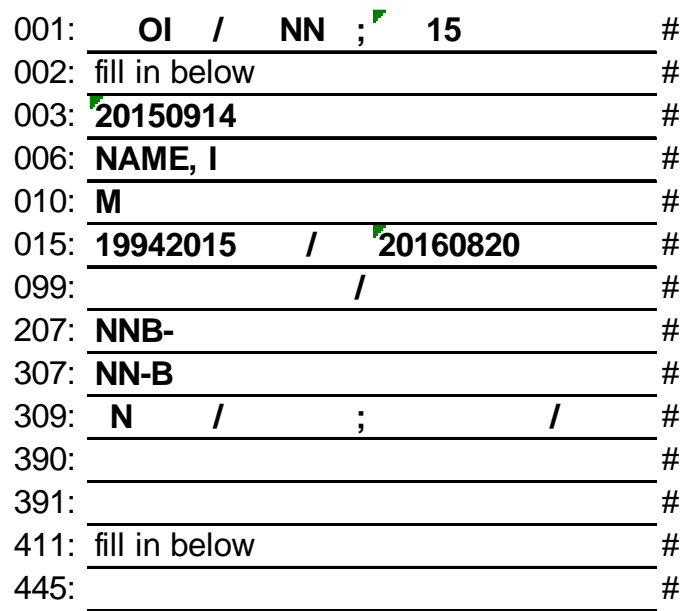

\section{MBR DATA ELEMENT}

REFERENCE NUMBER

ENTRY NUMBER / TOTAL NUMBER OF ENTRIES

REPORT DATE

ENCODER'S NAME

REPORT TYPE

REPORTING PERIOD

CONCISE NOTE REFERENCE

FACILITY CODE

MBA CODE

ENTRY STATUS AND CROSS REFERENCE CODE

CONCISE NOTE INDICATOR

TEXT OF CONCISE NOTE

TYPE OF INVENTORY CHANGE, TYPE OF ACCOUNTING ENTRY NON-LATIN ALPHABET IDENTIFICATION

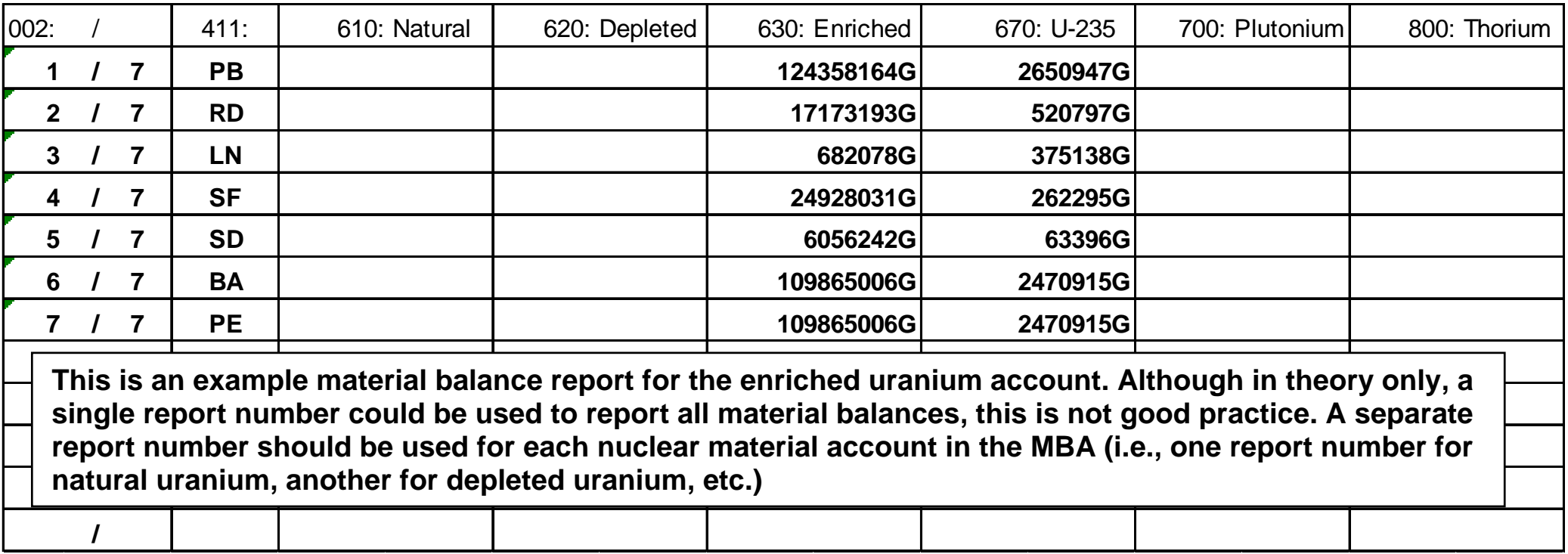


Example 10-MBR with category change (enriched uranium account).

LABEL

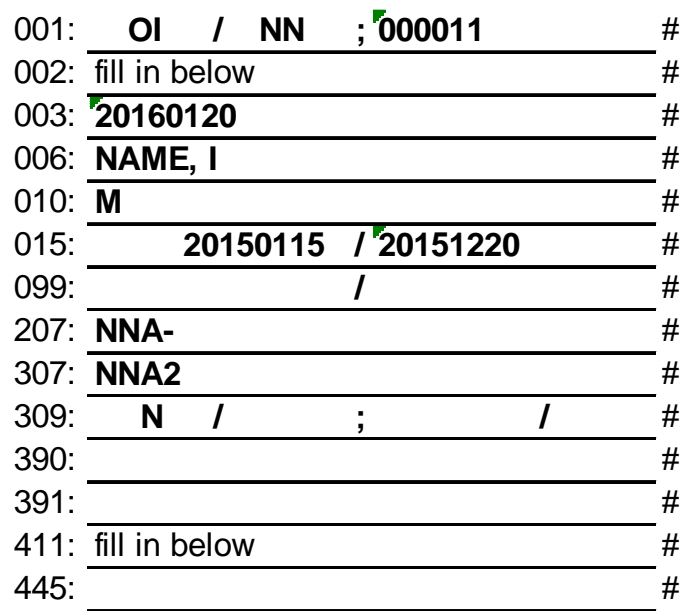

\section{MBR DATA ELEMENT}

REFERENCE NUMBER

ENTRY NUMBER / TOTAL NUMBER OF ENTRIES

REPORT DATE

ENCODER'S NAME

REPORT TYPE

REPORTING PERIOD

CONCISE NOTE REFERENCE

FACILITY CODE

MBA CODE

ENTRY STATUS AND CROSS REFERENCE CODE

CONCISE NOTE INDICATOR

TEXT OF CONCISE NOTE

TYPE OF INVENTORY CHANGE, TYPE OF ACCOUNTING ENTRY

NON-LATIN ALPHABET IDENTIFICATION

\begin{tabular}{|c|c|c|c|c|c|c|}
\hline 002: I & 411: & 610: Natural & 620: Depleted & 630: Enriched & 670: 1 & 800: Thorium \\
\hline 115 & PB & & & $7891.650 \mathrm{G}$ & & \\
\hline $\begin{array}{lll}2 & 1 & 5\end{array}$ & $\mathrm{NE}$ & & & $1000.000 \mathrm{G}$ & & \\
\hline $\begin{array}{lll}3 & 1 & 5\end{array}$ & BA & & & $8891.650 \mathrm{G}$ & & \\
\hline $4 \quad / 5$ & PE & & & 8889.150G & & \\
\hline $5 \quad / 5$ & MF & & & $2.500 \mathrm{G}$ & & \\
\hline & & & & & & \\
\hline & & & \\
\hline & & & & & & \\
\hline & & & & & & \\
\hline & & & & & & \\
\hline & & & & & & \\
\hline & & & & & & \\
\hline & & \multicolumn{4}{|c|}{$\begin{array}{l}\text { The category change entry NE should be } \\
\text { reported for both the enriched and natural } \\
\text { uranium accounts. Report number } 11 \\
\text { (label } 001 \text { ) is for the enriched account; report } \\
\text { number } 12 \text { (Example } 9 \text { ) is the natural uranium } \\
\text { account. }\end{array}$} & \\
\hline & & & & & & \\
\hline
\end{tabular}


Example 11-MBR with category change (natural uranium account).

LABEL

\begin{tabular}{|c|c|c|c|}
\hline 001: & Ol $\quad I \quad \mathrm{NN}$ & ; '000012 & \\
\hline 002: & fill in below & & \\
\hline 003: & 20160120 & & \\
\hline 006: & NAME, I & & \\
\hline 010: & M & & \\
\hline 015: & 20150115 & /20151220 & \\
\hline 99: & & I & \\
\hline 7: & NNA- & & \\
\hline 7: & NNA2 & & \\
\hline 309: & $\begin{array}{ll}\mathbf{N} & I \\
\end{array}$ & ; & $I$ \\
\hline 0: & & & \\
\hline & fill in below & & \\
\hline
\end{tabular}

\section{MBR DATA ELEMENT}

REFERENCE NUMBER

ENTRY NUMBER / TOTAL NUMBER OF ENTRIES

REPORT DATE

ENCODER'S NAME

REPORT TYPE

REPORTING PERIOD

CONCISE NOTE REFERENCE

FACILITY CODE

MBA CODE

ENTRY STATUS AND CROSS REFERENCE CODE

CONCISE NOTE INDICATOR

TEXT OF CONCISE NOTE

TYPE OF INVENTORY CHANGE, TYPE OF ACCOUNTING ENTRY

NON-LATIN ALPHABET IDENTIFICATION

\begin{tabular}{|c|c|c|c|c|c|c|c|}
\hline 002: $\quad 1$ & 411: & 610: Natural & 620: Depleted & 630: Enriched & 670: U-235 & 700: Plutonium & 800: Thorium \\
\hline $\begin{array}{lll}1 & 14\end{array}$ & PB & $5.319 \mathrm{~K}$ & & & & & \\
\hline 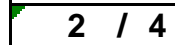 & $\mathrm{NE}$ & $1.000 \mathrm{~K}$ & & & & & \\
\hline \begin{tabular}{l|l|l}
3 & 1 & 4
\end{tabular} & BA & $4.319 \mathrm{~K}$ & & & & & \\
\hline 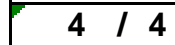 & PE & $4.319 \mathrm{~K}$ & & & & & \\
\hline & & & & & & & \\
\hline & & & & & & & \\
\hline & & & & & & & \\
\hline & & & \multirow{3}{*}{\multicolumn{3}{|c|}{$\begin{array}{l}\text { The category change entry NE for the natural } \\
\text { account only reports the element weight. }\end{array}$}} & & \\
\hline & & Ine & & & & & \\
\hline & & & & & & & \\
\hline & & & & & & & \\
\hline & & & & & & & \\
\hline & & & & & & & \\
\hline & & & & & & & \\
\hline & & & & & & & \\
\hline
\end{tabular}




\section{LABEL}

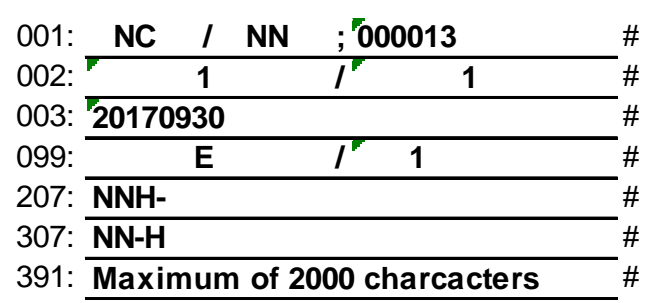

Example 12-Concise note. CONCISE NOTE DATA ELEMENT

REFERENCE NUMBER

ENTRY NUMBER / TOTAL NUMBER OF ENTRIES

REPORT DATE

CONCISE NOTE REFERENCE

FACILITY CODE

MBA CODE

TEXT OF CONCISE NOTE

This example shows a concise note that refers to entry 1 of report 13 for MBA NN-H. The report number is not included in the report numbering sequence for PILs, ICRs, MBRs, and textual reports. Concise notes are reported separately from the entry reporting nuclear material accounts. 


\section{LABEL}

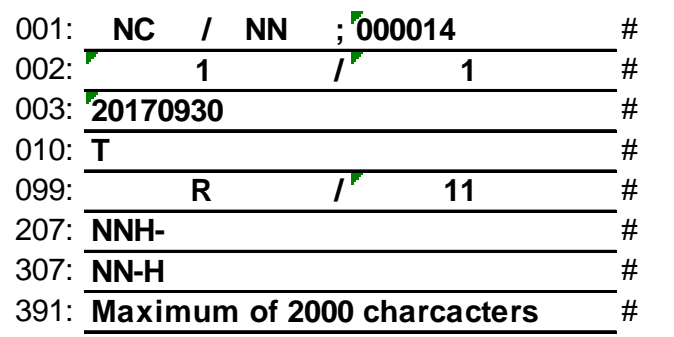

Example 13-Textual report.

TEXTUAL REPORT DATA ELEMENT

REFERENCE NUMBER

ENTRY NUMBER / TOTAL NUMBER OF ENTRIES

REPORT DATE

REPORT TYPE

TEXTUAL REPORT REFERENCE

FACILITY CODE

MBA CODE

TEXTUAL REPORT

A textual report is included in the numbering sequence along with nuclear material accounting reports (PILs, ICRs, and MBRs). This is an example of a textual report that applies to report 11 for MBA NN-H. 
